\title{
Effect of Circulation Control Blowing Slots on Stall Angles of a 10:1 Elliptical Airfoil
}

Jonathan Kweder

West Virginia University

Follow this and additional works at: https://researchrepository.wvu.edu/etd

\section{Recommended Citation}

Kweder, Jonathan, "Effect of Circulation Control Blowing Slots on Stall Angles of a 10:1 Elliptical Airfoil" (2008). Graduate Theses, Dissertations, and Problem Reports. 4394.

https://researchrepository.wvu.edu/etd/4394

This Thesis is protected by copyright and/or related rights. It has been brought to you by the The Research Repository @ WVU with permission from the rights-holder(s). You are free to use this Thesis in any way that is permitted by the copyright and related rights legislation that applies to your use. For other uses you must obtain permission from the rights-holder(s) directly, unless additional rights are indicated by a Creative Commons license in the record and/ or on the work itself. This Thesis has been accepted for inclusion in WVU Graduate Theses, Dissertations, and Problem Reports collection by an authorized administrator of The Research Repository @ WVU. For more information, please contact researchrepository@mail.wvu.edu. 


\title{
Effect of Circulation Control Blowing Slots on Stall Angles of a 10:1 Elliptical Airfoil
}

\author{
Jonathan Kweder, BSAE, BSME \\ A Thesis Submitted to the \\ College of Engineering and Mineral Resources \\ At West Virginia University \\ In Partial Fulfillment of the Requirements \\ For the Degree of \\ Master of Science \\ in \\ Aerospace Engineering \\ Dr. James E. Smith, Committee Chairperson \\ Dr. Jacky C. Prucz \\ Dr. Hailin Li \\ Department: Mechanical and Aerospace Engineering \\ West Virginia University \\ Morgantown, WV \\ 2008 \\ Keywords: Circulation Control, Stall Angle \\ Copyright 2008 Jonathan Kweder
}




\section{Abstract \\ Effect of Circulation Control Blowing Slots on Stall Angles of a 10:1 Elliptical Airfoil Jonathan Kweder}

Circulation control is a high-lift methodology that can be used on the wing of an aircraft. This technology has been in the research and development phase for over sixty years primarily for fixed wing aircraft when the early models were referred to as "blown flaps." Circulation control works by increasing the near surface velocity of the airflow over the leading edge and/or trailing edge of a specially designed aircraft wing using a series of blowing slots that eject high velocity jets of air. The wing has a rounded trailing edge, and ejects the air tangentially, through these slots inducing the Coandă effect. This phenomenon keeps the boundary layer jet attached to the wing surface longer than a conventional wing and thus increases the lift generated on the wing surface due to the relaxation of the Kutta condition for the rounded trailing edge. The circulation control airflow adds energy to the lift force through conventional airfoil lift production and by altering the circulation of stream lines around the airfoil.

The main purpose of circulation control for fixed wing aircraft is to increase the lifting force when large lifting forces and/or slow speeds are required, such as at take-off and landing. Wing flaps and slats are currently used during landing on almost all fixed wing aircraft and on take-off by larger jets. While flaps and slats are effective in increasing lift, they do so with a penalty of increased drag. The benefit of the circulation control wing is that no extra drag is created from the movement of conventional surfaces into the airflow around the wing and the lift coefficient is greatly increased. However, with the use of circulation control to increase the lift coefficient, there is the inherent increase in the induced drag over the airfoil.

For circulation control to be feasible for use on rotary aircraft (helicopters in particular), the effective angles of attack have to be studied. Because propellers on rotorcraft see wide ranges of angles of attack caused by the inflow of air through the rotor plane, it is necessary to study the effect that circulation control has on the stall angles of the rotor blade. Stall occurs when a sudden reduction in lift occurs over a lifting surface caused by a flow separation between the incoming air flow and the wing body. The angle at which this happens is commonly called the 
critical angle of attack, and is typically between eight and twenty degrees depending on the wing profile, aspect ratio, camber, and planform area.

For this study, a 10:1 aspect ratio elliptical airfoil with a chord length of 11.8 inches and a span of 31.5 inches was inserted into the West Virginia University Closed Loop Wind Tunnel and was tested at varying wind speeds (80,100, and 120 feet per second), angle of attack (zero to sixteen degrees), and blowing coefficients, ranging from 0.0006 to 0.0127 depending on plenum pressure. By comparing the non-circulation controlled wing with the active circulation control data, a trend was found as to the influence of circulation control on the stall characteristics of the wing for both leading and trailing edge active control. For this specific case, when the circulation control is in use on the 10:1 elliptical airfoil, the stall angle decreased, from eight degrees to six degrees, while providing a 70\% increase in lift coefficient. 


\section{Table of Contents}

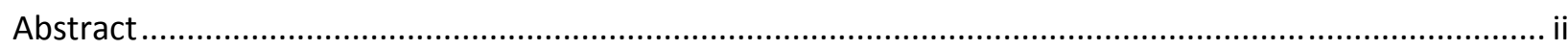

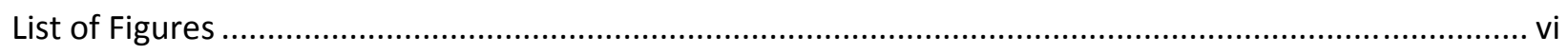

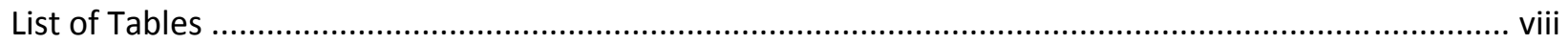

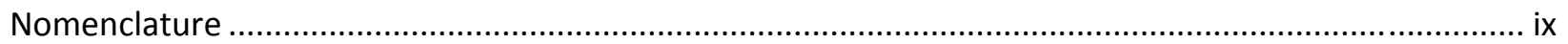

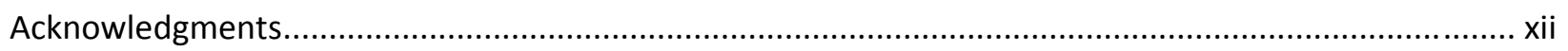

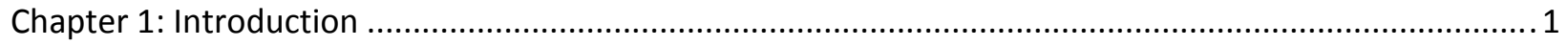

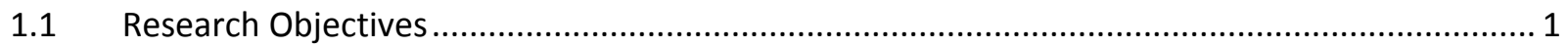

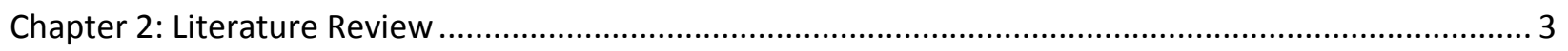

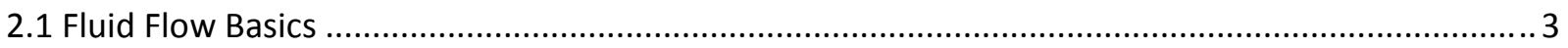

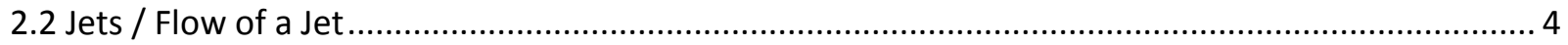

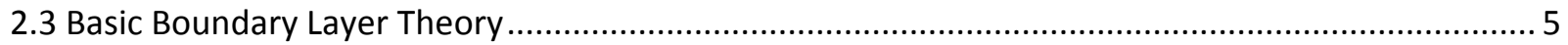

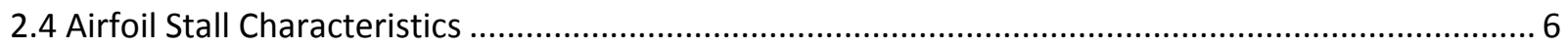

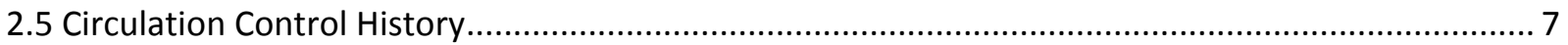

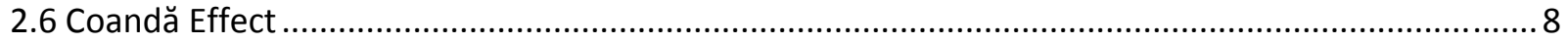

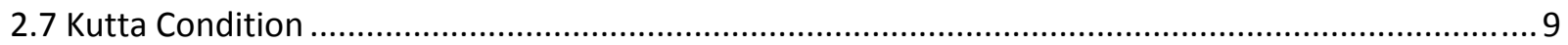

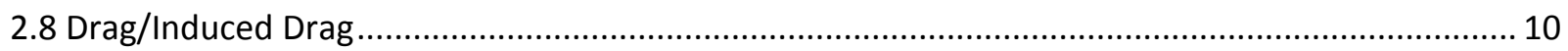

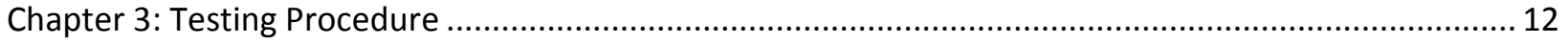

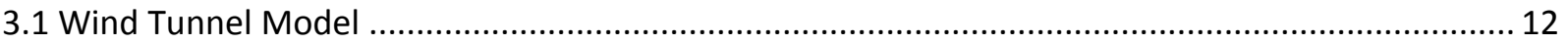

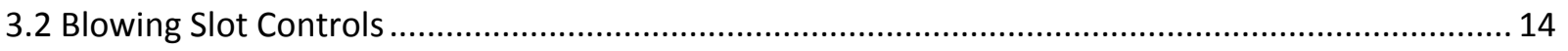

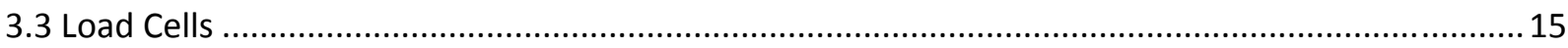

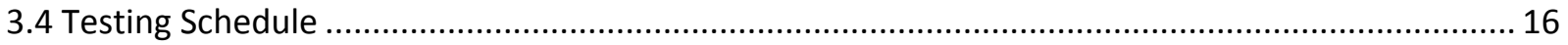

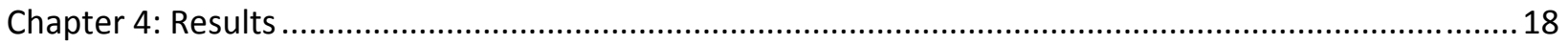

4.1 Stall Angles without Using Circulation Control .......................................................................... 18

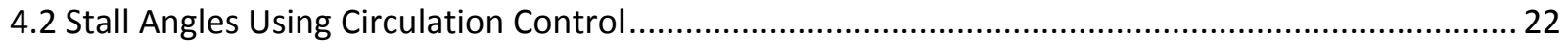

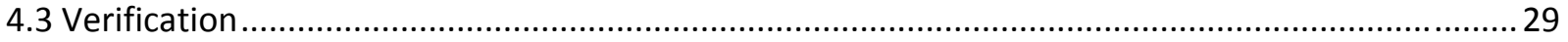

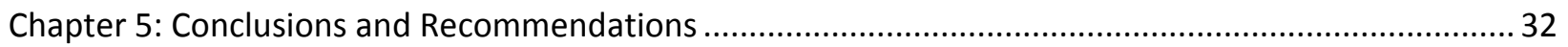

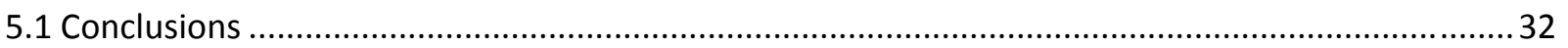

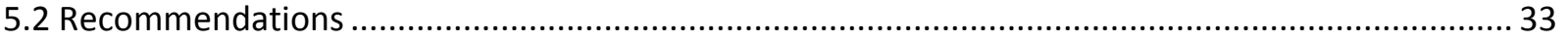

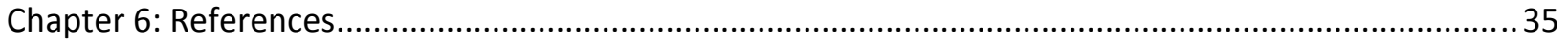

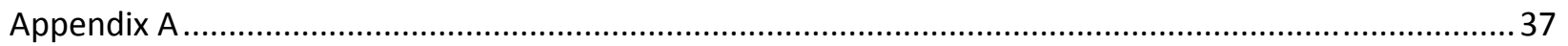




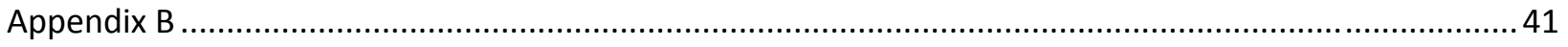

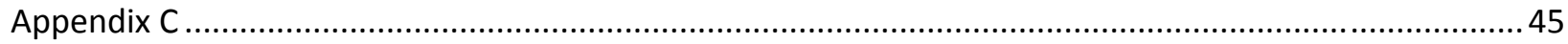

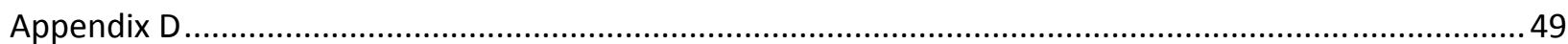

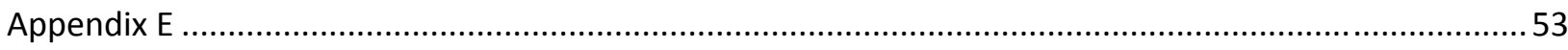

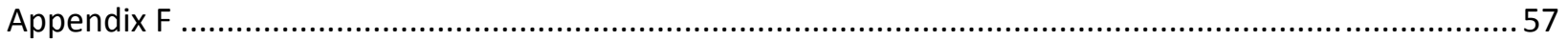

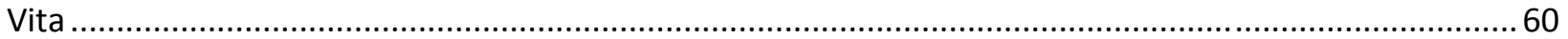




\section{List of Figures}

Figure 2.2.1 Effect of a Wall Jet on Boundary Layer [Meyer, 1972] .........................4

Figure 2.4.1 Effect of Change in Angle of Attack on Pressure Distribution.....................6

Figure 2.6.1 Flow of a 2-Dimensional Jet Around a Circular Cylinder [Newman, 1961] .........9

Figure 2.7.1 Possible Flow Solutions Over an Airfoil with a Sharp Trailing Edge .............10

Figure 3.1.1 Inside Structure of Circulation Control Wing (Computer Aided Drawing)..........12

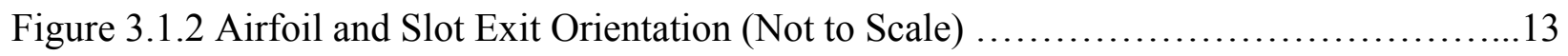

Figure 3.2.1 Leading Edge Blowing Slot Control Cam .................................. 15

Figure 3.2.2 Trailing Edge Blowing Slot Control Cam .................................. 15

Figure 4.1.1 Section Lift Coefficient versus Angle of Attack ..............................19

Figure 4.1.2 Section Drag Coefficient versus Angle of Attack ..............................20

Figure 4.1.3 Lift Coefficient Comparison to Previous Experiment

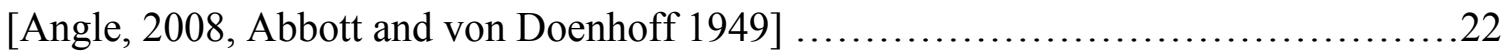

Figure 4.1.4 Drag Coefficient under No Blowing Conditions .............................22

Figure 4.2.1 Leading Edge Jet Exit Velocity Profile versus Span-wise Location................24

Figure 4.2.2 Trailing Edge Jet Velocity Profile versus Span-wise Location....................24

Figure 4.2.3 Section Lift Coefficient versus Angle of Attack (Tunnel Speed $120 \mathrm{fps}$ ) ..........25

Figure 4.2.4 Section Drag Coefficient versus Angle of Attack (Tunnel Speed $120 \mathrm{fps}$ ) .........26

Figure 4.2.5 Lift Coefficient versus Blowing Coefficient (Trailing Edge Slot AOA $=6^{\circ}$ ) ......27

Figure 4.2.6 Drag Coefficient versus Blowing Coefficient (Trailing Edge Slot AOA $=6^{\circ}$ ) ......27

Figure 4.2.7 Lift Coefficients of Multiple Activated Blowing Slots versus Angle of Attack .....28

Figure 4.2.8 Drag Coefficients of Multiple Activated Blowing Slots versus Angle of Attack ....29

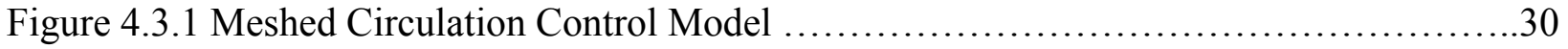

Figure 4.3.2 Experimental and Computational Lift coefficient Results $\left(\mathrm{AOA}=8^{\circ}\right) \ldots \ldots \ldots \ldots . . .31$

Figure 5.1.1 Physical Angle of Attack Compared to Virtual Angle of Attack ..................33

Figure A.1 Section Lift Coefficients versus Angle of Attack (Tunnel Velocity $80 \mathrm{fps}$ ) ...........38

Figure A.2 Section Drag Coefficients versus Angle of Attack (Tunnel Velocity 80 fps) ........38

Figure A.3 Section Lift Coefficients versus Angle of Attack (Tunnel Velocity 100 fps) ........39

Figure A.4 Section Drag Coefficients versus Angle of Attack (Tunnel Velocity 100 fps) .......39

Figure A.5 Section Lift Coefficients versus Angle of Attack (Tunnel Velocity $120 \mathrm{fps}$ ) ........40

Figure A.6 Section Drag Coefficients versus Angle of Attack (Tunnel Velocity $120 \mathrm{fps}$ ) .......40

Figure B.1 Section Lift Coefficients versus Angle of Attack (Tunnel Velocity $80 \mathrm{fps}$ ) ...........42 
Figure B.2 Section Drag Coefficients versus Angle of Attack (Tunnel Velocity $80 \mathrm{fps}$ ) ........42

Figure B.3 Section Lift Coefficients versus Angle of Attack (Tunnel Velocity $100 \mathrm{fps}$ ) .........43

Figure B.4 Section Drag Coefficients versus Angle of Attack (Tunnel Velocity $100 \mathrm{fps}$ ) ........43

Figure B.5 Section Lift Coefficients versus Angle of Attack (Tunnel Velocity $120 \mathrm{fps}$ ) ............44

Figure B.6 Section Drag Coefficients versus Angle of Attack (Tunnel Velocity 120 fps) .........44

Figure C-1 Lift Coefficient versus Blowing Coefficient $\left(0^{\circ}\right.$ Angle of Attack $)$..................46

Figure C-2 Drag Coefficient versus Blowing Coefficient $\left(0^{\circ}\right.$ Angle of Attack) …..............46

Figure C-3 Lift Coefficient versus Blowing Coefficient ( $6^{\circ}$ Angle of Attack) ..................47

Figure C-4 Drag Coefficient versus Blowing Coefficient $\left(6^{\circ}\right.$ Angle of Attack) …..............47

Figure C-5 Lift Coefficient versus Blowing Coefficient ( $8^{\circ}$ Angle of Attack) ..................48

Figure C-6 Drag Coefficient versus Blowing Coefficient $\left(8^{\circ}\right.$ Angle of Attack) ..................48

Figure D-1 Lift Coefficient versus Blowing Coefficient $\left(0^{\circ}\right.$ Angle of Attack) …..............50

Figure D-2 Drag Coefficient versus Blowing Coefficient ( $0^{\circ}$ Angle of Attack) ...................50

Figure D-3 Lift Coefficient versus Blowing Coefficient ( $6^{\circ}$ Angle of Attack) ..................51

Figure D-4 Drag Coefficient versus Blowing Coefficient $\left(6^{\circ}\right.$ Angle of Attack) …...............51

Figure D-5 Lift Coefficient versus Blowing Coefficient ( $8^{\circ}$ Angle of Attack) …..............52

Figure D-6 Drag Coefficient versus Blowing Coefficient ( $8^{\circ}$ Angle of Attack) ..................52

Figure E-1 Top Lift Load Cell Calibration Curve ….....................................54

Figure E-2 Top Drag Load Cell Calibration Curve …...................................5 54

Figure E-3 Bottom Lift Load Cell Calibration Curve ..........................................55

Figure E-4 Bottom Drag Load Cell Calibration Curve .......................................5

Figure F-1 Lift Coefficient versus Blowing Coefficient at $6^{\circ}$ Angle of Attack ..................58

Figure F-1 Lift Coefficient versus Blowing Coefficient at $8^{\circ}$ Angle of Attack ..................58

Figure F-1 Lift Coefficient versus Blowing Coefficient at $10^{\circ}$ Angle of Attack ..................59 


\section{List of Tables}

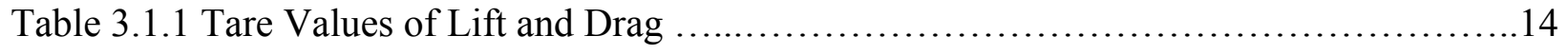

Table 3.3 .1 Loads Used For Calibration........................................... 16

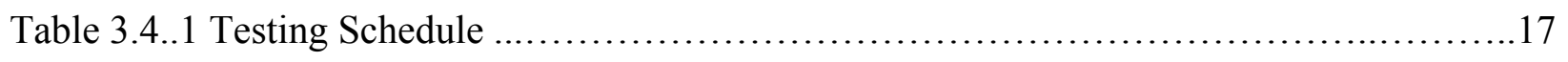

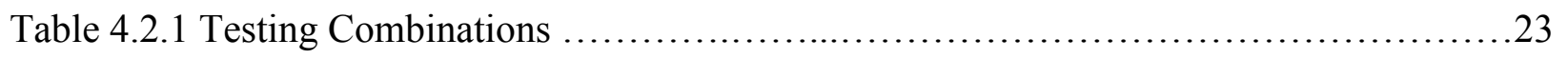




\section{Nomenclature}

Symbol

$\underline{\text { Description }}$

$\underline{\text { Units }}$

English

AOA

Angle of Attack

Degree

c

Chord length

Feet

$\mathrm{CC}$

Circulation Control

$\mathrm{CCHB}$

Circulation Control Helicopter Blade

$\mathrm{C}_{\mathrm{D}}$

Drag Coefficient

CFD

Computational Fluid Dynamics

$\mathrm{C}_{\mathrm{L}}$

Lift Coefficient

$\mathrm{C}_{\mathrm{m}}$

Moment Coefficient

$\mathrm{C}_{\mathrm{p}}$

Pressure Coefficient

$\mathrm{C}_{\mu}$

Blowing Coefficient

FBD

Bottom Drag Force

Pound

FBL

Bottom Lift Force

Pound

FTD

Top Drag Force

Pound

FTL

Top Lift Force

g

Gravitational Force

Pound

VBD

Bottom Drag Voltage

Feet/Second ${ }^{2}$

VBL

Bottom Lift Voltage

Volt

V/STOL

Vertical/Short Take-Off and Landing

VTD

Top Drag Voltage

Volt

VTL

Top Lift Voltage

Volt

$\mathrm{P}$

Pressure

Pound/Foot ${ }^{2}$

$\mathrm{R}$

Gas Constant

Foot-Pound/Slug- ${ }^{\circ} \mathrm{R}$

r

Radius of Curvature

Foot

t

Time

Second

$\mathrm{u}$

X-Velocity Component

Foot/Second

V

Y-Velocity Component 
Specific Heat Ratio

$\frac{\partial}{\partial t}$

$\frac{\partial}{\partial x}$

$\frac{\partial}{\partial y}$

$\frac{\partial}{\partial z}$

$\mu$

v

$\rho$

$\tau_{\mathrm{xx}}$

$\tau_{\mathrm{yy}}$

$\tau_{\mathrm{xy}}$

Dynamic Viscosity
Partial Derivative with Respect to time

Partial Derivative X-Direction

Partial Derivative Y-Direction

Partial Derivative Z-Direction

Kinematic Viscosity

Density

Normal Shear Stress X-Direction

Normal Shear Stress Y-Direction

XY Shear Stress
Pound-Second/Foot ${ }^{2}$

Foot ${ }^{2} /$ Second

Pounds/Foot ${ }^{3}$

Pound/Foot ${ }^{2}$

Pound/Foot ${ }^{2}$

Pound/Foot ${ }^{2}$

\section{Subscripts}

A

b

c

D

d

j

$\mathrm{L}$

$\mathrm{P}_{\infty}$

$\mathrm{T}$

$\mathrm{V}_{\infty}$
With respect to wing area

span

chord

With respect to drag

Plenum Exit

Jet

With respect to lift

With respect to ambient pressure

With respect to temperature

With respect to freestream velocity 
$\mathrm{X}$

$\mathrm{y}$

$\Delta \mathrm{P}$

$\rho$

$\infty$
X-direction

Y-direction

With respect to change in pressure

with respect to density

Freestream 


\section{Acknowledgments}

The author would like to take the opportunity to thank his family for their steadfast support in his endeavors and his girlfriend for her patience and understanding. He would also like to extend his appreciation to his thesis defense committee for their helpful suggestions and assistance, especially Dr. James E Smith for his unwavering guidance. In addition to the committee members, the author would like to express his gratitude the many members of the Center for Industrial Research Applications, including Dr. Gerald Angle for his technical and theoretical suggestions, Mr. Jay Wilhelm and Mr. Justin Smith for the help provided with data acquisition and Mr. Steven Hard, Mr. Patrick Wildfire, Mr. Andrew Nawrocki, and Mr. Michael Lyons for their help in collecting the data from the wind tunnel. 


\section{Chapter 1: Introduction}

In recent years there has been a renewed interest in high lift devices, as well as lift augmentation devices. This interest has been generated mainly for use on both fixed and rotary wing vertical/short take-off and landing (V/STOL) aircraft. In addition to the small areas that these aircraft need to land, they are incredibly flexible in their fight envelope, in that they can fly in any orientation of the aircraft's body. A problem with these aircraft is the amount of lift that is required to get the aircraft to take-off vertically or on small runways.

A rotor on a helicopter is similar to an airplane wing moving through the air in that it has a relative angle of attack with respect to the airflow. All aircraft are supported in the air by a lifting force, which is generated by the wings or rotor of the aircraft. As the air flows around the wings of the aircraft, these surfaces generate lift due to a pressure reduction above the wings. The lower pressure above the wing combined with the higher pressure under the wing results in the total lift for the body. An immediate increase in lift can be obtained by increasing the angle of attack (AOA) which is defined as the angle between the wing chord and the relative airflow. But increasing the AOA also increases drag. Above a particular angle, the critical angle of attack, the airflow behind and above the lifting bodies become turbulent, and the wing stalls. This means that the rotary wing could rapidly cease to provide enough lift to support the aircraft.

Another way of increasing the lift on an airfoil is to use circulation control (CC) technology. Circulation control is a form of lift enhancement that relies on the blowing of high velocity air around the leading and/or trailing edge of the lifting body. Circulation control works by increasing the near surface velocity of the airflow over a specially designed aircraft wing. The wing has a rounded trailing edge, and ejects the air tangentially, through these slots, inducing the Coandă effect. This phenomenon keeps the boundary layer jet attached to the wing surface longer than a conventional wing and thus increases the lift generated on the wing surface due to the relaxation of the Kutta condition for the rounded trailing edge. The circulation control airflow adds to the lift force through conventional airfoil lift production, by altering the circulation of stream lines around the airfoil.

\subsection{Research Objectives}

Circulation can be described as the line integral around a closed path of the velocity component tangential to the path [Kuethe and Schetzer, 1967]. Also, the Kutta-Joukowski 
Theorem states that the lift per unit span of an airfoil in moving air is equal to the product of the circulation, free stream velocity and the density of the fluid that the lifting body is moving through [Anderson, 2001]. This shows that the total lift force on the wing can be significantly controlled by restricting the circulation around it. As with changing the AOA of the wing to increase lift, it is necessary to analyze how $\mathrm{CC}$ affects the stall angles of the wing. It is the purpose of this study to identify and define the angles at which stall occurs without circulation control and compare them to the experimental stall angles using circulation control. 


\section{Chapter 2: Literature Review}

This section summarizes the flow physics of wind tunnels and their testing procedures, as well as prior research into circulation control wings, and stall angles. This summary starts with the basic fluid flow understanding, boundary layer theory, then summarizes the history of circulation control and some of the applicable sciences, such as Coandă surfaces and the Kutta Condition. The final topics include drag and some aerodynamic benefits, as well as, disadvantages of using circulation control.

\subsection{Fluid Flow Basics}

Wind tunnel research must begin with a general understanding of the basics behind fluid flow and relationships between the continuity equations and the conservation of momentum equations. The two-dimensional incompressible flow conservation equations, as shown in Equations 2.1.1, 2.1.2, and 2.1.3, are functions of density $(\rho)$, viscosity $(\mu)$, time $(t)$, the surface radius of curvature (R), height above the surface (y), the $\mathrm{x}$ directional fluid velocity $(\mathrm{u})$, and the $\mathrm{y}$ component of velocity (v) [Ambrosiani, 1971]. These equations define the normal and shear stresses to be used in the conservation of momentum equations.

$$
\begin{gathered}
\tau_{x x}=2 \mu\left[\frac{r}{r+y} \frac{\partial u}{\partial x}+\frac{u}{R+y}-\frac{1}{3}\left(\frac{r}{r+y} \frac{\partial u}{\partial x}+\frac{\partial v}{\partial y}+\frac{v}{r+y}\right),\right. \\
\tau_{y y}=2 \mu\left[\frac{\partial v}{\partial y}-\frac{1}{3}\left(\frac{r}{r+y} \frac{\partial u}{\partial x}+\frac{\partial v}{\partial y}+\frac{v}{r+y}\right),\right. \\
\tau_{x y}=\mu\left[\frac{r}{r+y} \frac{\partial v}{\partial y}+\frac{r+y}{r} \frac{\partial\left(\frac{r}{r+y} u\right)}{\partial y},\right.
\end{gathered}
$$

Below are the continuity (Equation 2.1.4) and conservation of momentum equations (Equation 2.1.5 and Equation 2.1.6). The x-direction conservation of momentum, Equation 2.1.5, uses the results of Equations 2.1.1 and 2.1.3. Conversely, the y-direction conservation, Equation 2.1.6, uses the results from Equations 2.1.4, 2.1.5, and 2.1.6.

$$
\begin{gathered}
\frac{\partial \rho}{\partial t}+\frac{r}{r+y} \frac{\partial(\rho u)}{\partial x}+\frac{r}{r+y} \frac{\partial\left(\frac{r+y}{r}(\rho v)\right.}{\partial y}=0 \\
\rho\left[\frac{\partial u}{\partial t}+\frac{r}{r+y} u \frac{\partial u}{\partial x}+v \frac{\partial u}{\partial y}+\frac{u v}{r+y}\right]+\frac{r}{r+y} \frac{\partial P}{\partial x}-\frac{r}{r+y} \frac{\partial \tau_{x x}}{\partial x}-\frac{\partial \tau_{x y}}{\partial y}-\frac{2}{r+y} \tau_{x y}=0 \\
\rho\left[\frac{\partial v}{\partial t}+\frac{r}{r+y} u \frac{\partial v}{\partial x}+v \frac{\partial v}{\partial y}+\frac{u^{2}}{r+y}\right]+\frac{\partial P}{\partial x}-\frac{r}{r+y} \frac{\partial \tau_{x x}}{\partial x}-\frac{\partial \tau_{y y}}{\partial y}-\frac{1}{r+y}\left[\tau_{y y}-\tau_{x x}\right]=0,
\end{gathered}
$$

These equations have aided scientists in predicting how a particular particle or object behaves in a closed system. The momentum of the object is constant and therefore the center of mass will move with the same velocity unless acted upon by an outside force. This theory 
includes the movement of air particles in a wind tunnel environment, the particles will behave in a consistent manner until it is influenced by an object outside of its original closed system (in the wind tunnel, an aerodynamic body).

\subsection{Jets / Flow of a Jet}

A jet is a continuous stream of fluid that is projected into a surrounding fluid, usually from some kind of a nozzle or opening. Frequently, the goal is to increase the kinetic energy of the flowing medium at the expense of its pressure energy and/or internal energy. The jet can also be used to energize the fluid it is flowing into. Figure 2.2.1 shows the interaction between the boundary layer around an object and a wall jet [Meyer, 1972]. Here, it can be seen that the jet adds energy to the boundary layer in the form of velocity and allows the flow to move around a curved surface instead of separating.

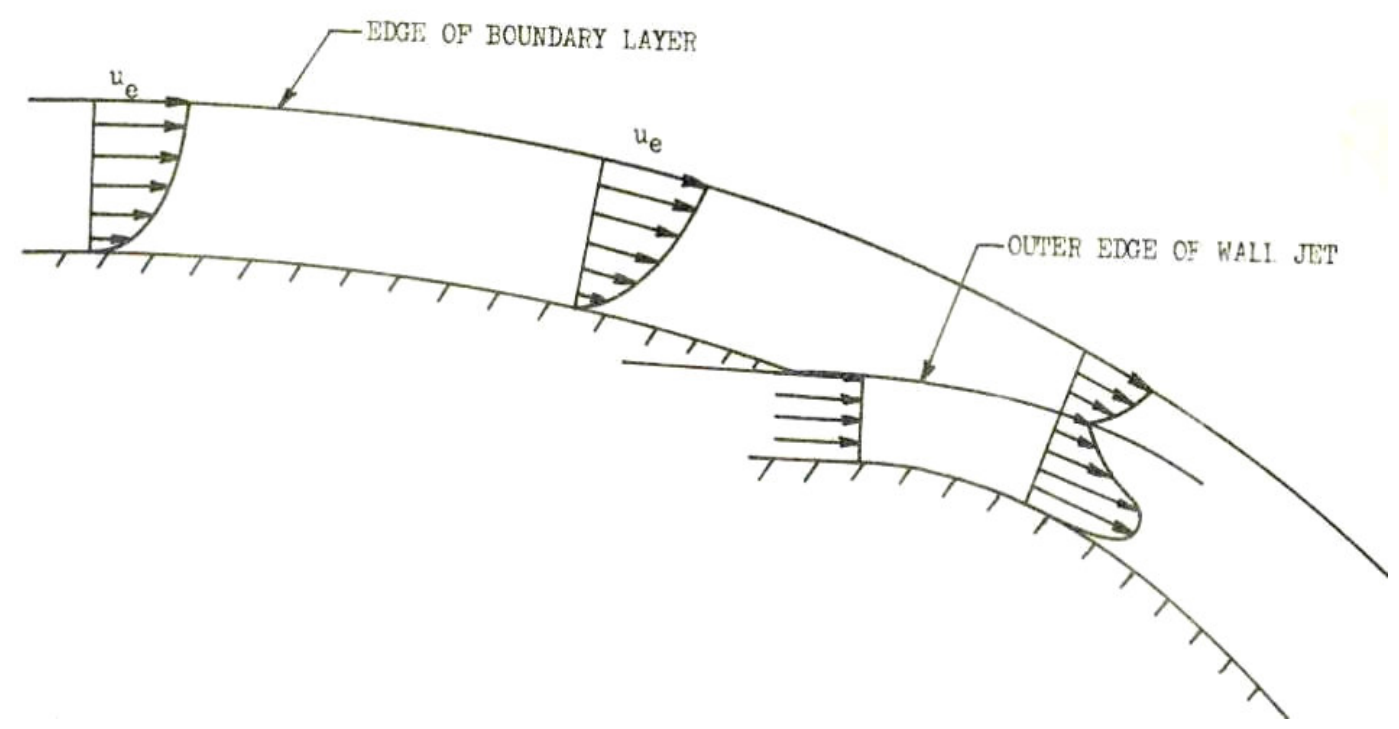

Figure 2.2.1 Effect of a Wall Jet on Boundary Layer [Meyer, 1972]

There are several different types of nozzles used in aerodynamics. They can be described as convergent (narrowing down from a wide diameter to a smaller diameter in the direction of the flow) or divergent (expanding from a smaller diameter to a larger one). There is also a third type, de Laval nozzle, which has a convergent section followed by a divergent section which is often called a convergent-divergent nozzle.

Convergent nozzles accelerate subsonic fluids. If the nozzle pressure ratio is high enough the flow will reach sonic velocity at the narrowest point. In this situation, the nozzle is said to be choked. Increasing the nozzle pressure ratio further will not increase the throat Mach number 
beyond unity. Downstream (i.e. external to the nozzle) the flow is free to expand to supersonic velocities. Conversely, divergent nozzles slow fluids. Convergent-divergent nozzles can therefore accelerate fluids that have choked in the convergent section to supersonic speeds. This process is more efficient than allowing a convergent nozzle to expand supersonically externally, thus a convergent-divergent nozzle is often used as a velocity control in wind tunnels.

\subsection{Basic Boundary Layer Theory}

First discovered in 1904 by Ludwig Prandtl, the boundary layer of an object immersed in a fluid is one of the two regions of flow [White, 2006]. The boundary layer is the portion immediately touching the surface of the object and is the region where the viscous force of the fluid is most dominant. Because of the command of the viscous force on the object, this is also where the greatest amount of drag force is experienced. There are two different thicknesses of the boundary layer around an aerodynamic body, the velocity and the thermal boundary layers. The thickness of the velocity boundary layer is normally defined as the distance from the solid body at which the flow velocity is $99 \%$ of the freestream velocity, that is, the velocity that is calculated at the surface of the body in an inviscid flow solution. The no-slip condition requires the flow velocity at the surface of a solid object be zero and the fluid temperature be equal to the temperature of the surface. The flow velocity will then increase rapidly within the boundary layer, governed by the boundary layer equations. The thermal boundary layer thickness is similarly the distance from the body at which the temperature is $99 \%$ of the temperature found from an inviscid solution. The ratio of the two thicknesses is governed by the Prandtl number. These simplified equations, also known as the Navier-Stokes equations, for three dimensional fluids are found below as Equations 2.3.1 through 2.3.4 [Mills, 1999].

$$
\begin{array}{cc}
\frac{\partial u}{\partial x}+\frac{\partial v}{\partial y}+\frac{\partial w}{\partial z}=0, & \text { Equation 2.3.1 } \\
\frac{\partial u}{\partial t}+u \frac{\partial u}{\partial x}+v \frac{\partial u}{\partial y}+w \frac{\partial u}{\partial z}=-\frac{1}{\rho} \frac{\partial p}{\partial x}+v\left(\frac{\partial^{2} u}{\partial x^{2}}+\frac{\partial^{2} u}{\partial y^{2}}+\frac{\partial^{2} w}{\partial z^{2}}\right)+\rho g_{x}, & \text { Equation 2.3.2 } \\
\frac{\partial v}{\partial t}+u \frac{\partial v}{\partial x}+v \frac{\partial v}{\partial y}+w \frac{\partial v}{\partial z}=-\frac{1}{\rho} \frac{\partial p}{\partial y}+v\left(\frac{\partial^{2} v}{\partial x^{2}}+\frac{\partial^{2} v}{\partial y^{2}}+\frac{\partial^{2} w}{\partial z^{2}}\right)+\rho g_{y}, & \text { Equation 2.3.3 } \\
\frac{\partial w}{\partial t}+u \frac{\partial w}{\partial x}+v \frac{\partial w}{\partial y}+w \frac{\partial w}{\partial z}=-\frac{1}{\rho} \frac{\partial p}{\partial z}+v\left(\frac{\partial^{2} w}{\partial x^{2}}+\frac{\partial^{2} w}{\partial y^{2}}+\frac{\partial^{2} w}{\partial z^{2}}\right)+\rho g_{z}, & \text { Equation 2.3.4 }
\end{array}
$$

These equations are used in science to model a large number of phenomena in the world including weather patterns, ocean currents, and flow over an aerodynamic body. These equations have been the backbone of aerodynamic research since their introduction by Claude 
Louis Navier and George Gabriel Stokes in 1822. Coupled with Newton's conservation of momentum, when solved explicitly, relate variables such as velocity, pressure, and viscosity, to one another.

\subsection{Airfoil Stall Characteristics}

A stall is a condition in aerodynamics where the angle between the chord line of the object moving through a fluid and the incoming velocity increases beyond a certain point such that the lift begins to decrease [Bertin, 2002]. The angle at which the reduction in lift occurs is called the critical angle of attack and is dependent upon the profile of the wing, its planform, and its aspect ratio. For subsonic flow, this critical angle is typically in the range of eight to twenty degrees relative to the incoming velocity. This is also the angle at which the maximum lift coefficient occurs, and it usually represents the boundary between the wing's linear and nonlinear airflow characteristics. Flow separation begins to occur at this point, decreasing lift, increasing drag, and changing the wing's center of pressure. A fixed-wing aircraft during a stall may experience a change in attitude, sometimes causing the aircraft to be unrecoverable.

As an airfoil changes its angle of attack with respect to the incoming velocity streamlines, a separation occurs over the wing causing the pressure distribution to change. In Figure 2.4.1 as the angle of attack of the airfoil increases, the seperation point moves further toward the leading edge of the airfoil causing an aerodynamic stall and reverse flow over the top of the wing [Thwaites, 1960].

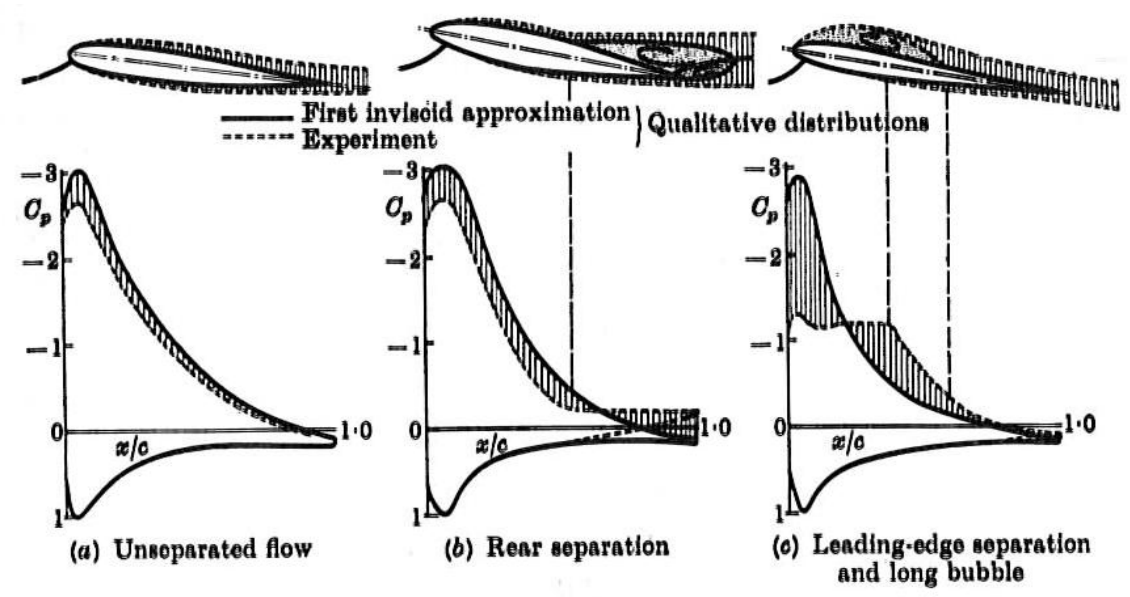

Figure 2.4.1 Effect of Change in Angle of Attack on Pressure Distribution 


\subsection{Circulation Control History}

Circulation control as a high-lift device is normally used on the main wing of an aircraft. This technology has been in the research and development phase for over sixty years, primarily for fixed wing aircraft when the early models were referred to as "blown flaps." The first reported use of blowing slots to control lift is attributed to H. Hagedorn and P. Ruden, in 1938, who noticed an unaccountable increase in lift at high blowing rates during investigations into boundary layer control on a flap [Maskell and Spence, 1959]. Interest in active blowing systems increased with the arrival of the turbojet engine, initially in Great Britain and France on a jet flap configuration. The flow of a fluid over curved surfaces has since been studied for a variety of applications. Circulation control works by increasing the near surface velocity of the airflow over the leading edge and/or trailing edge of a specially designed aircraft wing using a series of blowing slots that eject high velocity jets of air [Kind and Maull, 1968]. These wings have a rounded trailing edge, and eject the air tangentially, through these slots inducing the Coandă effect. This phenomenon keeps the boundary layer jet attached to the wing surface longer than a conventional wing and thus increases the lift generated on the wing surface due to the relaxation of the Kutta condition for the rounded trailing edge. The circulation control airflow adds to the lift force through conventional airfoil lift production by altering the circulation of stream lines around the airfoil.

The main purpose of the circulation control for fixed wing aircraft is to increase the lifting force when large lifting forces and/or slow speeds are required, such as at take-off and landing. Wing flaps and slats are currently used during landing on almost all fixed wing aircraft and on take-off by larger jets. While flaps and slats are effective in increasing lift, they do so with a penalty of increased drag. The benefit of the circulation control wing is that no extra drag is created from the movement of surfaces into the airflow around the wing and the lift coefficient is greatly increased. However, with the use of circulation control to increase lift coefficient, there is an inherent increase in the induced drag over the airfoil.

In past trials, a circular airfoil shape was used to analyze the potential fluid flow, [Theodorsen, 1931]. The original methods are for frictionless, incompressible fluids, thus not truly valid for circulation control airfoils, especially those using active circulation control, due to the compression of air at the blowing slot. In 1975, more experimentation was done using the Theodorsen method in a potential flow analysis of circulation controlled airfoils [Gibbs, 1975]. 
A Coandă simulation was then conducted which under-predicted the decay of the maximum jet velocity [Churchill, 1992].

From previous experimentation, four main benefits were achieved by using an active circulation control method on fixed wing aircraft to control moment augmentation [Ambrosiani, 1971 and Englar, 2005]. These benefits are:

1. Very small movement, or even non-moving, control surfaces are required,

2. Lift augmentation can be achieved, independent of the airfoil angle of attack,

3. Jet turning angle is no longer limited by physical jet exit angle or flap deflection angle,

4. Very high force augmentation can be achieved per unit blowing momentum input.

The pitching moment $\left(\mathrm{C}_{\mathrm{m}}\right)$ and center-of-pressure $\left(\mathrm{C}_{\mathrm{p}}\right)$ of the model are very important parameter when testing the stall angles in a wind tunnel environment. In 1970, two models were examined for the change in the pitching moment and center of pressure, the results concluded that at three different angles of attack, neither of these two parameters are not significantly affected by a change in lift coefficient [Harness, 1970].

Very few stall experimentations were conducted in past work with a circulation control airfoils, however, an experiment was conducted on a $20 \%$ elliptical airfoil with $5 \%$ camber and the blowing velocity $\left(\mathrm{C}_{\mu}\right)$ was varied between 0.006 to 0.119 with a constant free stream velocity of $100 \mathrm{~m} / \mathrm{sec}$ [Harness, 1970]. Stall angles of this airfoil were increased from nine to fourteen degrees through this range of $\mathrm{C}_{\mu}$. This stall study did not, however, take into account leading or trailing edge separation effects, only the effects of the entire suction surface of the airfoil. This airfoil's trailing edge was also unaltered, so the Kutta Condition still held true.

\subsection{Coandă Effect}

A complex type of flow is the deflection of a fluid jet by a curved surface near the boundary. This effect is called the Coandă effect. When fluids act under this principle, they move in streamlines over the top of a convex surface away from the original path. This resulting deflection is created by the balance of the centrifugal force in the jet and the reduced pressure at the wall, caused by the jet velocity [Englar, 1975]. In everyday life, one can see the Coandă effect by turning on a faucet. Move the convex side of a tablespoon toward the jet of water. When the spoon gets close enough to the fluid's boundary, the streamlines will change, thus, 
deflecting the water over the spoon's surface. The wall jet energizes the boundary layer creating a lower pressure near the surface than in the free stream which delays the separation of the free stream from the surface. As the wall jet thickens due to the additional entrained mass, from free stream and viscous dissipation, the pressure at the wall increases until the pressures (surface and free stream) equalize at which point jet separation typically occurs [Ambrosiani, 1971]. The early stages of circulation control research were based on the premise that the specially designed wings with ejectors would adhere to the Coandă effect and increase the distance along the wing chord that the separation point occurred.

A physical representation of the Coandă effect is shown by the two dimensional flow over a circular cylinder in figure 2.6.1. In this situation, the jet is shown on the bottom of the cylinder as having a velocity $(U)$. The jet makes the flow bend upwards and consequently flow further around the cylinder, delaying the separation of the boundary layer.

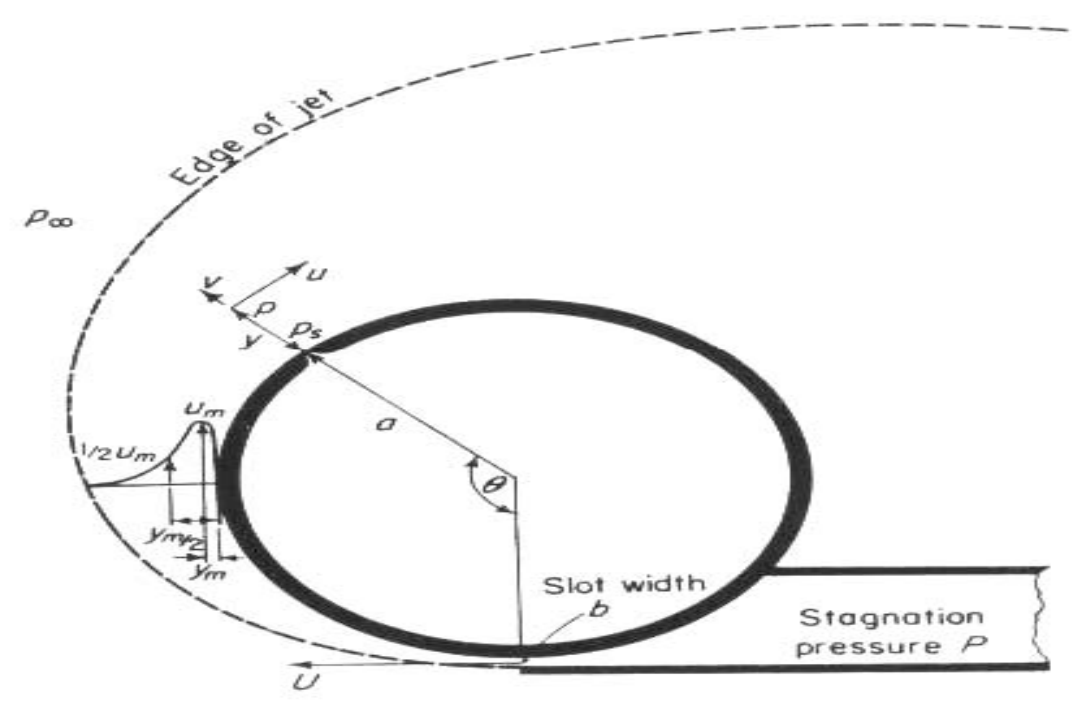

Figure 2.6.1 Flow of a Two-Dimensional Jet Around a Circular Cylinder [Newman, 1961]

\subsection{Kutta Condition}

W.M. Kutta was a German mathematician who developed the theory that the location of the rear stagnation point of an airfoil is dependent upon the circulation around the airfoil. Kutta's condition states that if the flow leaves a sharp trailing edge of an airfoil smoothly, the velocity there is finite [Katz and Plotkin, 2001]. Figure 2.7.1 shows the three different ways that the flow can theoretically leave the trailing edge of an airfoil. Following Kutta's hypothesis, it can be seen how the rear stagnation point shifts to a different place on the airfoil depending on the amount of circulation over the wing. In the figure, (a) shows the resultant flow when there is 
no circulation, (b) shows the perfect amount of circulation over an airfoil, and (c) shows more than enough circulation to satisfy the Kutta condition. Because the airfoil being tested in this experiment has a rounded trailing edge, the flow over the trailing edge of the airfoil while circulation control is being employed, will act similar to the situation seen in (c) in Figure 2.7.1 [Katz and Plotkin, 2001].
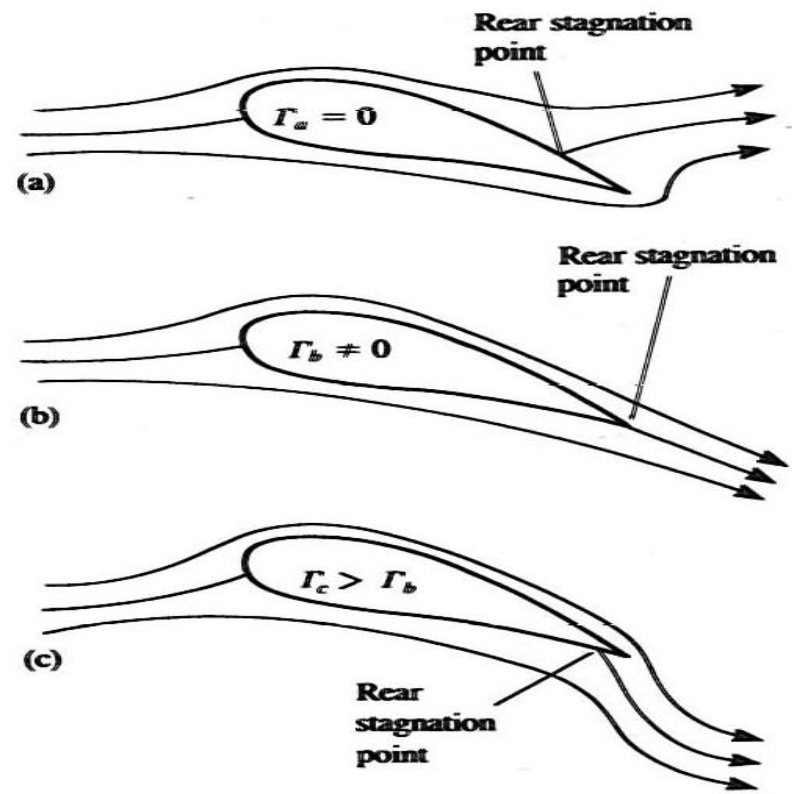

Figure 2.7.1 Possible Flow Solutions Over an Airfoil with a Sharp Trailing Edge

\subsection{Drag/Induced Drag}

In general fluid dynamics, drag is defined as the resistance force which prevents a body from moving through a liquid or gas [Anderson, 2001]. This force is comprised of both perpendicular pressure force acting on the body, as well as a parallel shear, or friction force acting opposite the direction of the body's movement. In aerodynamics, these drag forces are further broken down into several sub components based upon what shape is moving through the fluid. Among these categories are parasitic, lift-induced, and wave drag.

Parasitic drag, sometimes referred to as form drag, is dependent on the shape of the object moving through the fluid and the density of the fluid itself. There is also a skin friction force which contributes to the overall parasitic drag over an object. This is the reason thin bodies usually have less drag than blunt bodies moving through a liquid or gas.

Lift-induced drag, or sometimes just induced drag, is a function of the angle of attack of the body moving through the fluid. This induced drag force is the component force of the local lift 
vector in the direction of the freestream velocity [Anderson, 2001]. The higher the angle of attack, the higher the induced drag will be. This drag force can be neglected on a flat plate, or a symmetric airfoil without circulation control activation.

Wave drag is caused by the formation of shock waves around the aircraft. Shock waves radiate energy that is experienced by the aircraft as drag. Although shock waves are typically associated with supersonic flow, they can form at much lower speeds at areas on the aircraft where, according to Bernoulli's principle, local airflow accelerates to supersonic speeds over curved areas [Anderson, 2001]. The effect is typically seen at speeds of about Mach 0.8, but it is possible to notice the problem at any speed over that of the critical Mach of that aircraft's wing. 


\section{Chapter 3: Testing Procedure}

\subsection{Wind Tunnel Model}

For this experiment, an airfoil was designed and constructed to have both a leading edge and trailing edge blowing slot, completely separate from one another. To achieve this, two air plenums were constructed inside the wing, between the ribs. These plenums were separated and sealed so that the air pressure could be regulated for the trailing edge separately from the leading edge. Figure 3.1.1 shows a computer aided drawing of the inside of the wing model.

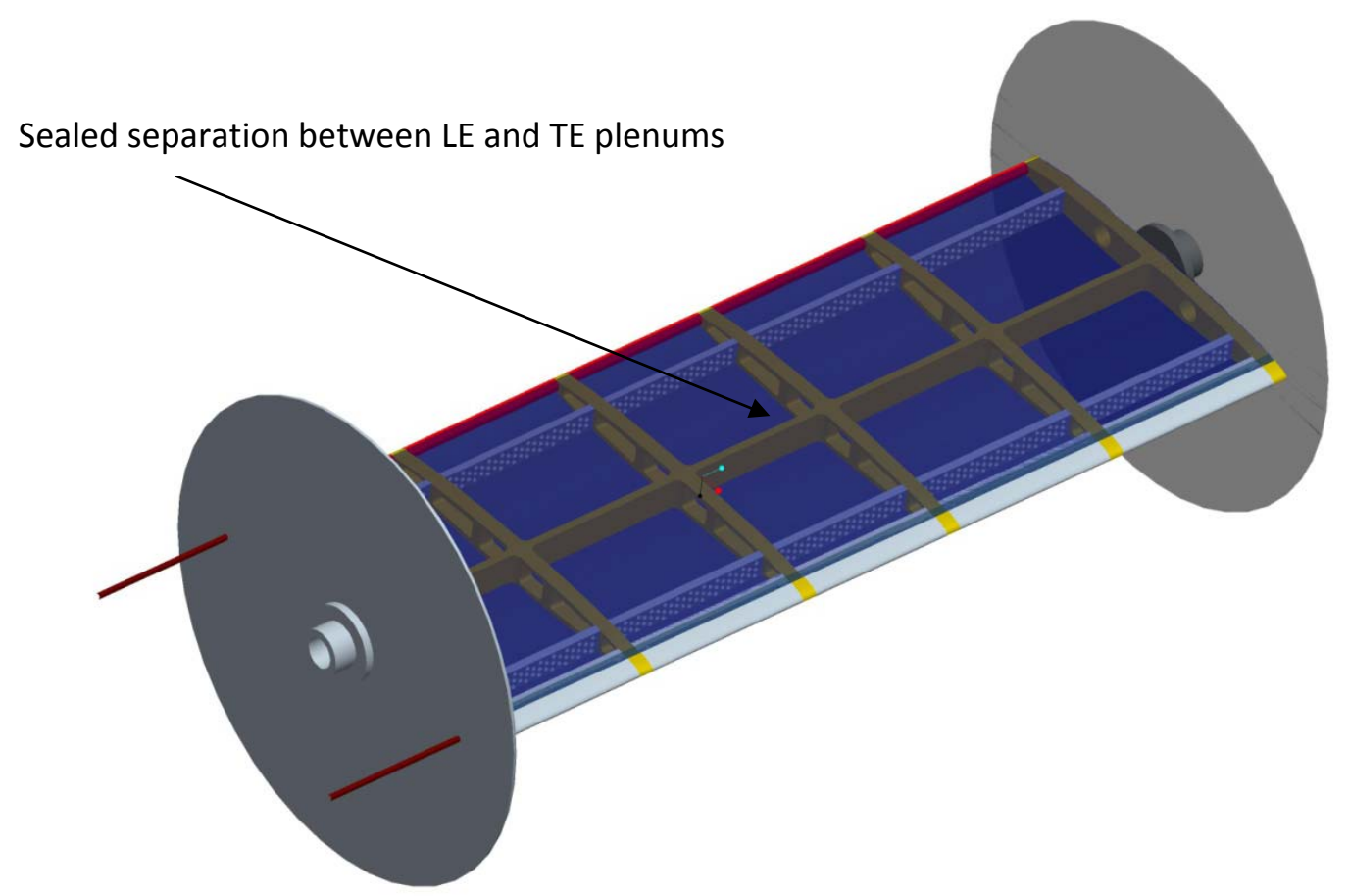

Figure 3.1.1 Inside Structure of Circulation Control Wing (Computer Aided Drawing)

The center spar which runs along the span of the wing is sealed to both the upper and lower skins so that the two air plenums are separate from one another. There are also five porous walls situated before both the leading and trailing edges used in an attempt to create a uniform exit jet velocity. The orientation of the wing model in the wind tunnel with respect to the free stream velocity is shown in Figure 3.1.2. It can also be seen that the leading and trailing edge blowing slots have exits which are tangential to the wing surface. A novel aspect of this model, the small radius Coandă surface along the trailing edge is also shown 


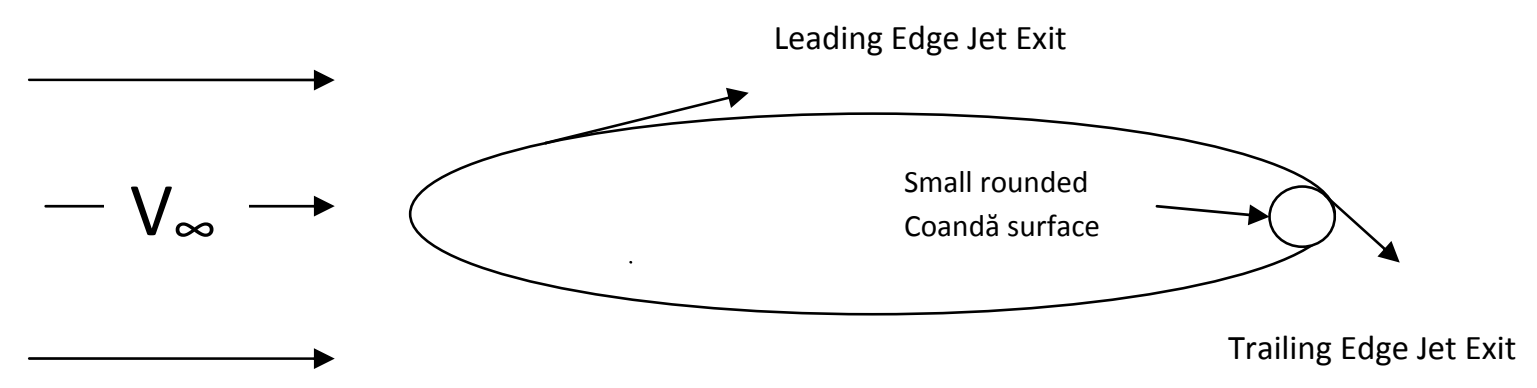

Figure 3.1.2 Airfoil and Slot Exit Orientation (not to scale)

The CC model used for this experiment was suspended in West Virginia University's Closed Loop Wind Tunnel via a support structure which reached around the top and bottom of the test section, but did not allow the model to touch the wind tunnel. This reduced the amount errors potentially caused by vibration that might be transferred to the model through the tunnel. The loading on the model was recorded using four linear load cells and because the model was also suspended from these load cells, it was necessary to record the tare values at each angle of attack. These values are shown in Table 3.1.1 according to each measured angle of attack (AOA). 
Table 3.1.1 Tare Values of Lift and Drag

\begin{tabular}{|c|c|c|c|c|c|c|}
\hline $\begin{array}{c}\text { Angle of Attack } \\
\text { (degrees) }\end{array}$ & $\begin{array}{c}\text { Top Lift } \\
\text { (pounds) }\end{array}$ & $\begin{array}{c}\text { Bottom Lift } \\
\text { (pounds) }\end{array}$ & $\begin{array}{c}\text { Top Drag } \\
\text { (pounds) }\end{array}$ & $\begin{array}{c}\text { Bottom Drag } \\
\text { (pounds) }\end{array}$ & $\begin{array}{c}\text { Total Lift } \\
\text { (pounds) }\end{array}$ & $\begin{array}{c}\text { Total Drag } \\
\text { (pounds) }\end{array}$ \\
\hline-22 & -0.4155 & 17.0464 & 1.7471 & -12.6025 & 16.6309 & -10.8554 \\
\hline-20 & 2.5123 & 12.2669 & -1.4519 & -8.3485 & 14.7792 & -9.8004 \\
\hline-18 & 6.2976 & 5.9869 & -6.2809 & -2.8303 & 12.2846 & -9.1111 \\
\hline-16 & 5.6924 & 5.5113 & -5.4784 & -2.5563 & 11.2036 & -8.0346 \\
\hline-14 & 6.1112 & 3.7243 & -5.8066 & -0.9537 & 9.8354 & -6.7604 \\
\hline-12 & 1.6492 & 6.4212 & -0.2882 & -3.2229 & 8.0704 & -3.5111 \\
\hline-10 & 4.6561 & 0.9397 & -4.4309 & 1.5745 & 5.5957 & -2.8565 \\
\hline-8 & 2.3847 & 4.6981 & -1.2863 & -1.6729 & 7.0828 & -2.9593 \\
\hline-6 & 3.8415 & -0.6505 & -2.8326 & 3.2321 & 3.1910 & 0.3995 \\
\hline-4 & 3.0459 & -0.8958 & -1.7856 & 3.4741 & 2.1501 & 1.6885 \\
\hline-2 & -2.3529 & 4.8755 & 4.6626 & -1.6685 & 2.5226 & 2.9941 \\
\hline 0 & -2.1797 & 2.5729 & 4.4855 & 0.5069 & 0.3931 & 4.9924 \\
\hline 2 & -0.4305 & 0.5867 & 2.7801 & 2.1676 & 0.1562 & 4.9478 \\
\hline 4 & -3.3877 & 1.2028 & 7.0670 & 1.8546 & -2.1848 & 8.9217 \\
\hline 6 & -2.9784 & -4.4167 & 6.3864 & 6.9261 & -7.3951 & 13.3125 \\
\hline 8 & -5.0925 & 1.1083 & 10.6057 & 2.3249 & -3.9842 & 12.9306 \\
\hline 10 & -6.0396 & 2.1480 & 11.1606 & 3.8646 & -3.8916 & 15.0252 \\
\hline 12 & -5.7784 & 0.7908 & 10.0674 & 5.9554 & -4.9876 & 16.0227 \\
\hline 14 & -6.1220 & 2.3122 & 11.3881 & 4.8427 & -3.8097 & 16.2308 \\
\hline 16 & -1.3452 & -3.8397 & 5.8587 & 10.2950 & -5.1848 & 16.1537 \\
\hline 18 & -3.4341 & -4.3208 & 7.7450 & 10.2736 & -7.7549 & 18.0187 \\
\hline 20 & -5.0602 & -4.9471 & 9.0638 & 10.6274 & -10.0074 & 19.6912 \\
\hline 22 & -6.2698 & -4.8599 & 10.2264 & 10.3838 & -11.1296 & 20.6103 \\
\hline & & & & &
\end{tabular}

\subsection{Blowing Slot Controls}

Two cylindrical cams were used to control the jet outflow. These cams have the ability to be in three different positions, simply by turning them. Each of these cams were designed in order to seal one side of the wing while opening the other side. The "top open position" allows the circulation control jet to exit on the top side of the airfoil. Similarly, the "bottom open position" allows the airflow to exit over the bottom surface of the wing. The third position is the "closed position" which restricts any airflow from exiting both the top and bottom blowing slots. Figures 3.2.1 and 3.2.2 show the cross sectional areas, as well as the dimensions, of the leading edge and trailing edge cams, respectively. 


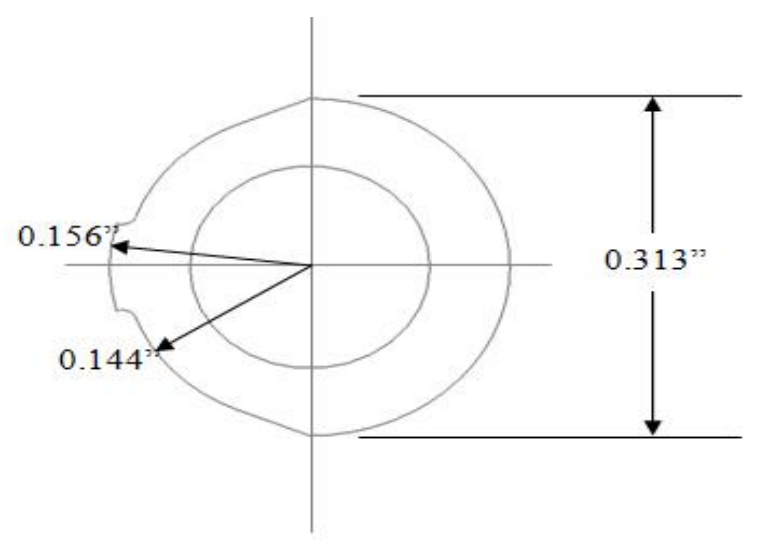

Figure 3.2.1 Leading Edge Blowing Slot Control Cam

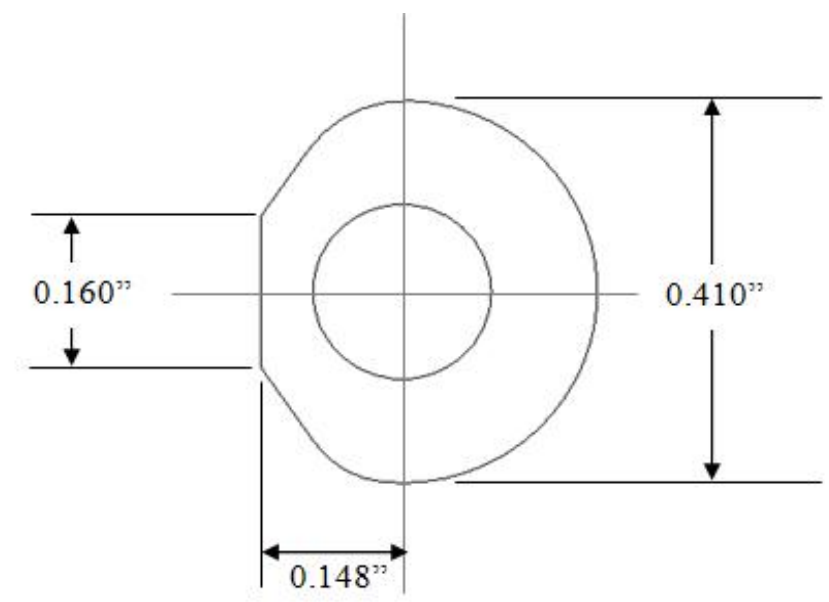

\section{Figure 3.2.2 Trailing Edge Blowing Slot Control Cam}

\subsection{Load Cells}

To ascertain where the stall of the airfoil occurred in a wind tunnel environment, the lifting force, as well as the drag force, needed to be measured. For this experimentation, four linear regression type load cells were attached to the tunnel stand holding the model. Because the test stand was not in contact with the wind tunnel, minimizing vibrations from the tunnel motor and fan did not affect the test results. The load cells were positioned on-axis in relation to the lift and drag force directions to prevent having to find the force components based on the angle of attack for each data series of the experiment, as well as on both the top and bottom of the model to avoid saturating the load cells at high angles of attack. The rated loading for these 
gauges were 25 pounds. With one set at the top and one set at the bottom of the model, a total of 50 pounds could be measured without over stressing the load cells.

These load cells used a set of multi-directional strain gauges to read a voltage into the data acquisition software. Using a calibration curve, the voltage could then be converted to a force. A top lift and drag measurement was taken in conjunction with a bottom lift and drag reading. The resultant forces were added together to come up with the total loading applied to the wing in the lift and drag directions.

A linear calibration was required to mathematically change the read voltage from the strain gauges to a physical loading. This calibration needed to be done for each of the four load cells used for this experimentation. To get a suitable set of data points, known weights, shown in Table 3.3.1, were hung in all 4 directions of loading, and the voltages were read by the data acquisition software. The loadings were applied and recorded in both the negative and positive directions of lift and drag.

Table 3.3.1 Loads Used for Calibration

\begin{tabular}{|c|c|c|}
\hline & Mass (Grams) & Force (Pounds) \\
\hline Negative Heavy & -4471 & -9.850314326 \\
\hline Negative Medium & -1858.9 & -4.095448289 \\
\hline Negative Light & -950.9 & -2.094981859 \\
\hline Zero & 0 & 0 \\
\hline Light & 950.9 & 2.094981859 \\
\hline Medium & 1858.9 & 4.095448289 \\
\hline Heavy & 4471 & 9.850314326 \\
\hline
\end{tabular}

The samples were taken at 200 Hertz for 3 seconds. After the samples were reduced, and averaged, it was shown that there was a drag force cross-loading when weight was applied to the lift direction only, as well as lifting force cross-loading when load was applied in the drag direction only. Consequently, several multi-loading data fields were recorded to add into the calibration. Appendix E shows the final on and off axis loading equations, as well as the calibration curves for each of the four load cells used to convert load cell read voltages to forces.

\subsection{Testing Schedule}

Several different parameters were varied to obtain a set of usable data for the $\mathrm{CC}$ wing model. One parameter that was varied was tunnel speed, from $80 \mathrm{fps}$ to $100 \mathrm{fps}$, and finally to 
120 fps. No slower speeds were tested because of wind tunnel limitations. At each of these three velocities, three different circulation control jet velocities were also examined. These jets velocities were dependent upon the regulated pressure of the storage tank where the air was kept. The three regulated pressures tested on the leading and trailing edge slots were ten, twenty, and thirty psi. Each of these tests were run at angles of attack from zero degrees to sixteen degrees in two degree increments. Table 3.4.1 shows the testing schedule used for data acquisition in this experiment.

Table 3.4.1 Testing Schedule

\begin{tabular}{|c|c|c|c|c|c|c|c|c|c|}
\hline Tunnel Velocity & \multicolumn{3}{|c|}{80} & \multicolumn{3}{|c|}{100} & \multicolumn{3}{c|}{120} \\
\hline Plenum Pressure & 10 & 20 & 30 & 10 & 20 & 30 & 10 & 20 & 30 \\
\hline Angle of Attack & $0-16$ & $0-16$ & $0-16$ & $0-16$ & $0-16$ & $0-16$ & $0-16$ & $0-16$ & $0-16$ \\
\hline & & & & & & & & & \\
\hline \# of Runs & 3 & 3 & 3 & 3 & 3 & 3 & 3 & 3 & 3 \\
\hline
\end{tabular}




\section{Chapter 4: Results}

\subsection{Stall Angles without Using Circulation Control}

The first task in testing the model was to obtain the baseline data without the circulation control activated. This produced the expected values of lift and drag to be used as a reference when circulation control was turned on. Three freestream air velocities were tested, 80, 100, and 120 feet per second. Due to tunnel limitations, namely unsteady tunnel section velocity, lower velocities were not considered. Theoretically, due to the fact that the section lift coefficient and section drag coefficient are dimensionless values, there should be no change due to a velocity differential. The formulae for the section lift coefficient $\left(C_{L}\right)$ and section drag coefficient $\left(C_{D}\right)$ are given by Equations 4.1.1 and 4.1.2, respectively [Anderson,2001 and Bertin, 2002].

$$
\begin{aligned}
& C_{L}=\frac{2 L}{\rho V_{\infty}^{2} S} \\
& C_{D}=\frac{2 D}{\rho V_{\infty}^{2} S}
\end{aligned}
$$

Equation 4.1.1

Equation 4.1.2

These lift and drag equations, in addition to depending on lift (L) and drag (D), also rely upon the density of the fluid $(\rho)$, freestream velocity $\left(\mathrm{V}_{\infty}\right)$, and the wing area $(\mathrm{S})$. The values for these model parameters were measured over a series of testing runs. The data acquisition software was set to record the voltage readings of the load cells in a text file at a rate of 10,000 $\mathrm{Hz}$ for a three second duration. This sample rate gave 30,000 recorded points for each of the four load cells which were then averaged to get a voltage reading for the forces in each load cell direction. The calibration data done for the load cells was then used to transfer the voltages read over to a force value. Figures 4.1.1 shows the lift coefficient as a function of angle of attack of the model compared for each of the three velocities tested. The stall characteristics of this particular airfoil, Figure 4.1.1 shows that stall would be predicted to occur between a four and six degree angle of attack. In the section drag coefficient plot, there is an increase in the value found for the negative angles of attack, however this is attributed to the fact that the wing tested had a sealant added under the skin to prevent airflow between the two circulation control plenums. This sealant was unavoidable, and needed to be installed to prevent circulation control flow from the leading edge slot from interfering with flow to the trailing edge slot. It is shown in Figure 4.1.2 that the sealant under the negative surface produces an artificial increase in section drag coefficient making the airfoil act like it contained some camber. However, even with these imperfections in the wing surface, these plots prove two things, 
1) The wing acts as a symmetric airfoil where the lift and drag are the same in positive angles of attack as they are in the negative orientation, and

2) The section lift and drag coefficients are not a function of the wind tunnel freestream velocity

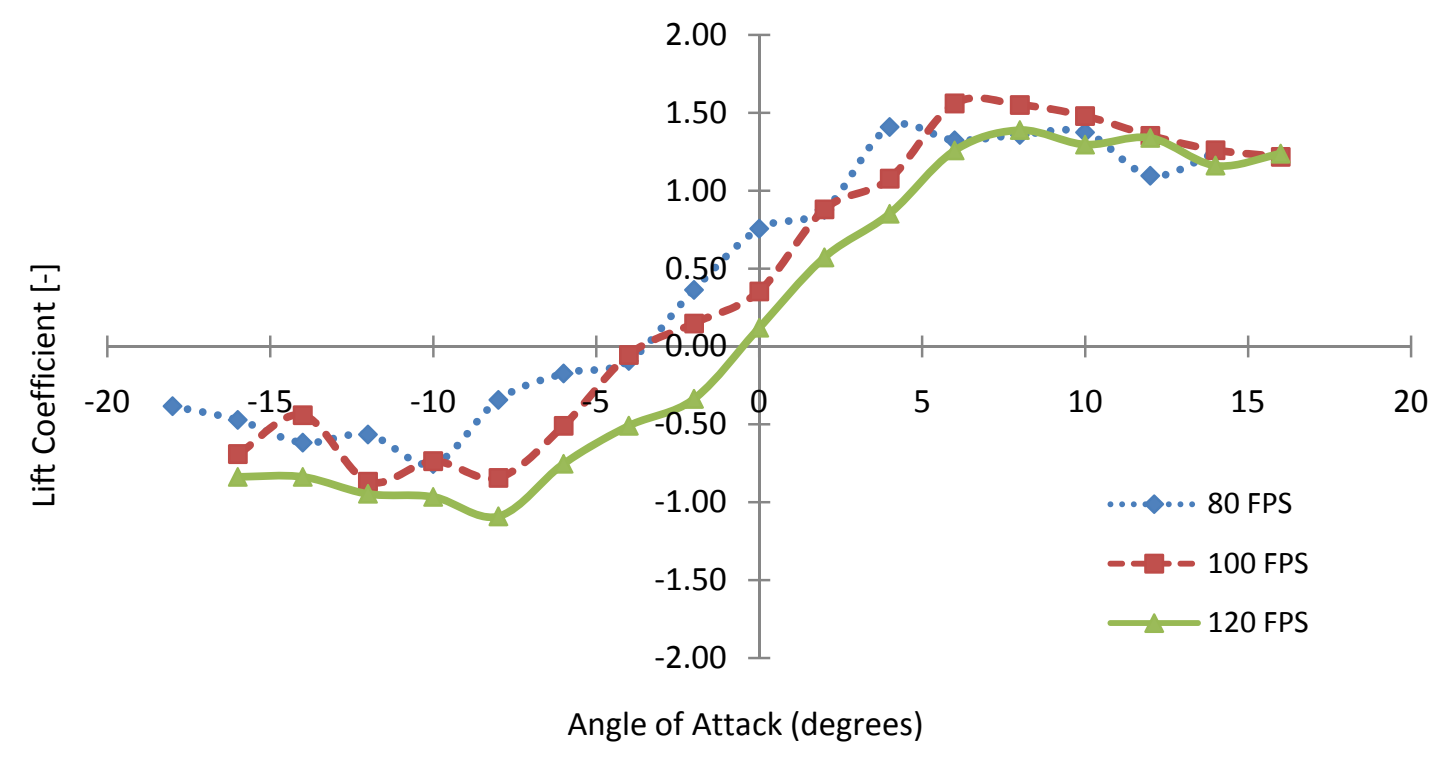

Figure 4.1.1 Section Lift Coefficient Under no Blowing Conditions 


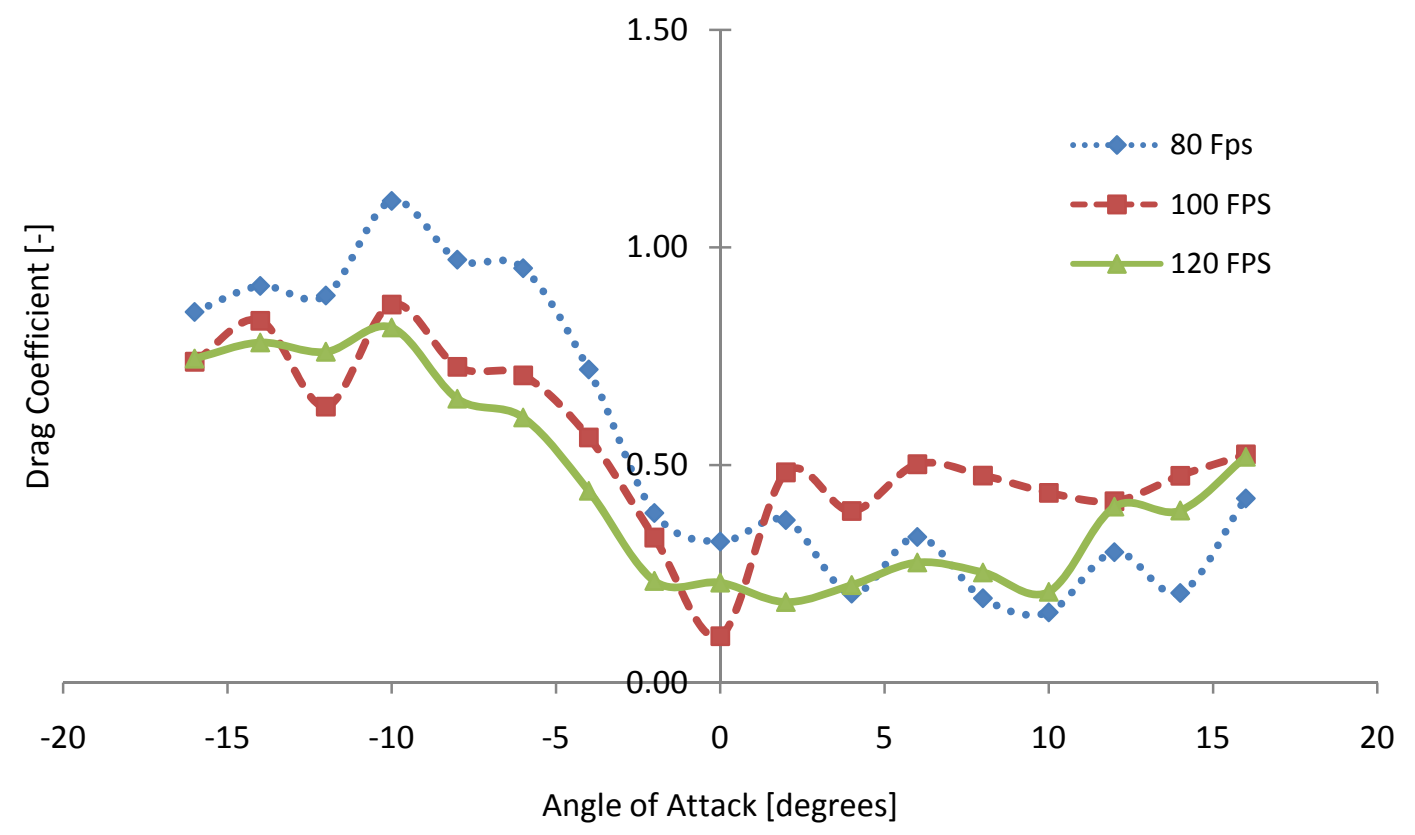

Figure 4.1.2 Section Drag Coefficient Under no Blowing Conditions

The resulting value for section lift was then compared with historical data done in previous research. Below, the formulae for the computed error values which were used to calculate for the instrumentation used in the experiment are shown. Each of these equations are based on the partial derivatives of each of the measured quantity, as well as the instrumentation uncertainty. As an example, the error in lift coefficient is based on the lift force error $\left(w_{L}\right)$, the density error $\left(\mathrm{w}_{\mathrm{\rho}}\right)$, freestream velocity error $\left(\mathrm{w}_{\mathrm{v} \infty}\right)$, and the wing area error $\left(\mathrm{w}_{\mathrm{A}}\right)$.

$$
\begin{gathered}
W_{C_{L}}=\left[\left(\frac{2 w_{L}}{\rho V_{\infty}^{2} S}\right)^{2}+\left(\frac{2 L w_{\rho}}{\rho^{2} V_{\infty}^{2} S}\right)^{2}+\left(\frac{4 L w_{V_{\infty}}}{\rho V_{\infty}^{3} S}\right)^{2}+\left(\frac{2 L w_{A}}{\rho V_{\infty}^{2} S^{2}}\right)^{2}\right]^{0.5} \\
W_{C_{D}}=\left[\left(\frac{2 w_{D}}{\rho V_{\infty}^{2} S}\right)^{2}+\left(\frac{2 D w_{\rho}}{\rho^{2} V_{\infty}^{2} S}\right)^{2}+\left(\frac{4 D w_{V_{\infty}}}{\rho V_{\infty}^{3} S}\right)^{2}+\left(\frac{2 D w_{A}}{\rho V_{\infty}^{2} S^{2}}\right)^{2}\right]^{0.5} \\
W_{\rho}=\left[\left(\frac{w_{P_{\infty}}}{R T}\right)^{2}+\left(\frac{P_{\infty} w_{T}}{R T^{2}}\right)^{2}\right]^{0.5}
\end{gathered}
$$

Equation 4.1.4

Equation 4.1.5 


$$
\begin{gathered}
W_{V_{\infty}}=\left[\left(\frac{w_{\Delta P}}{2} \sqrt{\frac{2}{\Delta P * \rho}}\right)^{2}+\left(\frac{w_{\rho}}{2} \sqrt{\frac{2 \Delta P}{\rho^{3}}}\right)^{2}\right]^{0.5} \\
w_{A}=\left[\left(b w_{c}\right)^{2}+\left(b w_{b}\right)^{2}\right]^{0.5}
\end{gathered}
$$

Equation 4.1.7

With instrumentation errors calculated and plotted along with the tested and historical data, it is shown in Figure 4.1.3 that the values of lift coefficient the tested model fall within the error values. The previous trial only experimented at angles of attack ranging from zero to six degrees. The results of this study were tested out to sixteen degrees angle of attack. The drag coefficient results in Figure 4.1.4, however, could not be compared to the data from previous experimentation because the primary focus of the previous research done with this model has been on lift augmentation, not on the effects that circulation control had on drag values and thus these values were not available. Also compared in Figure 4.1.3 is the results from wind tunnel work done on a NACA 0010-34 airfoil [Abbott and von Doenhoff, 1949]. Because the airfoil tested in this experimentation does not have any historical work completed, the closest fit was chosen for comparison. This data does not fall within the error calculations for this experiment mainly because of the small radius Coandă surface on the trailing edge of the model. This alteration inhibits the Kutta condition at the trailing edge of the model while providing the elliptical airfoil with an increased lift coefficient by bending the streamlines around the trailing edge. 


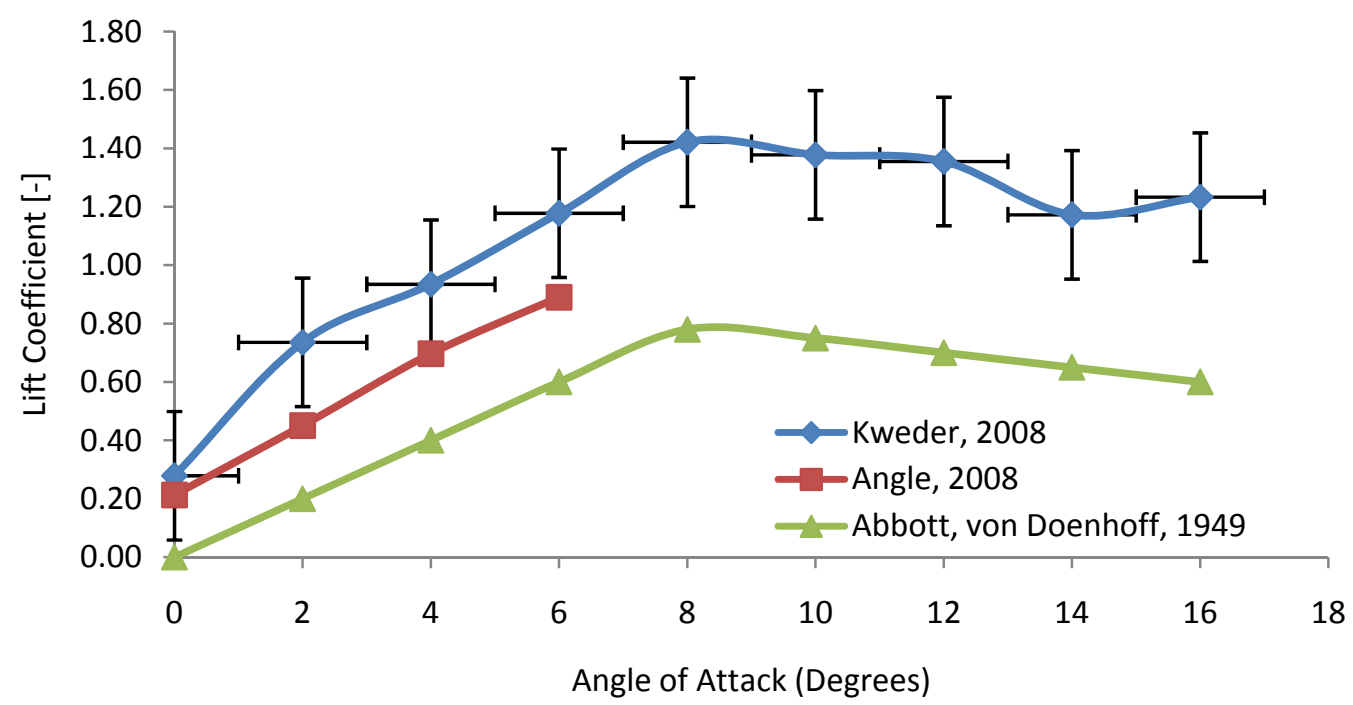

Figure 4.1.3 Lift Coefficient Comparison to Previous Experiment [Angle, 2008, Abblott and von Doenhoff, 1949]

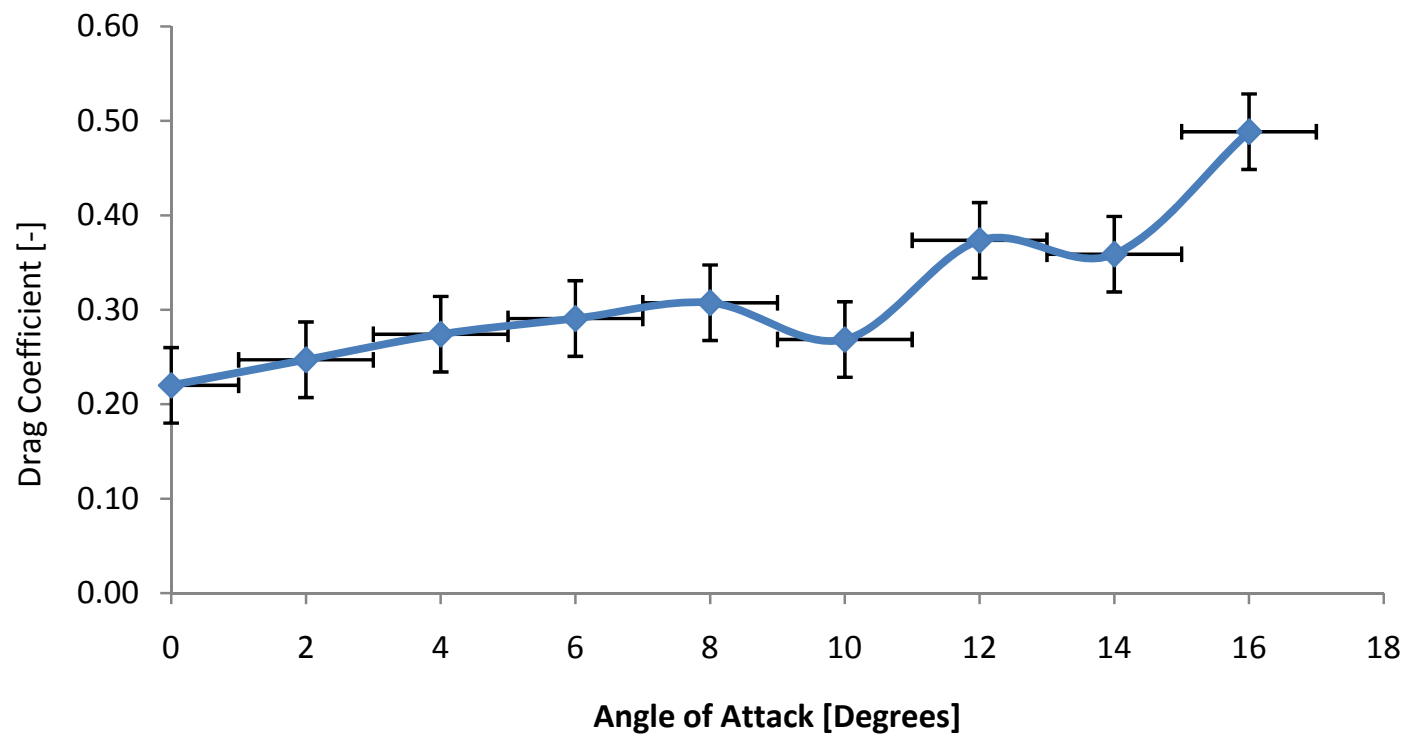

Figure 4.1.4 Drag Coefficient Under No Blowing Conditions

\subsection{Stall Angles Using Circulation Control}

When investigating the effect of circulation control on an aerodynamic body, it is important to note that the results are based on a blowing coefficient $\left(\mathrm{C}_{\mu}\right)$. In past experiments conducted in circulation control theory, the blowing coefficient has been defined in several different ways. The most common experiments define $C_{\mu}$ in terms of velocity (v), slot thickness 
(t), chord length (c) and density $(\rho)$ of the free stream and jet exit. The equation for this relationship is shown below in Equation 4.2.1 [Harness, 1970]. For this experiment, the blowing coefficient ranged from 0.0006 to 0.0127 by varying the freestream velocity in the tunnel, as well as varying the air pressure in each of the two blowing slot plenums.

$$
\mathrm{C}_{\mu}=\frac{\rho_{\mathrm{j}} \mathrm{v}_{\mathrm{j}}^{2} \mathrm{t}}{\frac{1}{2} \rho_{\infty} \mathrm{v}_{\infty}^{2} \mathrm{c}}
$$

Equation 4.2.1

Flow characterization of the velocity of the jet exiting the blowing slots of the airfoil was necessary. This data was taken using a water manometer and a pitot static pressure probe. A sample was taken one third of the distance between each of the five exit jets on both the leading and trailing edges. The three regulated jet pressures that were examined were 10, 20 and 30 psi. Table 4.2.1 shows the different testing combinations used to analyze the circulation control airfoil model.

Table 4.2.1 Testing Combinations

\begin{tabular}{|c|c|c|c|c|c|c|c|c|c|}
\hline Tunnel Velocity & \multicolumn{3}{|c|}{80} & \multicolumn{3}{|c|}{100} & \multicolumn{3}{|c|}{120} \\
\hline Plenum Pressure & 10 & 20 & 30 & 10 & 20 & 30 & 10 & 20 & 30 \\
\hline Angle of Attack & $0-16$ & $0-16$ & $0-16$ & $0-16$ & $0-16$ & $0-16$ & $0-16$ & $0-16$ & $0-16$ \\
\hline & & & & & & & & & \\
\hline \# of Runs & 3 & 3 & 3 & 3 & 3 & 3 & 3 & 3 & 3 \\
\hline
\end{tabular}

Jet velocity was then calculated through incompressible relations using Equation 4.2.2. In this equation, jet velocity $\left(\mathrm{V}_{\mathrm{j}}\right)$ is dependent on, the gas constant $(\mathrm{R})$, the ration of freestream pressure $\left(\mathrm{P}_{\infty}\right)$ to plenum exit pressure $\left(\mathrm{P}_{\mathrm{d}}\right)$, specific heat ratio $(\gamma=1.4$ for air $)$ and plenum exit temperature $\left(\mathrm{T}_{\mathrm{d}}\right)$.

$$
V_{j}=\sqrt{\frac{2 \gamma R T_{d}}{\gamma-1}\left[1-{\frac{P_{\infty}}{P_{d}}}^{\frac{\gamma-1}{\gamma}}\right]}
$$

The leading and trailing edge jet velocities were calculated and normalized according to the maximum across the entire exit slot. The results are found in Figures 4.2.1 and 4.2.2 for the leading edge and trailing edge, respectively. 


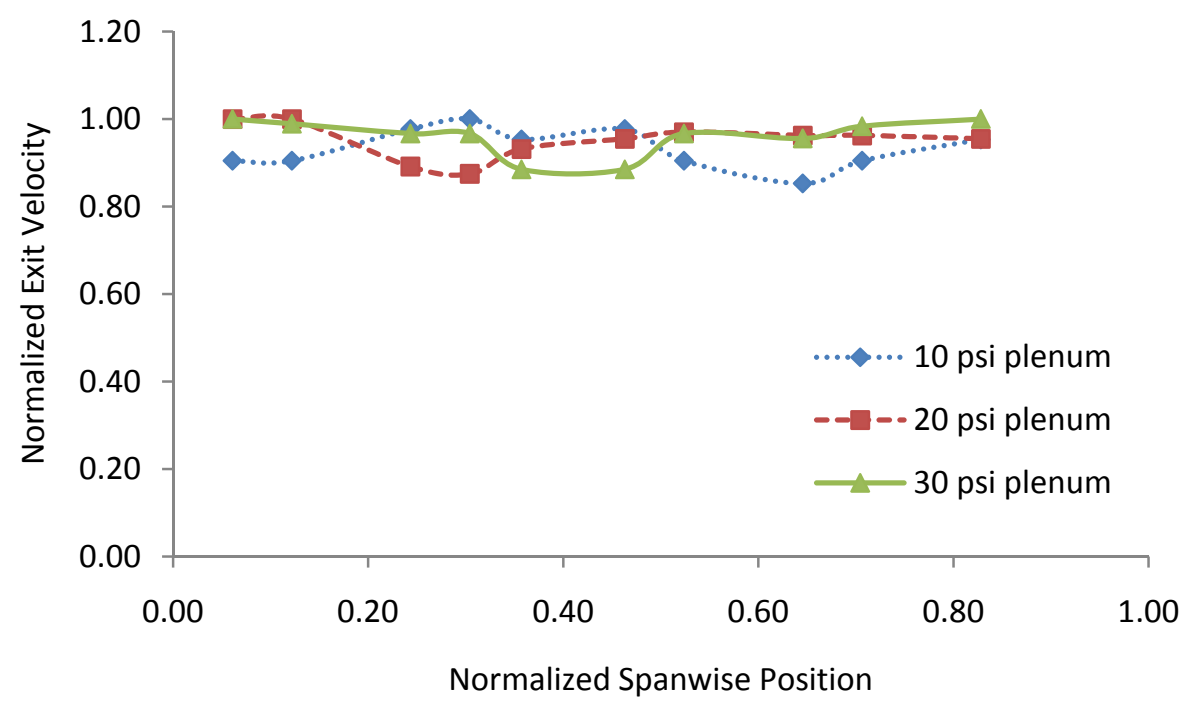

Figure 4.2.1 Leading Edge Jet Exit Velocity Profile

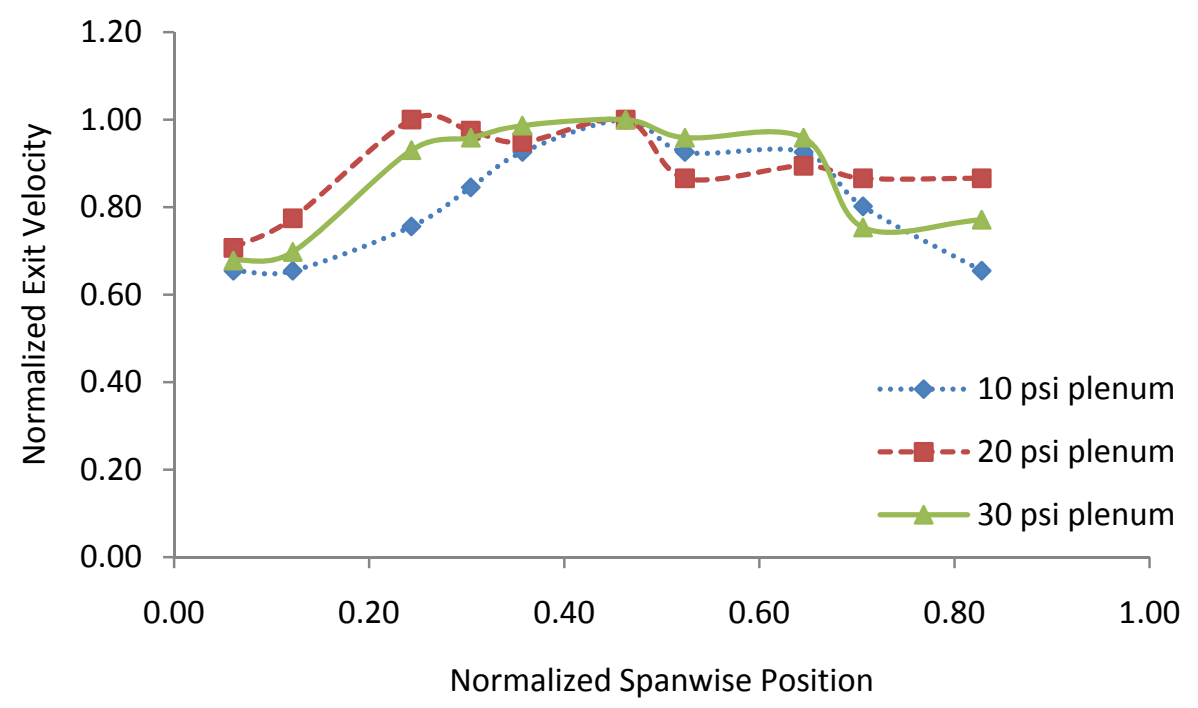

Figure 4.2.2 Trailing Edge Jet Velocity Profile Versus Spanwise Location

Following the completion of the test cases at angles of attack from zero to sixteen degrees, the section lift coefficient for the various tunnel speeds could be compared to the results of the airfoil without active circulation control to show the effect they had on the stall angles of the airfoil. As an example, Figure 4.2.3 shows the effect of trailing edge circulation control on the airfoil. The stall angle is decreased from eight degrees without $\mathrm{CC}$ to six degrees with the 
active circulation control. This trend continues as blowing coefficient $\left(\mathrm{C}_{\mu}\right)$ varies from 0.0006 to 0.0011 and finally to 0.0019 . The plot also shows as the blowing coefficient decreases, that is the tunnel velocity increases or the jet velocity increases, the circulation control becomes less effective. Similarly, in Figure 4.2.4, as the blowing coefficient increases, the drag coefficient goes down. This is predicted since the more lift added to a particular airfoil, the more drag force it experiences. These plots also illustrate that the use of circulation control ejector slots on the trailing edge of an airfoil shows evidence of camber on the airfoil, so the model ceases to act as an elliptical airfoil under blowing conditions.

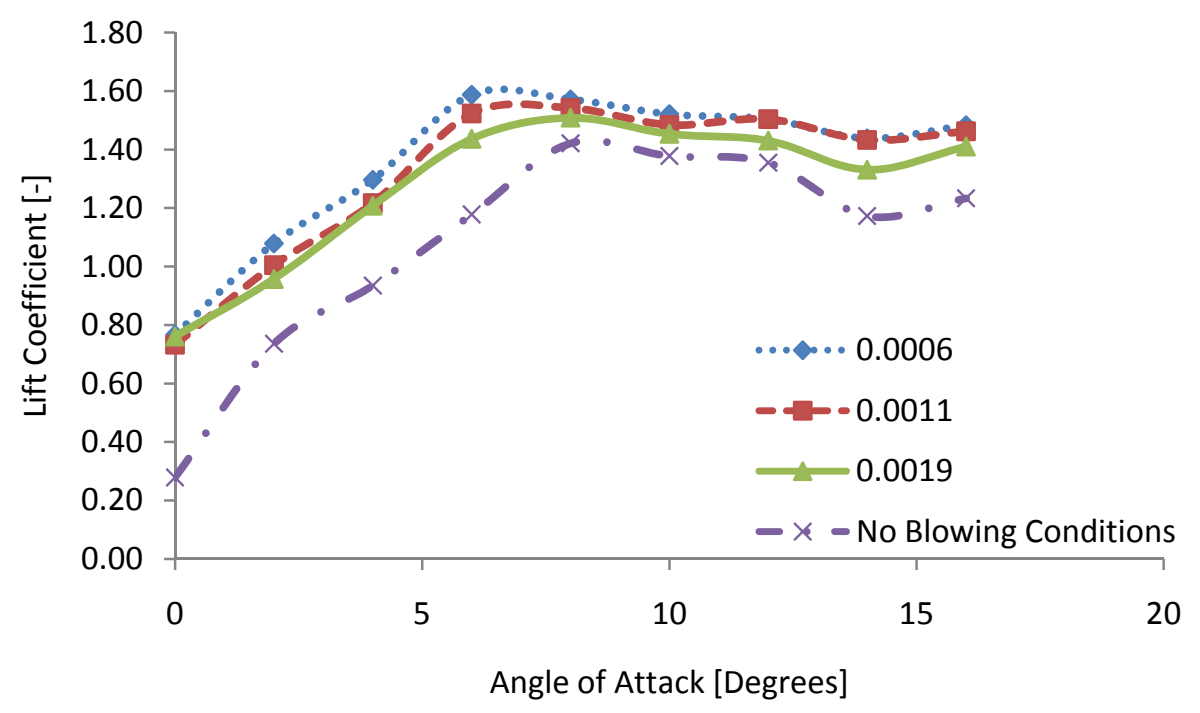

Figure 4.2.3 Section Lift Coefficient Versus Angle of Attack (Tunnel Speed 120 FPS) 


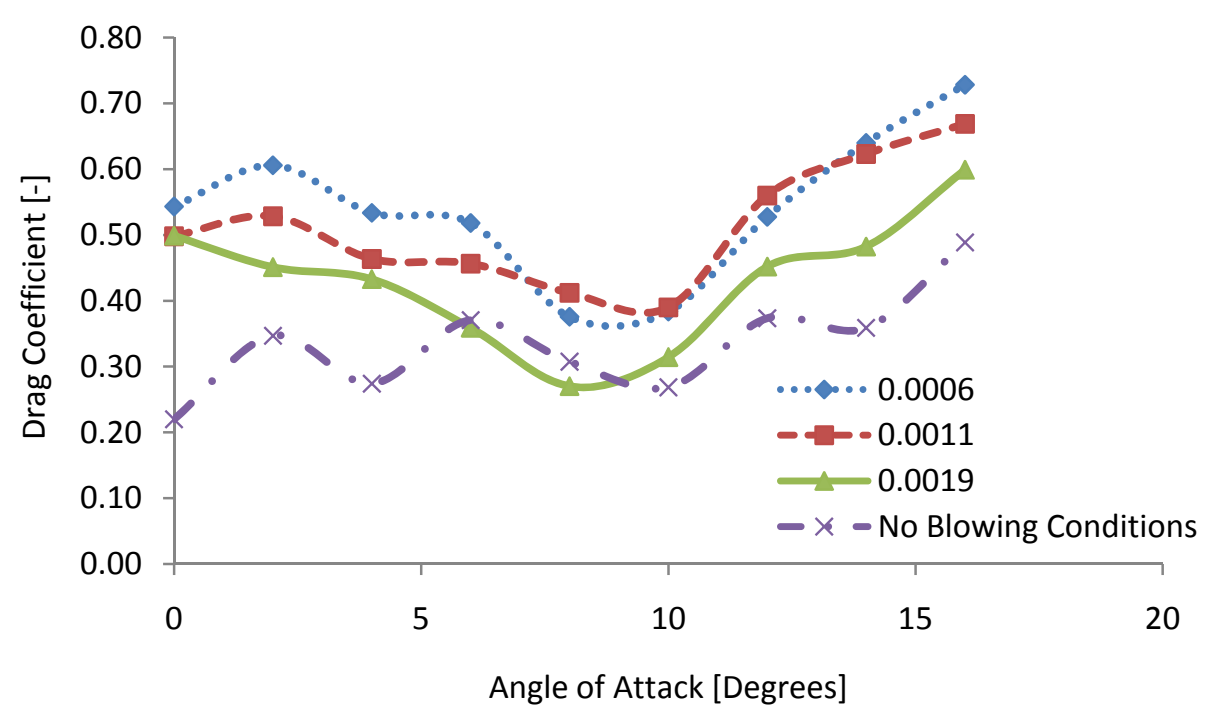

\section{Figure 4.2.4 Section Drag Coefficient Versus Angle of Attack (Tunnel Speed 120 FPS)}

At other tunnel speeds tested ( 80 and 100 FPS), the results are similar, with the stall angle occurring between six and seven degrees. The same trends also occurs in the lift coefficient, the maximum increase is when the blowing coefficient is lowest, suggesting that the higher the tunnel speed or exit jet velocity is the less of an effect that $\mathrm{CC}$ has on the airfoil. The remaining trailing edge activated results can be found in Appendix A, and the leading edge data can be found in Appendix B.

A second data comparison was conducted as to examine the relationship between lift coefficient and blowing coefficient at certain selected angles of attack, also known as the lift augmentation ratio. These values were compared to previous experimental data, which stated that the maximum lift augmentation ratio achievable was 80 [Englar, 2005]. Below, Figure 4.2.5 shows the scatter of each lift coefficient in relation to its corresponding blowing coefficient. A linear fit was applied to the plot to show the effective lift augmentation ratio. According to the results, the lift augmentation ratio is 141.8 at the model's stall angle. This is $75 \%$ higher than the results predicted to give a lift augmentation ratio of 80 . The previous experiments were able to study blowing coefficients ranging from 0.02 to 0.16 and did not focus on low speed results. This study focused on slower tunnel velocities and smaller plenum pressures, and as a result, the maximum blowing coefficient experienced was 0.0042 on the trailing edge. This only compares to twelve percent of the results from Englar's experiments. Because the lift augmentation ratio affected the slope of the $C_{L}$ vs. $C_{\mu}$ plot, the division of such a small value of blowing coefficient 
will skew the values of the lift augmentation ratio. Similar results are shown in Figure 4.2.6 for the drag coefficient as a function of the blowing coefficient. Appendix $\mathrm{C}$ shows the results from similar data at zero angle of attack as well as an angle of attack of eight degrees for both the leading and trailing edge activated slots.

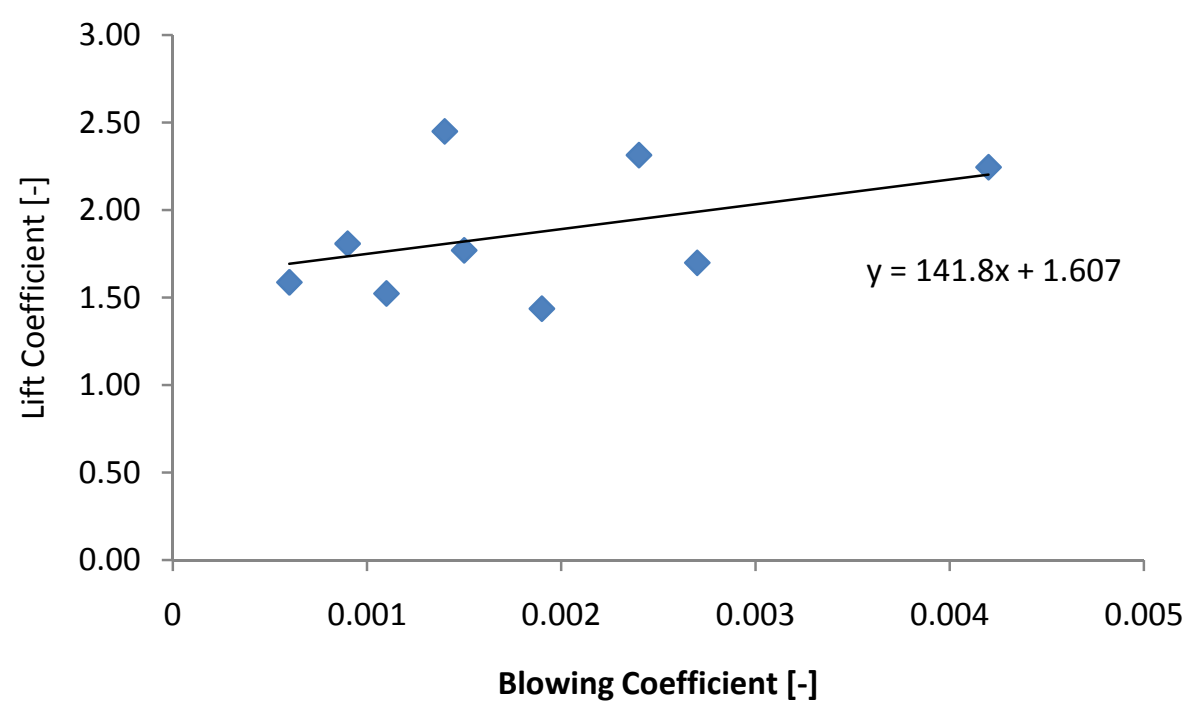

Figure 4.2.5 Lift Coefficient versus Blowing Coefficient (Trailing Edge Slot AOA $=6^{0}$ )

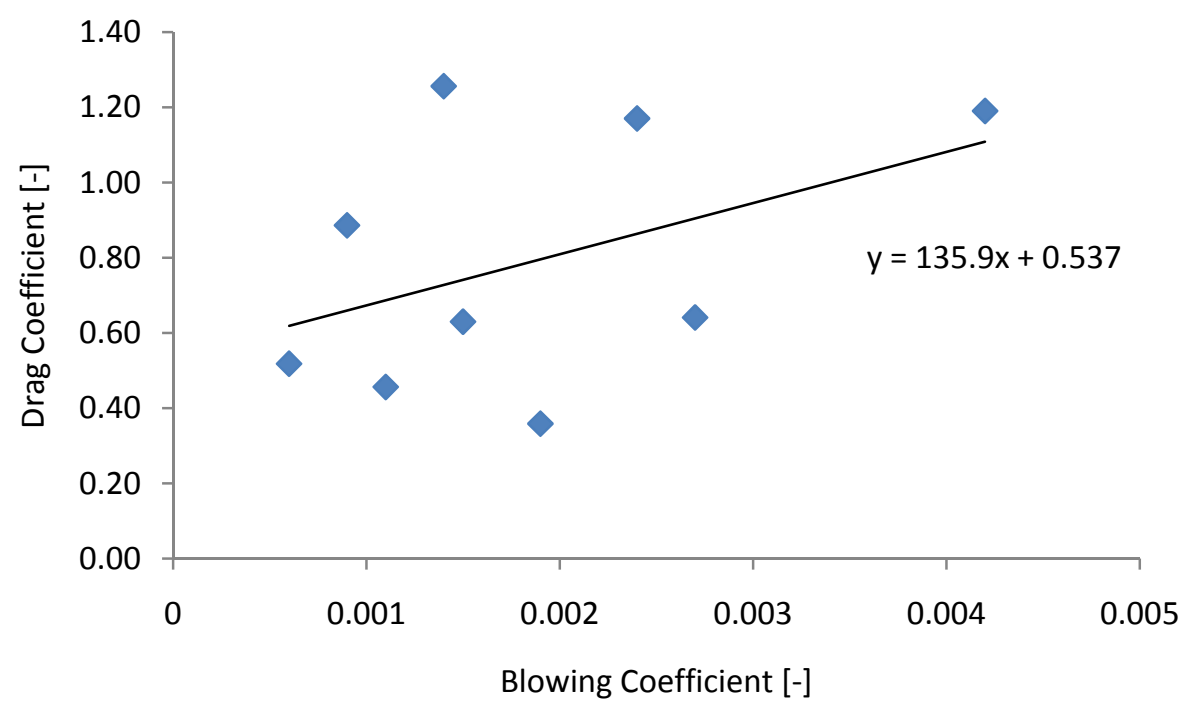

Figure 4.2.6 Drag Coefficient versus Blowing Coefficient (Trailing Edge Slot AOA $=6^{\circ}$ ) 
A preliminary set of data was taken with multiple circulation control slots activated. This testing was only done once and held velocity, as well as plenum pressure constant. The only two parameters varied were angle of attack and the activated slots. The three slot configurations tested were leading edge top and trailing edge top activated leading edge top and trailing edge bottom activated, and leading edge bottom and trailing edge top activated. These experiments resulted in the data shown in Figures 4.2.7 and 4.2.8. Because the experiment was only done at one tunnel speed and one blowing condition, no real trend could be assumed, however, the data does look promising, and the three tests give an experimental increase in lift of around $72 \%$ at the stall angles.

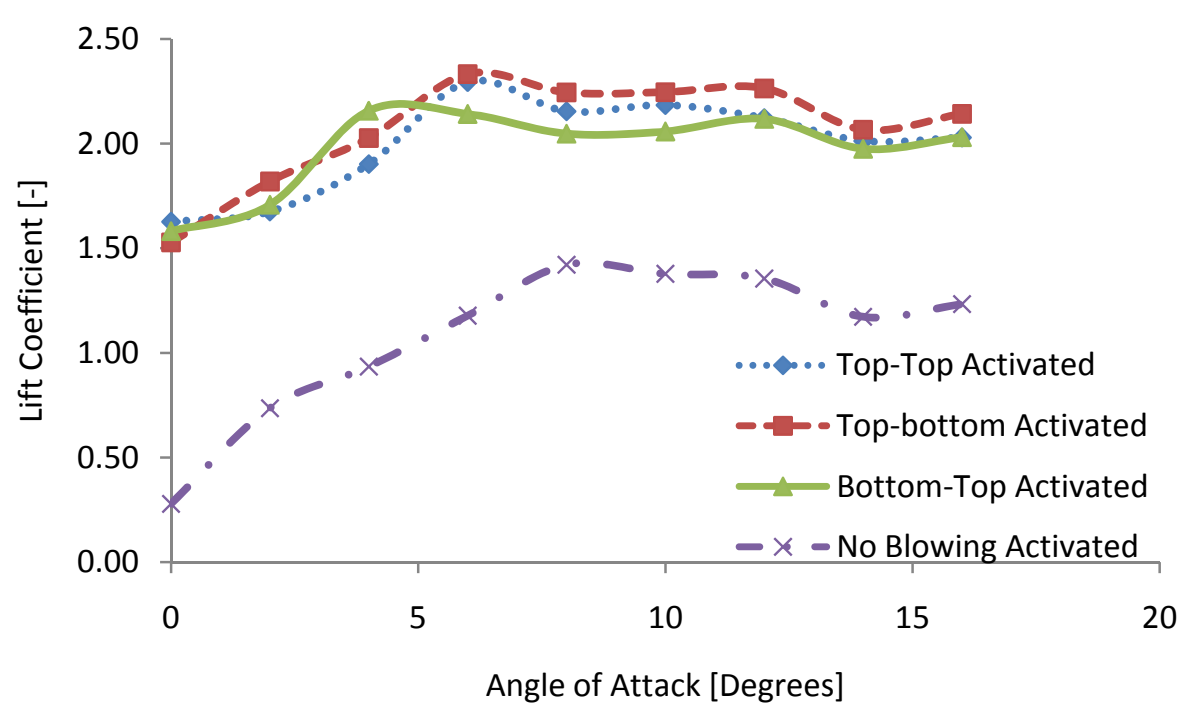

Figure 4.2.7 Lift Coefficients of Multiple Activated Blowing Slots Versus Angle of Attack 


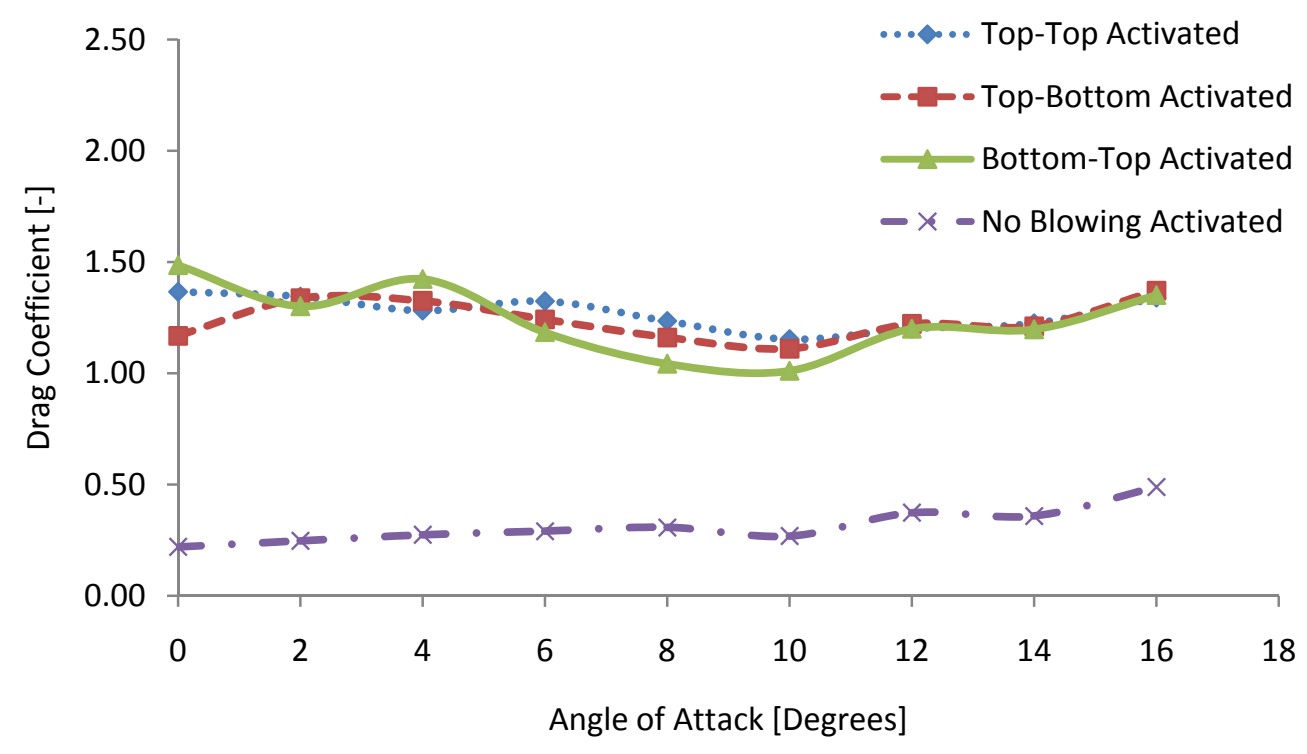

Figure 4.2.8 Drag Coefficients of Multiple Activated Blowing Slots Versus Angle of Attack

\subsection{Verification}

In order to check the accuracy of the experimental results, a model simulation was conducted using a computational fluid dynamics (CFD) software package. A CCHB model was constructed in Gambit, including a mesh with two separate sections, a close field and a far field, to add precision directly around the airfoil surface. The near field growth rate was 1.15 and had a maximum distance between mesh points of 0.2 inches. The far field dimensions used a growth rate of 2.5 and had a maximum distance between mesh points equal to 1 inch. This meshed model is shown in Figure 4.3.1, where the airfoil is at zero angle of attack. 


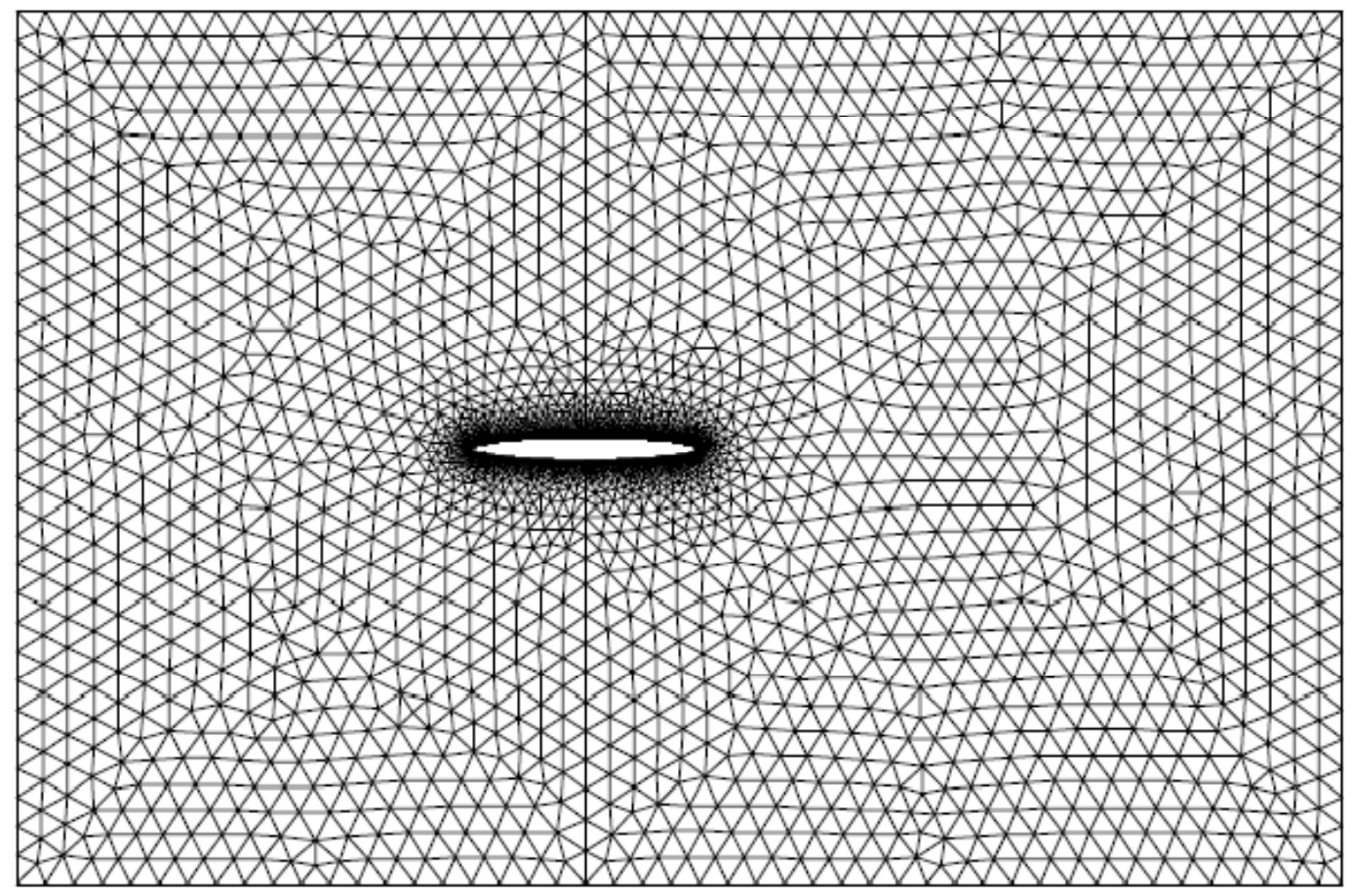

Figure 4.3.1 Meshed Circulation Control Model

Using a two-dimensional double precision $\mathrm{k}-\omega$ turbulence simulation in the Fluent software package. Using the energy equation as well as the viscosity model solution settings, as well as a $1 \times 10^{-3}$ continuity convergence criteria, angles of attack of six, eight, and ten were examined at a tunnel speed of 120 feet per second. The first sets of trials were run with no blowing conditions to examine how accurate the wind tunnel experiments were for the baseline model case. Three more case runs were tested with the top trailing edge jet velocities corresponding to 10,20 and 30 psi plenum pressures. These slot activated tests were also run at six, eight, and ten degrees angle of attack, similar to the trials completed with no blowing conditions activated. Figure 4.3.2 shows the lift coefficient CFD results plotted with the experimental results versus the four different blowing conditions at tunnel wind speed of 120 feet per second. In this plot, the model rests at eight degrees angle of attack, and shows a 2-3\% difference between the experimental and computational results at blowing coefficients less than 0.001. In the results for blowing coefficients larger than 0.001 shows a difference of 6-9\% between the CFD work and the experimental lift coefficients. This shows a congruency in the data taken in the wind tunnel with the results found through computational analysis. Similar plots for six and ten degrees angle of attack can be found in Appendix F. 


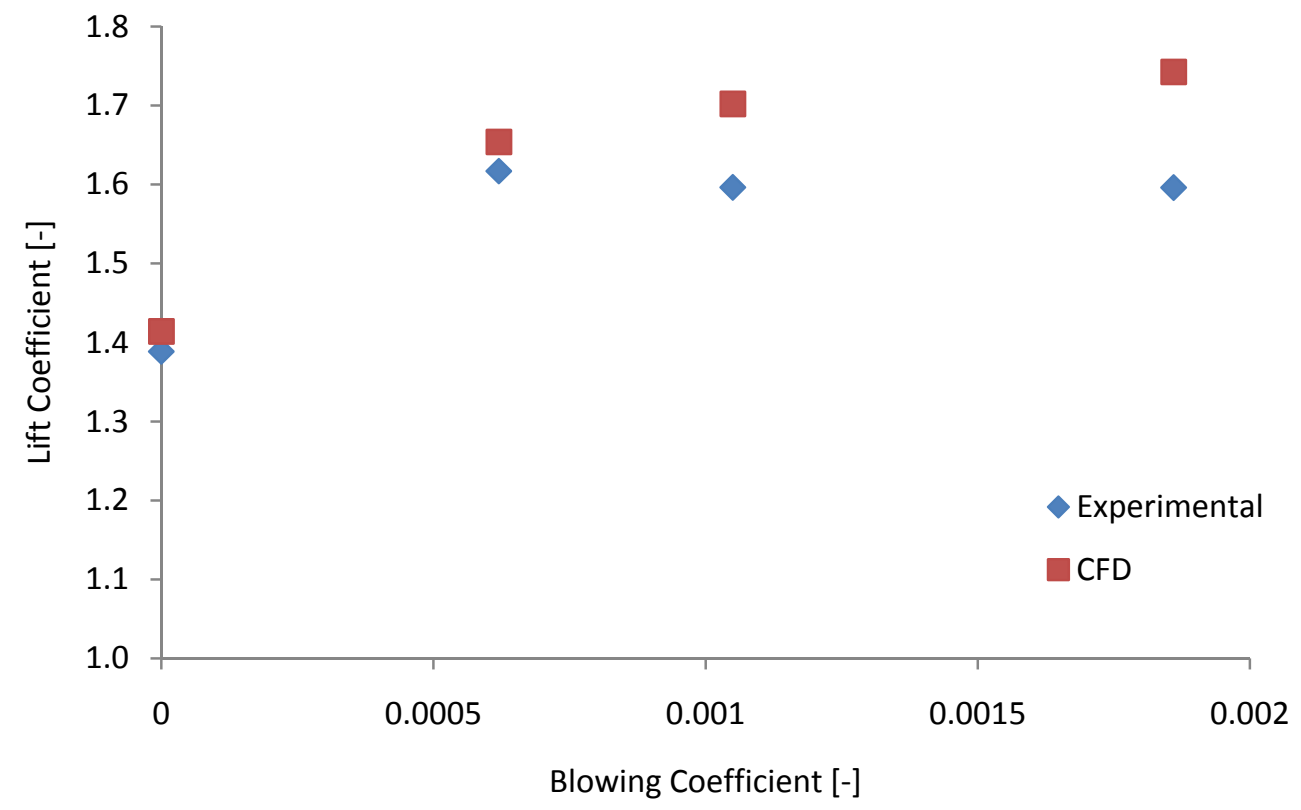

Figure 4.3.2 Experimental and Computational Lift Coefficient Results $\left(\mathrm{AOA}=8^{0}\right)$ 


\section{Chapter 5: Conclusions and Recommendations}

\subsection{Conclusions}

This research set out to study the effect that circulation control had on the stall angles of a 10:1 elliptical airfoil. A variety of different test scenarios were completed which examined blowing coefficients varying between 0.0006 and 0.0127 by fluctuating wind tunnel speed between 80, 100 and 120 feet per second, as well as changing the jet exit plenum pressures between 10,20, and 30 pounds per square inch. The result as to how the circulation control causes the stall angle of this particular airfoil was found to occur at six degrees for both leading and trailing edge active blowing control.

The section lift coefficient of the airfoil was greatly increased from a maximum of 1.4 at stall without circulation control to a maximum value of 2.4 using $\mathrm{CC}$, a $70 \%$ increase. With this increase in lift coefficient, the section drag coefficient was also raised from a maximum of 0.5 without $\mathrm{CC}$ to a value of 1.4 with active controls to achieve a $70 \%$ increase in lift. This increase in lift and consequently, in drag as well, comes at a reduction of stall angle of two degrees.

In previous research, several experiments were conducted on a $20 \%$ elliptical airfoil with a $5 \%$ camber ratio, which showed an increase in stall angle from eight to fourteen degrees. Several conditions can be attributed to the fact that the data in this work does not compare, including,

- Blockage ratio changes when circulation control is activated on either leading or trailing edge slots, and therefore wall interference could become troublesome at high angles of attack,

- There is a force reaction on the wing when circulation control is activated, producing an artificial lifting force, and

- Physical angle of attack is different than the virtual angle of attack the freestream air flow sees, this phenomenon is shown in Figure 5.1.1.

Due to the presence of these physical aspects, the results from this experimentation indicate the possibility of novel significance in the world of circulation control. 


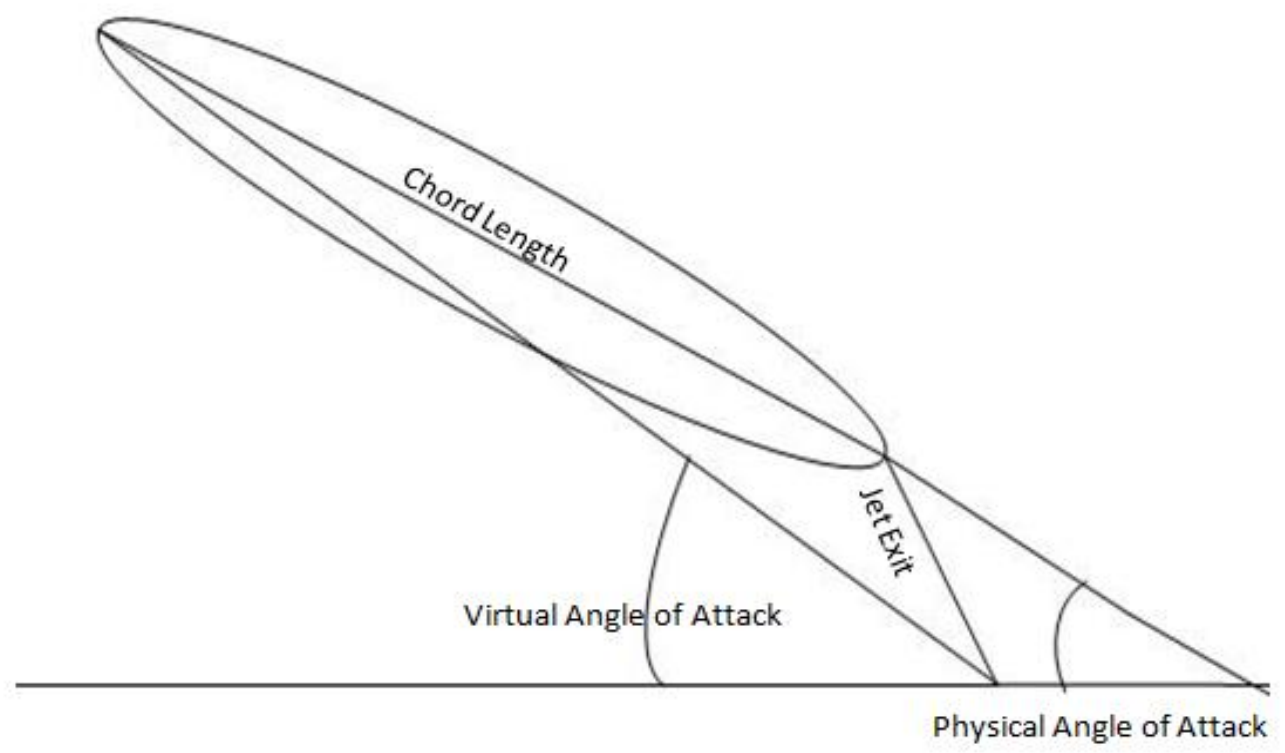

Figure 5.1.1 Physical Angle of Attack Compared to Virtual Angle of Attack

\subsection{Recommendations}

To continue with future research in the area of circulation control, several aspects need to be studied. The first of these topics is low speed results. It has been shown that circulation control is less effective as the free-stream velocity of the air moving around the wing increases. Because of tunnel limitations, velocities lower than 80 feet per second were excluded from this experiment. Slower speeds must be examined to be able to use the circulation control wing in other applications, such low rotor speeds and primarily as windmills.

The second facet needing future consideration is to look more closely at the leading edge effects of circulation control on aerodynamic forces, as well as the stall angles. According to the resultant data in this experiment, the leading edge activation impacts the wing's drag on a larger scale because of the increased surface area that the jet has to interact with the model.

Another suggestion for future research is to experiment with different exit jet angles to see what effect this jet has on the virtual camber of the airfoil shape. It has been shown that because the jet exits at an angle different from the chord length, this changes the camber characteristics of the airfoil, and changes an elliptical airfoil into an effective cambered airfoil. 
A fourth phase to be studied is multiple slot blowing conditions. This research looked at the effect that one activated slot had on the lift and drag of the entire airfoil. Three separate multiple activated configurations were tested. These tests included both leading and trailing edge top slots activated leading edge top and trailing edge bottom slots activated, and the bottom leading edge and top trailing edge slots activated. In these experiments, tunnel velocity and plenum pressure were both held constant, only the activated slots were changed. In addition, data for this aspect of the work was only recorded once, simply to see what the trend might represent. Further research will need to be done in the future in order to achieve reliable results. As the data shows, the maximum lift coefficient increases from 1.4 without active circulation control to 2.4 with activated CC, producing a $72 \%$ overall increase in lift. Drag coefficient also increases with activated circulation control, from 0.4 to 1.4 , or $71.4 \%$.

Most previous experimentation has been conducted with models which have not changed the trailing edge shape, taking advantage of the Kutta Condition around the wing. In this study, however, the use of a large rounded trailing edge invokes the Coandă effect, in that the stream lines around the airfoil stay attached where streamlines of conventional models would separate. This circumstance leave the door open for more future interesting investigation into the effects of non-Kutta Condition models and their applications, both in high speed rotorcraft specifically helicopters, as well as low speed functions (windmills).

CFD modeling is an important tool to be used in conjunction with these future considerations. These situations can be studied on the computer to get an idea of what to expect before a model is even put into the wind tunnel and tested. There is an inherent problem with using CFD to run circulation control modeling, namely, the inexistence of one true accepted way to accurately model CFD. In other words there are several different methods that have been used in previous experimentation and though results are similar, the procedures are all very different. Computational results need to be further inspected for each of these cases as well, weather examined by itself or in conjunction with experimental results, new models, different speeds and several different blowing conditions need to be examined using CFD for circulation control to be accurately tested. 


\section{Chapter 6: References}

Abbott, I.H., Von Doenhoff, A. E., Theory of Wing Sections, Dover Publications, Inc, New York, NY, 1959.

Ambrosiani, J.P., "Analysis of a Circulation Controlled Elliptical Airfoil,” Ph.D. Dissertation, Department of Aerospace Engineering, West Virginia University, Morgantown, WV, 1971.

Anderson Jr, J.D., Fundamentals of Aerodynamics, McGraw Hill, Inc., New York, NY, 2001.

Angle II, G.M., “Aerodynamic Benefits of Near-Surface-Actuated Circulation Control Blowing Slots for Rotorcraft Use," Ph.D. Dissertation, Department of Aerospace Engineering, West Virginia University, Morgantown, WV, 2008.

Bertin, J.J., Aerodynamics for Engineers, Prentice -Hall, Inc., Upper Saddle River, NJ, 2002.

Englar, R.J., "Experimental Investigation of the High Velocity Coandă Wall Jet Applied to Bluff Trailing Edge Circulation Control Airfoils," Naval Research and Development Center Report 4708, September 1975.

Englar, R.J., "Overview of Circulation Control Pneumatic Aerodynamics: Blown force and Moment Augmentation and Modification as Applied Primarily to Fixed Wing Aircraft," Proceedings of the 2004 NASA/ONR Circulation Control Workshop, NASA CP-2005-213509, Pages 23-66, 2005.

Gibbs, E.H., “Analysis of Circulation Controlled Airfoils,” Ph.D. Dissertation, Department of Aerospace Engineering, West Virginia University, Morgantown, WV, 1975.

Harness, G.S., “An Experimental Investigation of a Circulation Controlled Cambered Elliptical Airfoil," Master's Thesis, Department of Aerospace Engineering, West Virginia University, Morgantown, WV, 1970.

Katz, J., Plotkin, A. Low Speed Aerodynamics, Cambridge University Press, Cambridge, NY, 2001.

Kind, R.J., Maul, D.J., “An Experimental Investigation of a Low-Speed Circulation-Controlled Aerofoil," The Aeronautical Quarterly, Vol. XIX, May, 1968.

Kueth, A.M., Schetzer, J.D., Foundations of Aerodynamics, John Wiley and Sons Inc., New York, NY, 1967.

Maskell, E.C., Spence D.A., “A Theory of the Jet Flap in Three Dimensions,” Proceedings of the Royal Society of London, A Mathematical and Physical Sciences Series, Vol. 251, No. 1266, 1959.

Mills, A.F., Basic Heat and Mass Transfer, Prentice Hall, Inc. Upper Saddle River, NJ, 1999. 
Myer, D.P., "An Investigation of a Circulation Controlled Cambered Elliptical Airfoil with a Rounded Trailing Edge," Master's Thesis, Aerospace Engineering Department, West Virginia University, Morgantown, WV, 1972.

Newman, B.G. "The Deflexion of Plane Jets by Adjacent Boundaries - Coandă Effect," Boundary Layer Flow Control, Pergamon Press, Vol. 1, 1961.

Theodorsen, T., "Theory of Wing Sections of Arbitrary Shape,” NACA-TR-411, 1931.

Thwaites, B., Incompressible Aerodynamics - An Account of the Theory and Observation of the Steady Flow of Incompressible Fluid Past Aerofoils, Wings, and Other Bodies, Oxford University Press, New York, NY, 1960.

White, F.M., Viscous Fluid Flow, McGraw-Hill, Inc., New York, NY, 2006. 


\section{Appendix A}

Section lift coefficient and section drag coefficients versus angle of attack with the trailing edge slot activated on the 10:1 elliptical circulation control airfoil for each test case recorded at tunnel velocities of 80,100 , and 120 feet per second. 


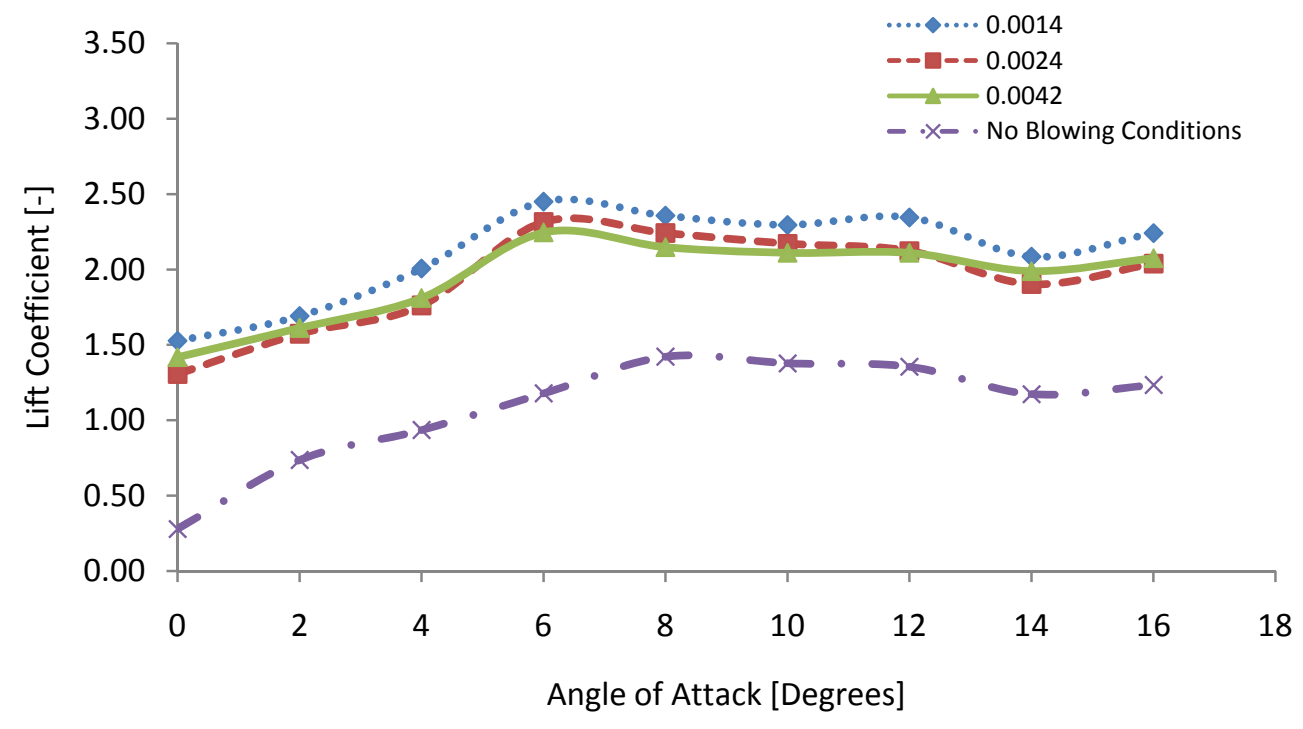

Figure A.1 Section Lift Coefficients Versus Angle of Attack (Tunnel Velocity 80 FPS)

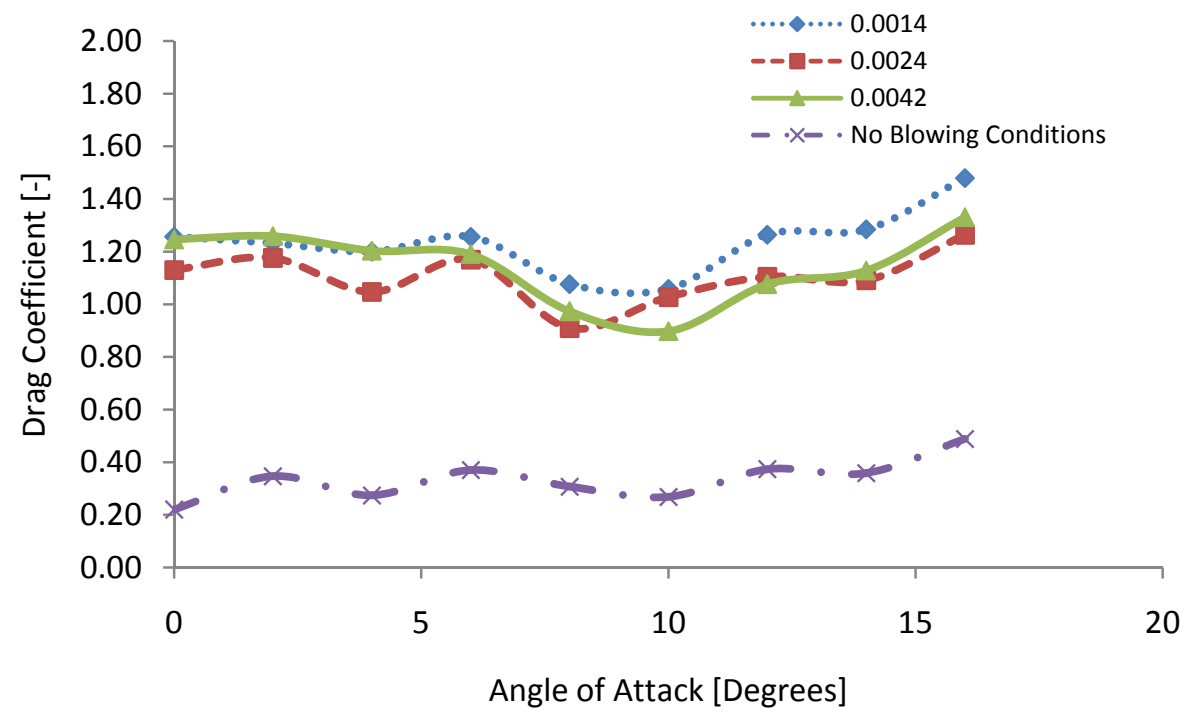

Figure A.2 Section Drag Coefficients Versus Angle of Attack (Tunnel Velocity 80 FPS) 


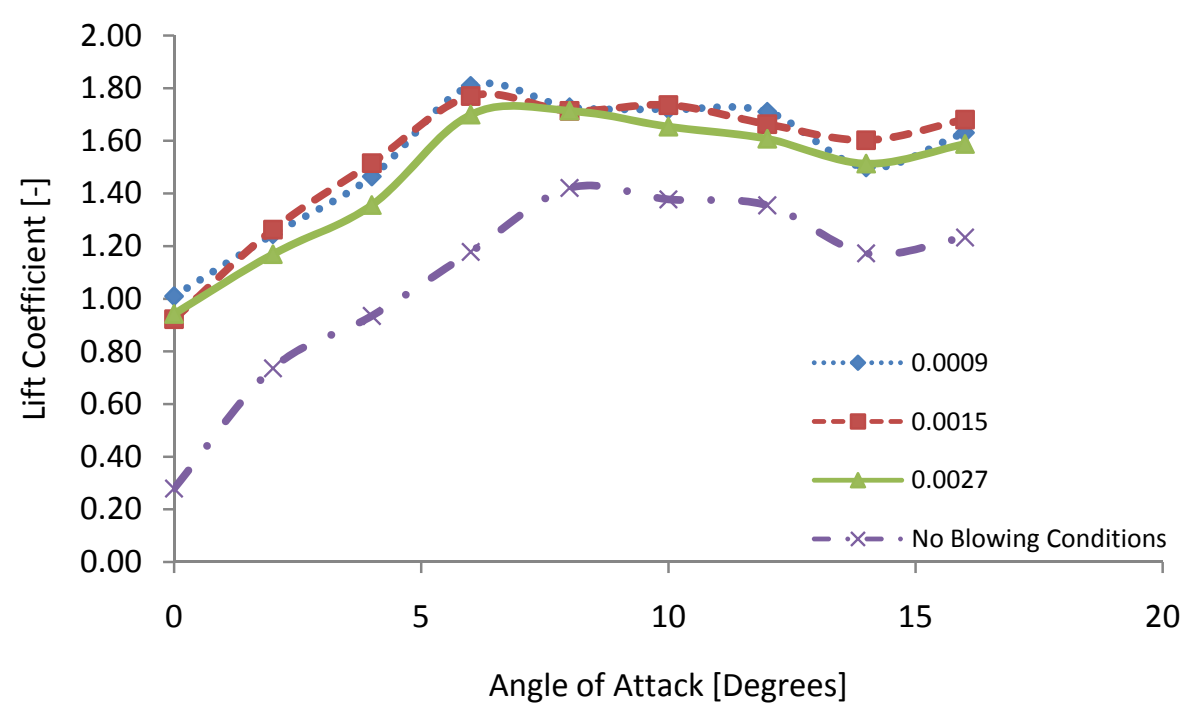

Figure A.3 Section Lift Coefficients Versus Angle of Attack (Tunnel Velocity 100 FPS)

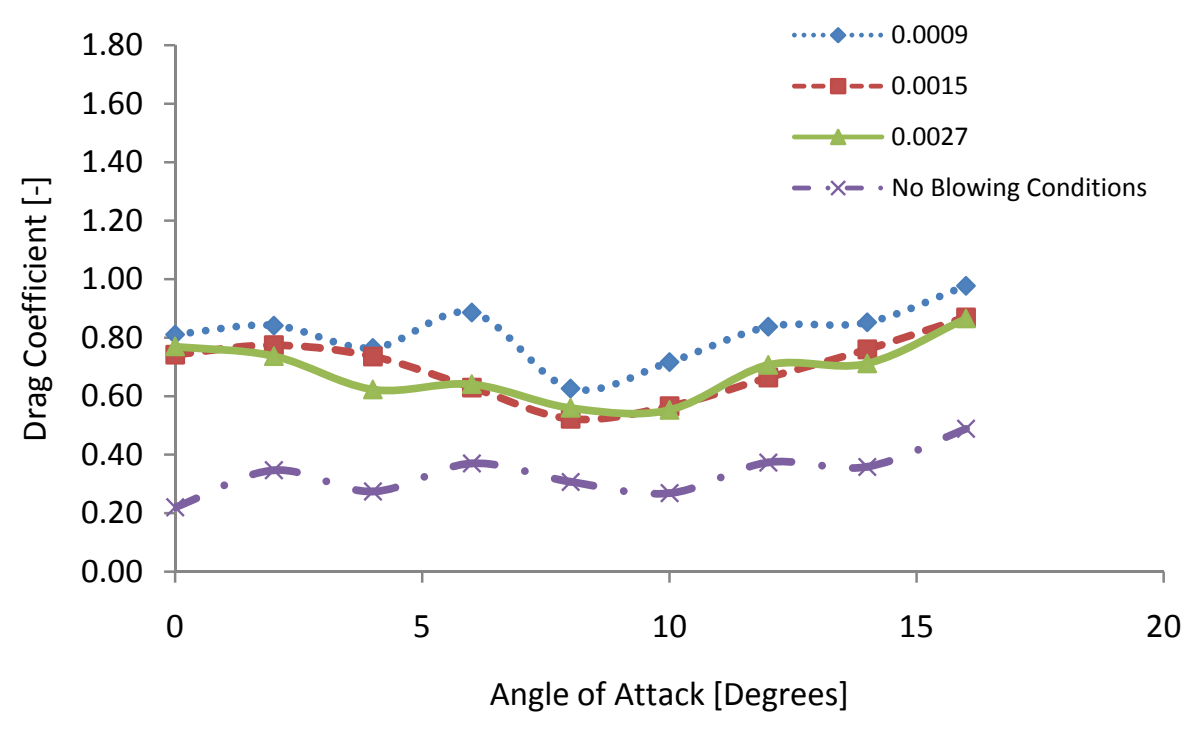

Figure A.4 Section Drag Coefficients Versus Angle of Attack (Tunnel Velocity 100 FPS) 


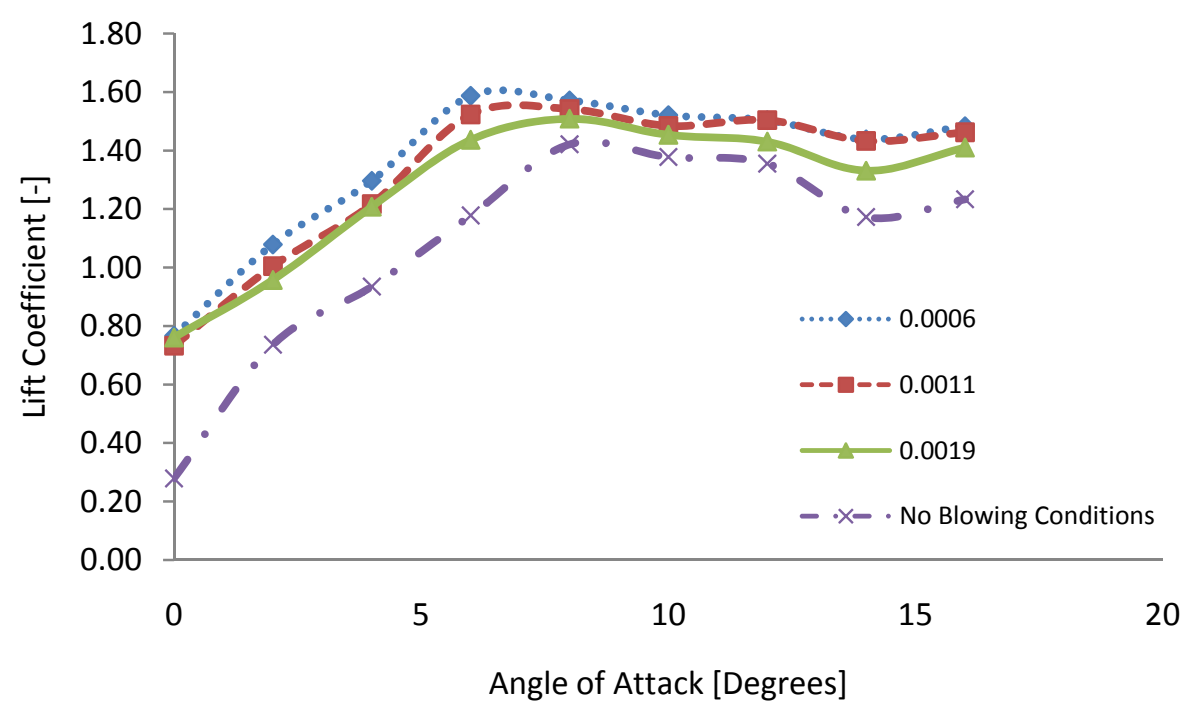

Figure A.5 Section Lift Coefficients Versus Angle of Attack (Tunnel Velocity 120 FPS)

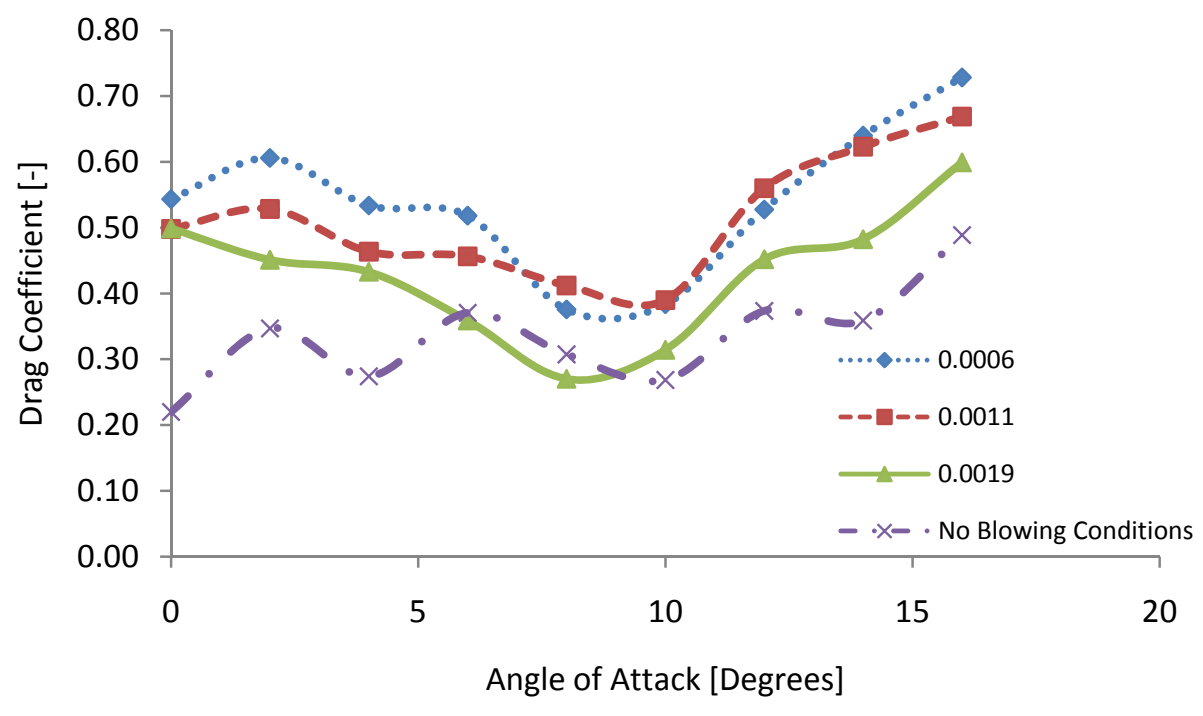

Figure A.6 Section Drag Coefficients Versus Angle of Attack (Tunnel Velocity 100 FPS) 


\section{Appendix B}

Section lift coefficient and section drag coefficients versus angle of attack with the leading edge slot activated on the 10:1 elliptical circulation control airfoil for each test case recorded at tunnel velocities of 80,100 , and 120 feet per second. 


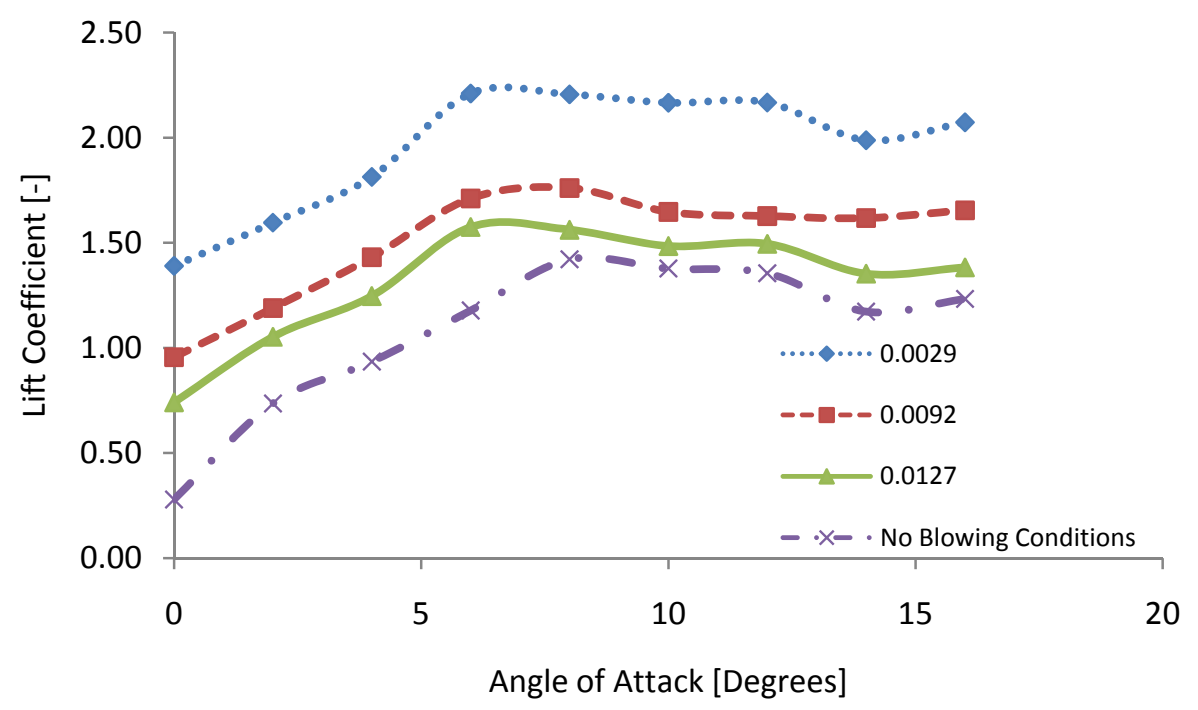

Figure B.1 Section Lift Coefficients Versus Angle of Attack (Tunnel Velocity 80 FPS)

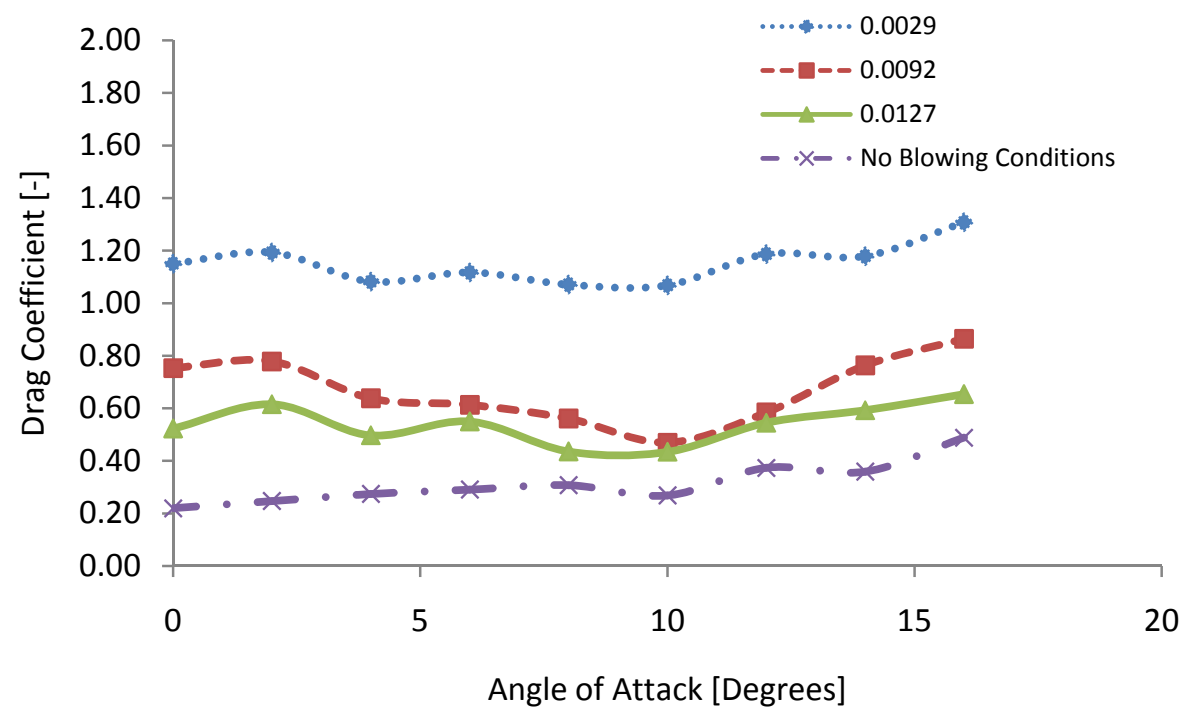

Figure B. 2 Section Drag Coefficients Versus Angle of Attack (Tunnel Velocity 80 FPS) 


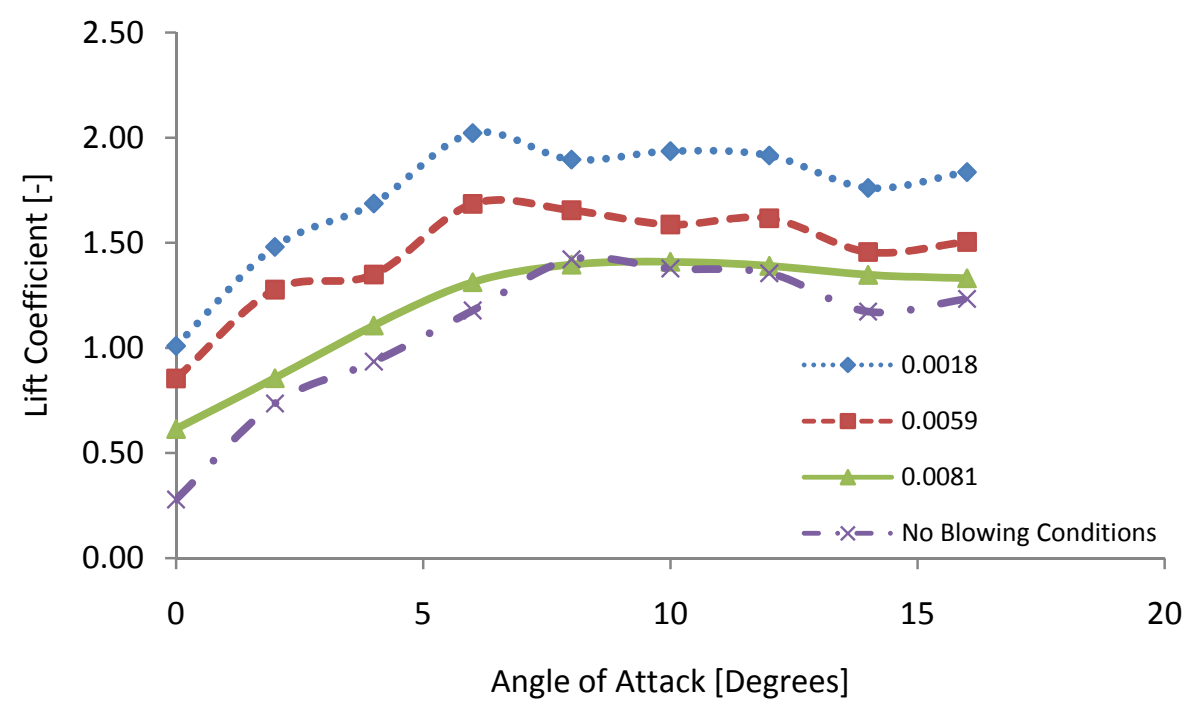

Figure B.3 Section Lift Coefficients Versus Angle of Attack (Tunnel Velocity 100 FPS)

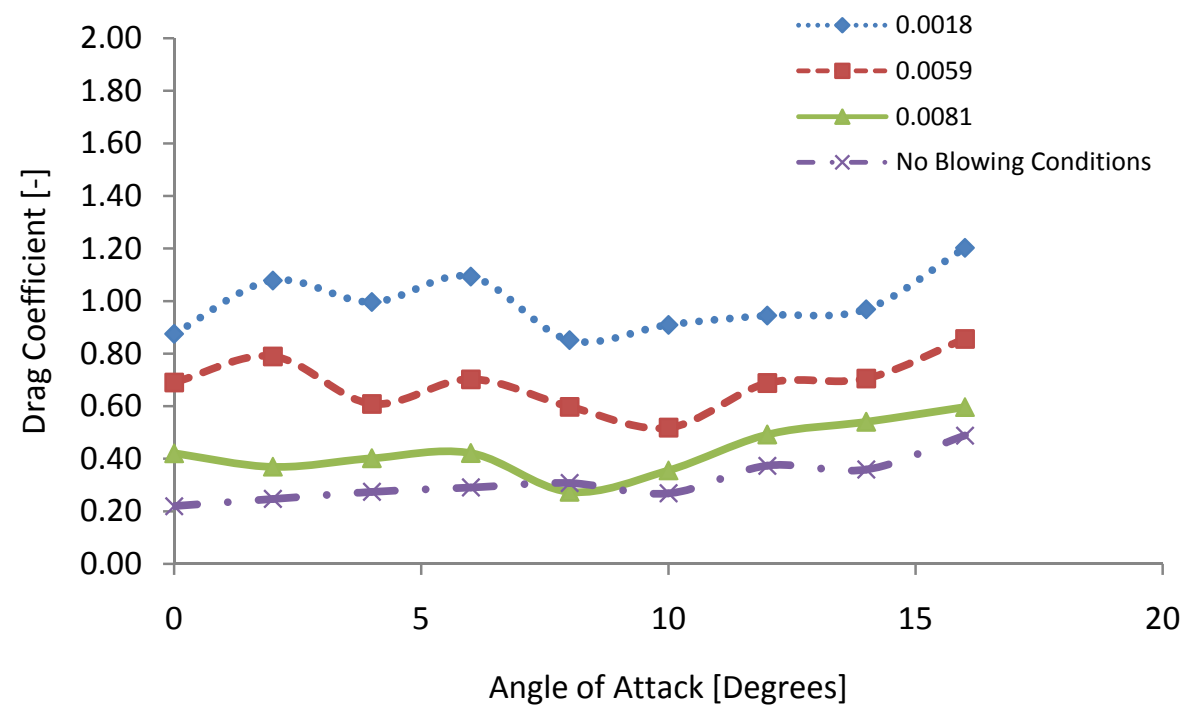

Figure B.4 Section Drag Coefficients Versus Angle of Attack (Tunnel Velocity 100 FPS) 


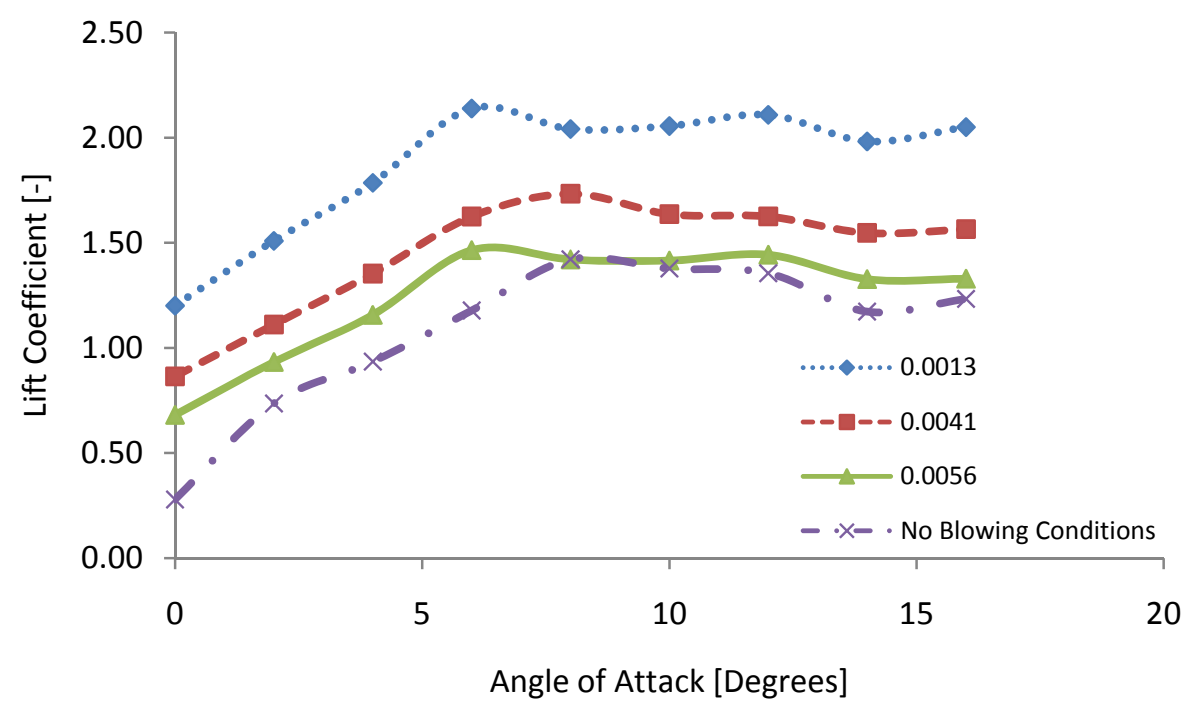

Figure B.5 Section Lift Coefficients Versus Angle of Attack (Tunnel Velocity 120 FPS)

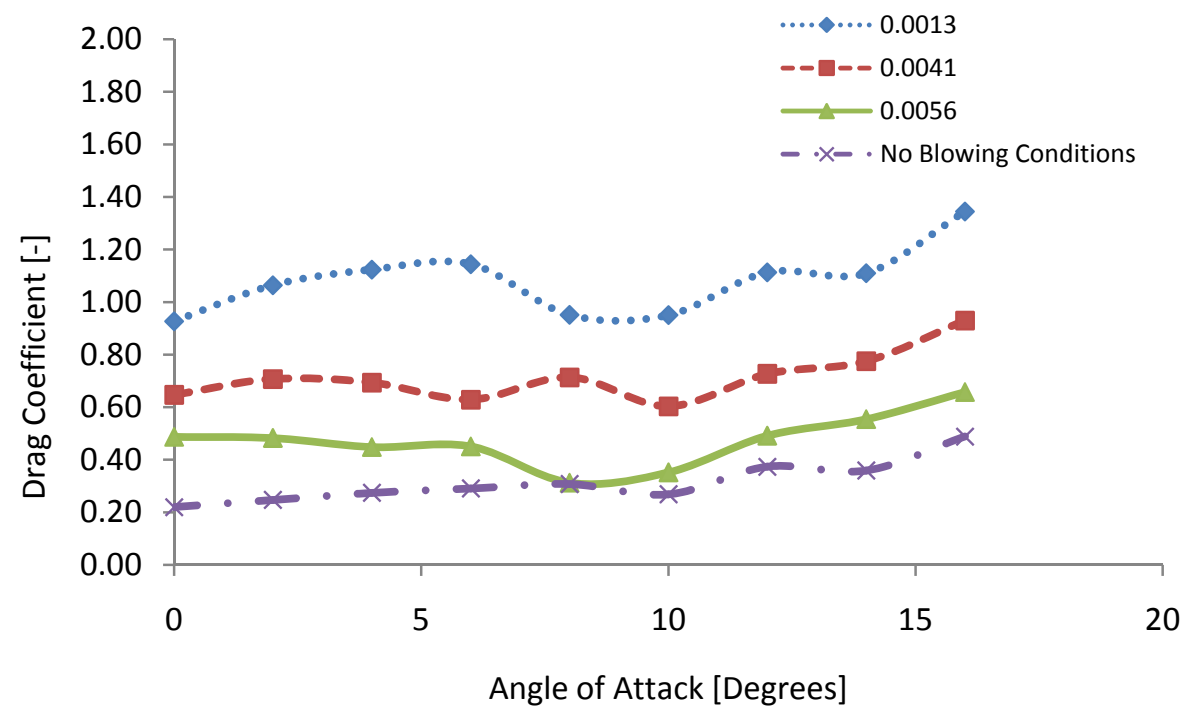

Figure B.6 Section Drag Coefficient Versus Angle of Attack (Tunnel Velocity 120 FPS) 


\section{Appendix C}

This appendix shows the results of the lift augmentation ratio study for the leading edge activated over a range of angles of attack including zero, six, and eight degrees. Also shown in this section are the results for a similar study done on the drag versus blowing coefficient ratio. 


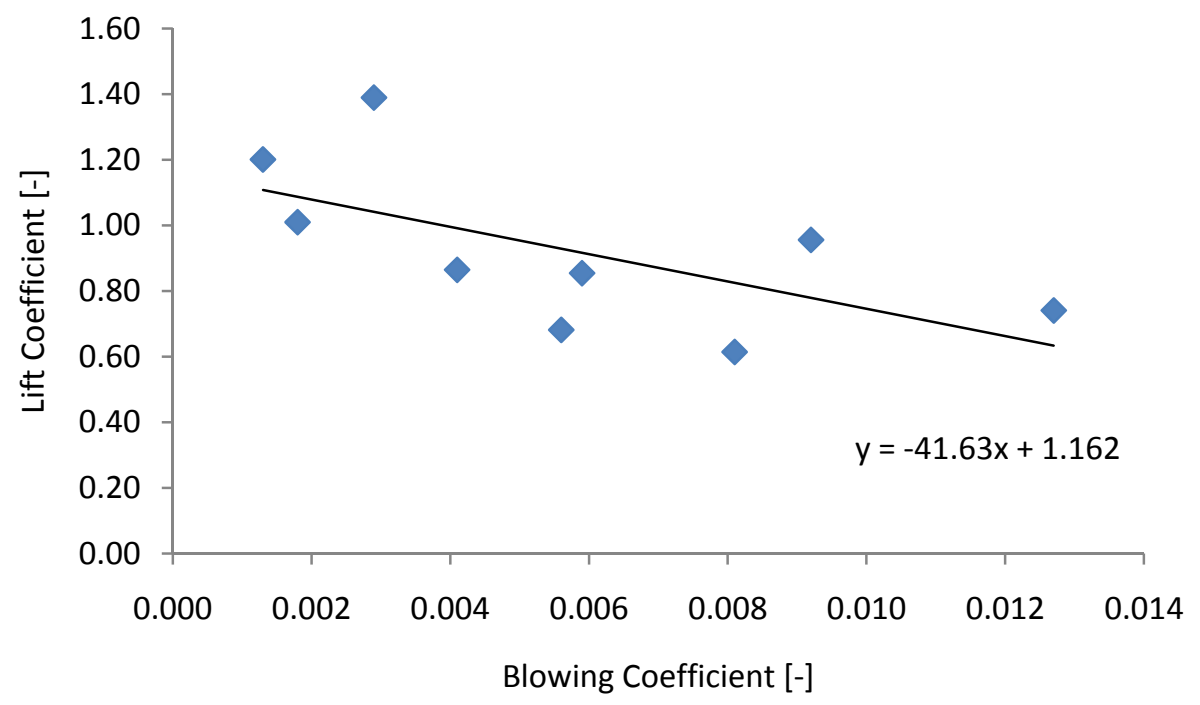

Figure C.1 Lift Coefficient versus Blowing Coefficient ( $\left(0^{\circ}\right.$ Angle of Attack)

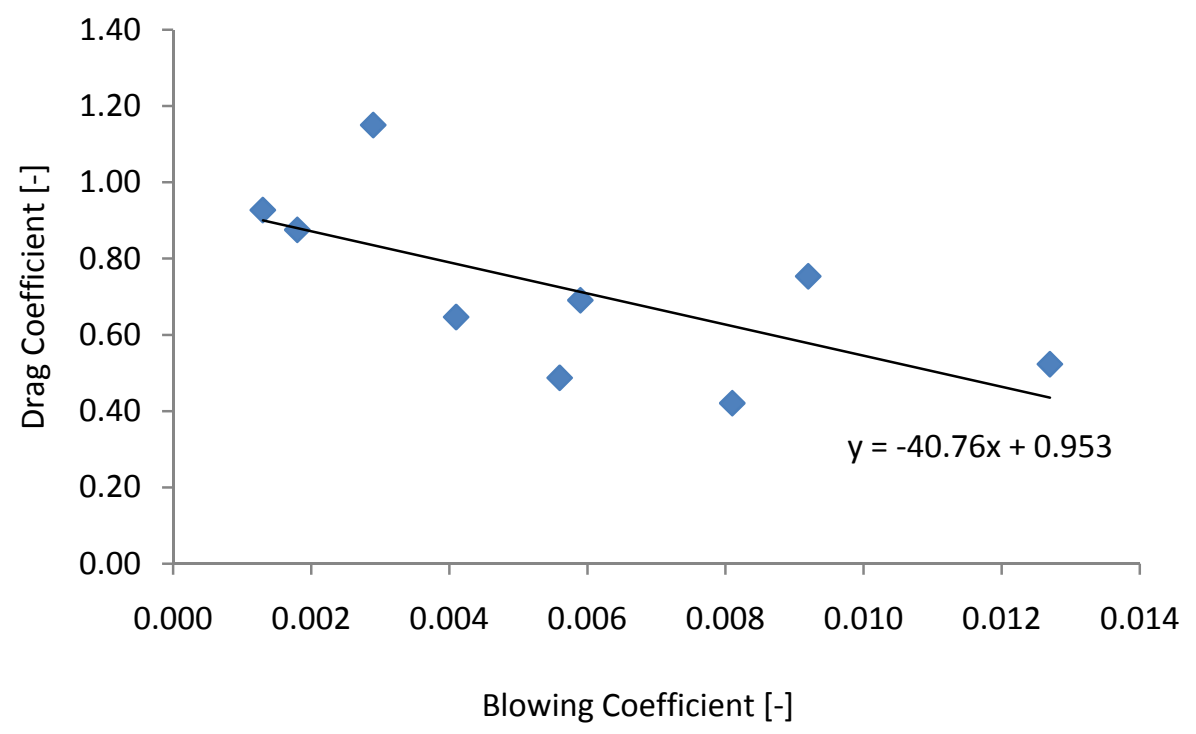

Figure C.2 Drag Coefficient versus Blowing Coefficient ( $\left(0^{\circ}\right.$ Angle of Attack) 


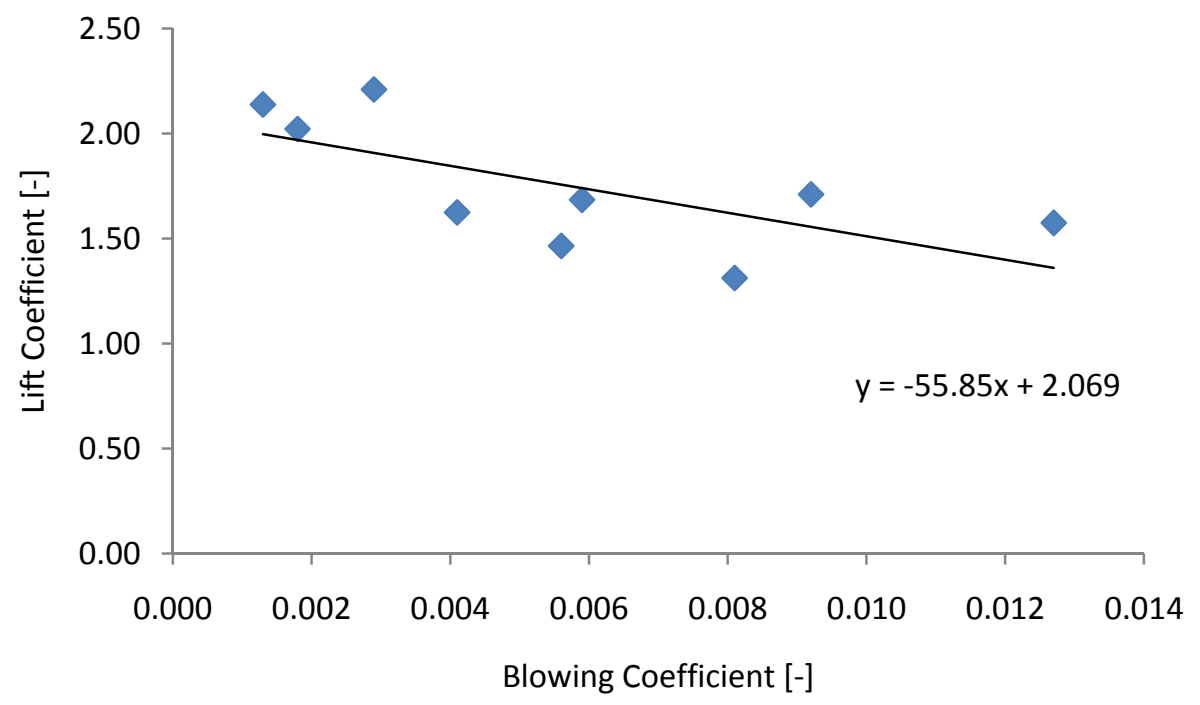

Figure C.3 Lift Coefficient versus Blowing Coefficient ( $6^{\circ}$ Angle of Attack)

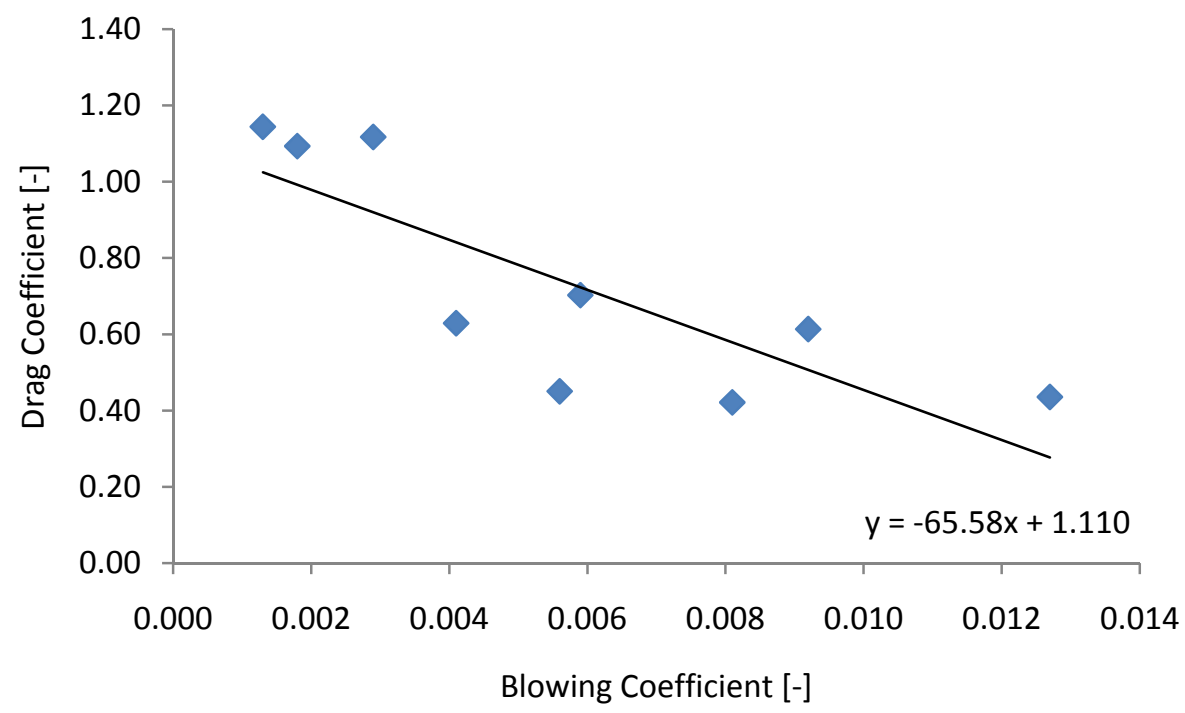

Figure C.4 Drag Coefficient versus Blowing Coefficient (6 ${ }^{\circ}$ Angle of Attack) 


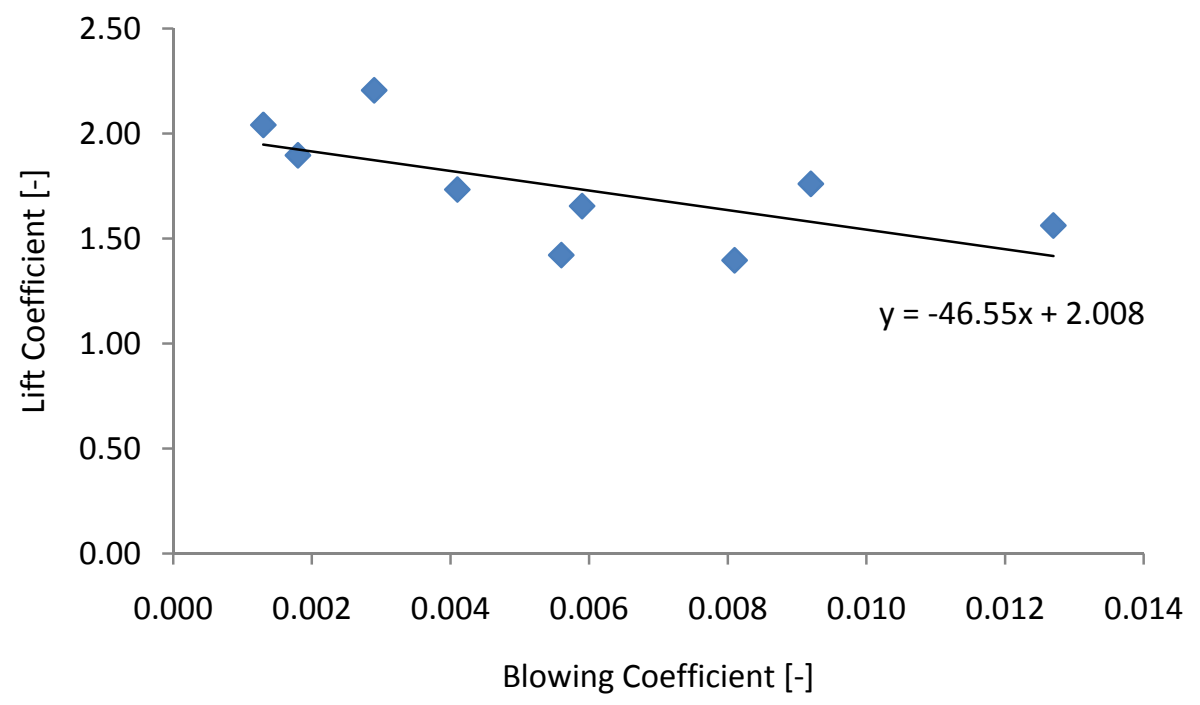

Figure C.5 Lift Coefficient versus Blowing Coefficient ( $\left(8^{\circ}\right.$ Angle of Attack)

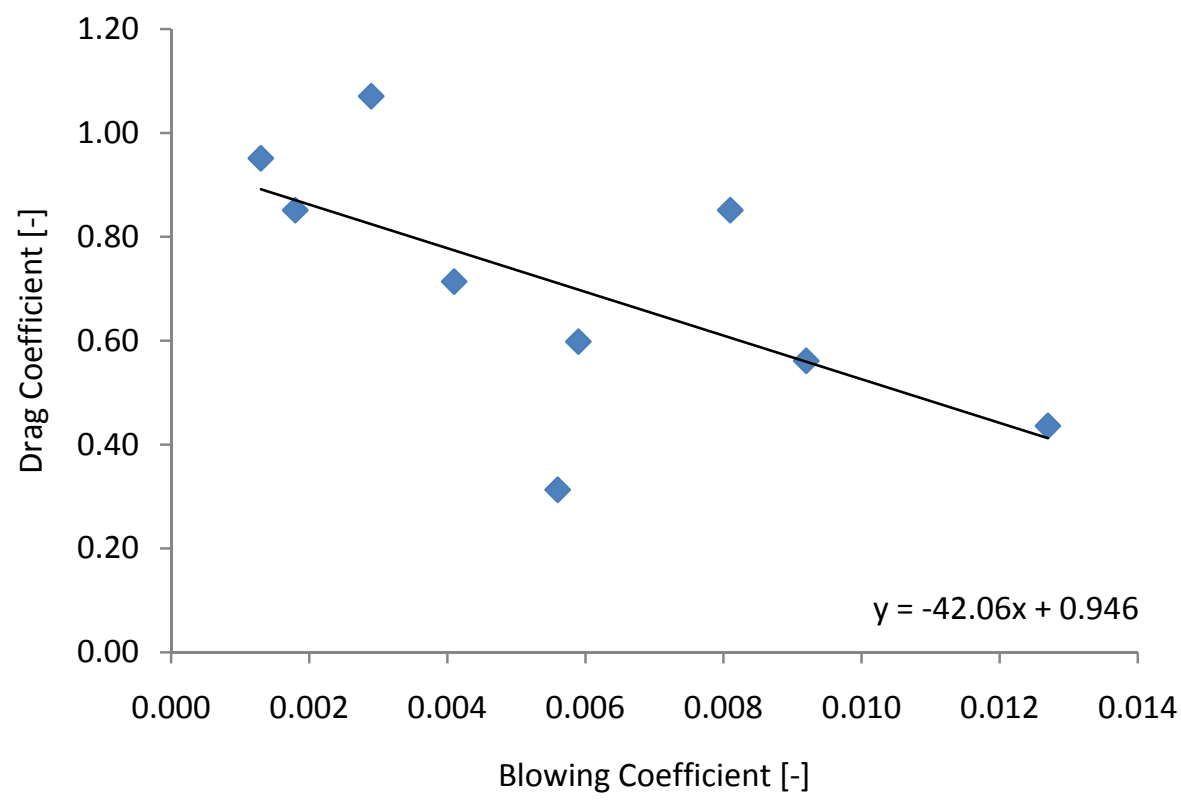

Figure C.6 Drag Coefficient versus Blowing Coefficient ( $8^{\circ}$ Angle of Attack) 


\section{Appendix D}

This appendix shows the results of the lift augmentation ratio study for the trailing edge activated over a range of angles of attack including zero, six, and eight degrees. Also shown in this section are the results for a similar study done on the drag versus blowing coefficient ratio. 


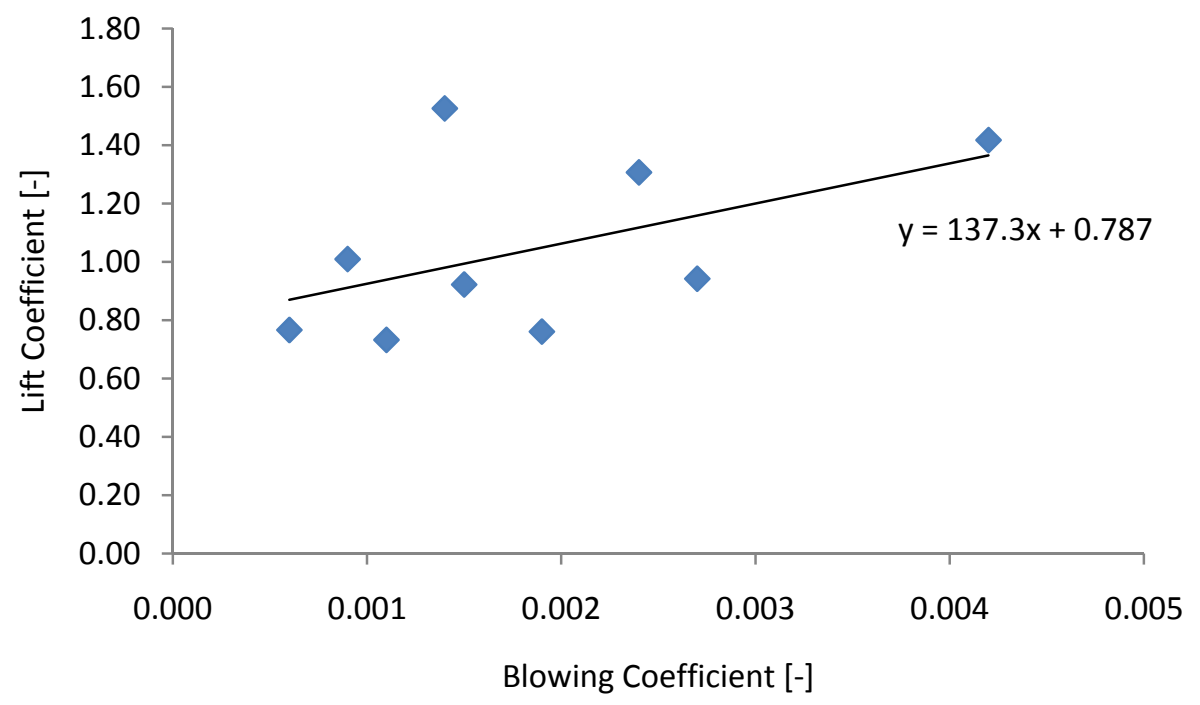

Figure D.1 Lift Coefficient versus Blowing Coefficient ( $\left(0^{\circ}\right.$ Angle of Attack)

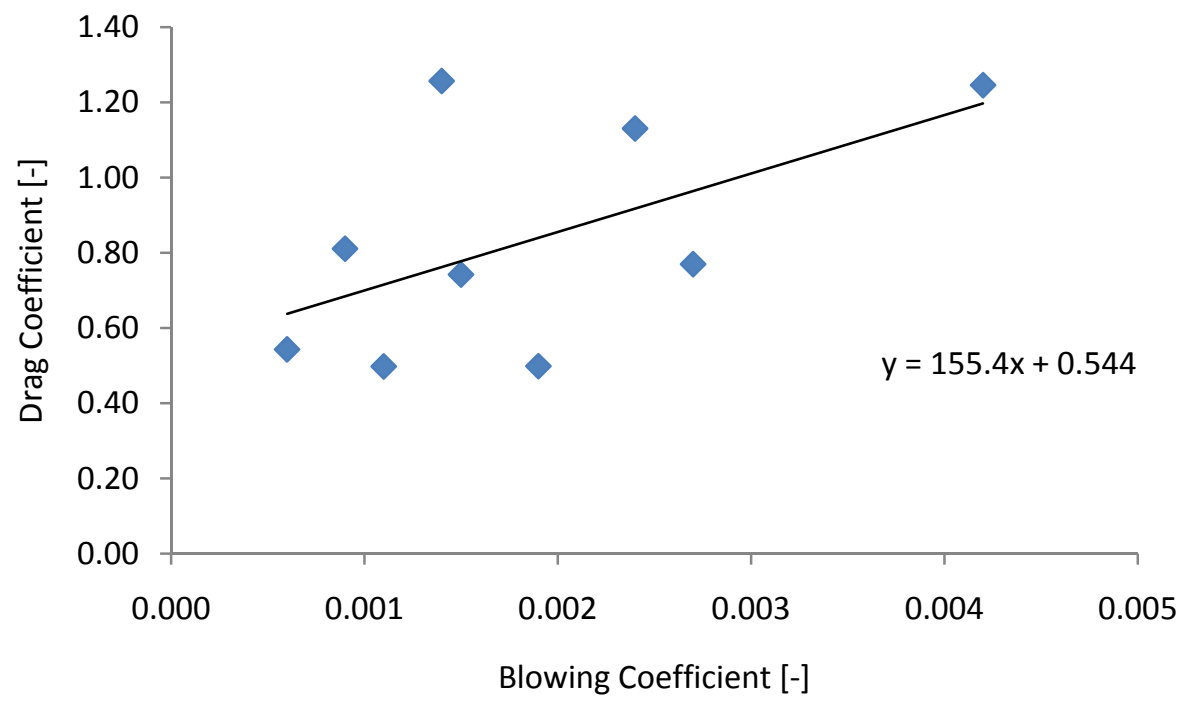

Figure D.2 Drag Coefficient versus Blowing Coefficient ( $\left(0^{\circ}\right.$ Angle of Attack) 


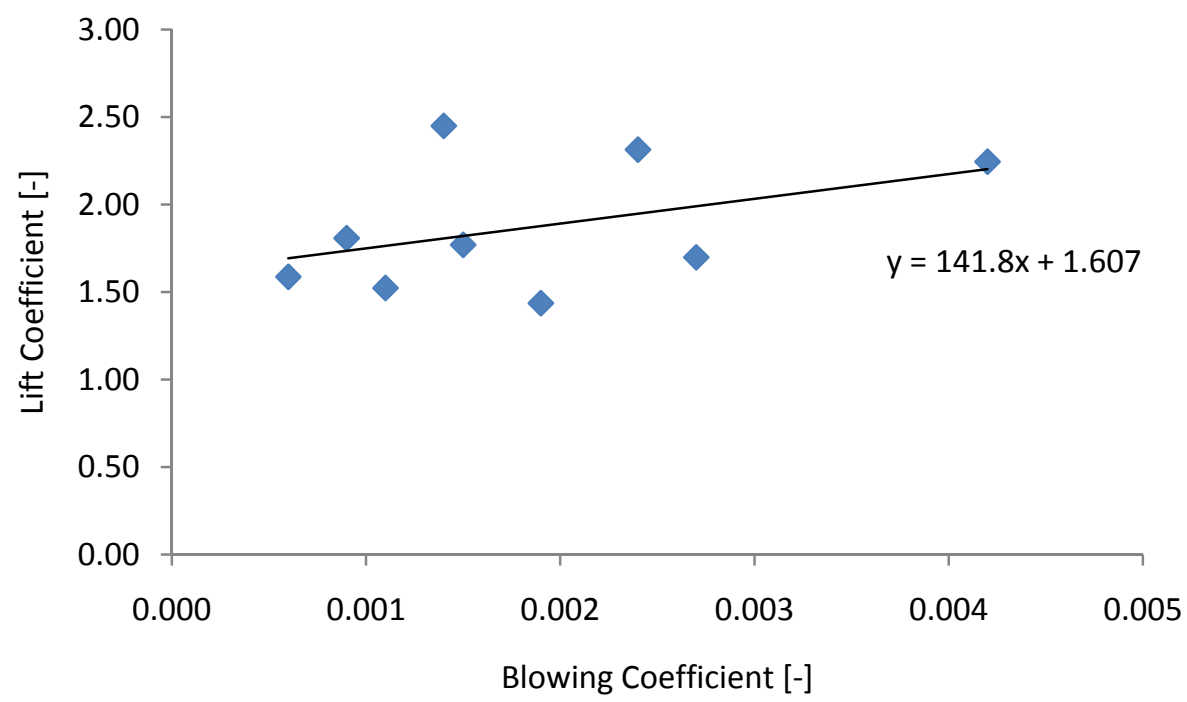

Figure D.3 Lift Coefficient versus Blowing Coefficient ( $6^{\circ}$ Angle of Attack)

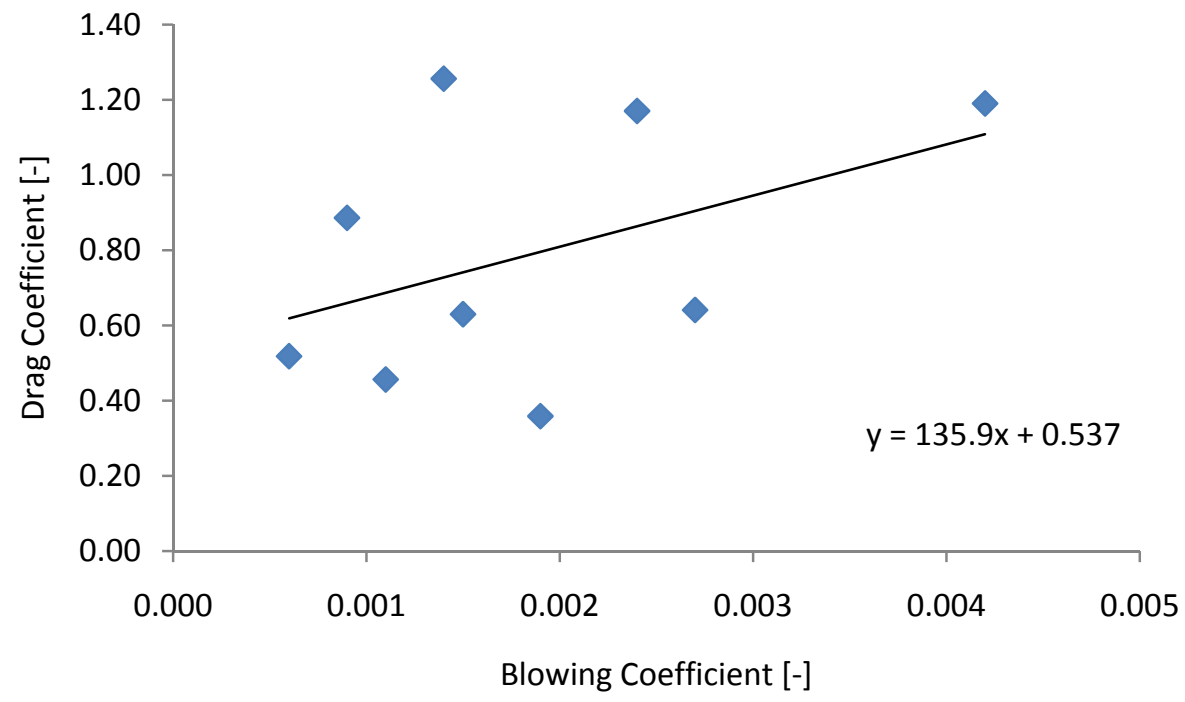

Figure D.4 Drag Coefficient versus Blowing Coefficient ( $6^{\circ}$ Angle of Attack) 


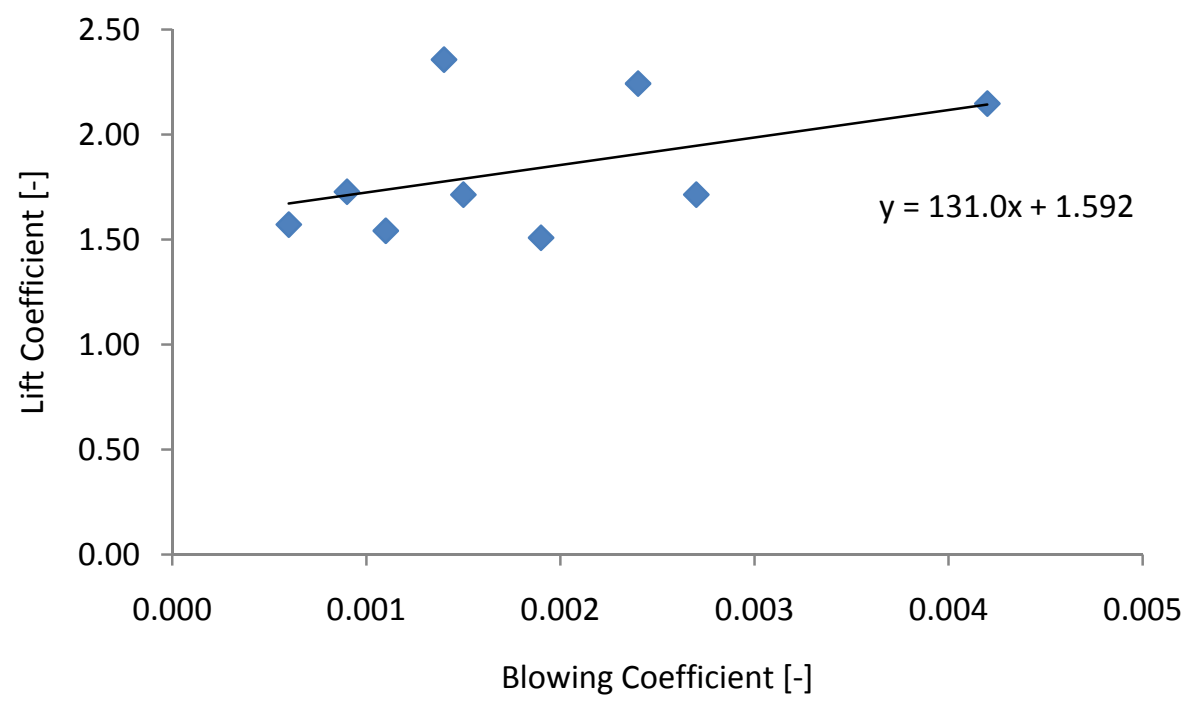

Figure D.5 Lift Coefficient versus Blowing Coefficient ( $\left(8^{\circ}\right.$ Angle of Attack)

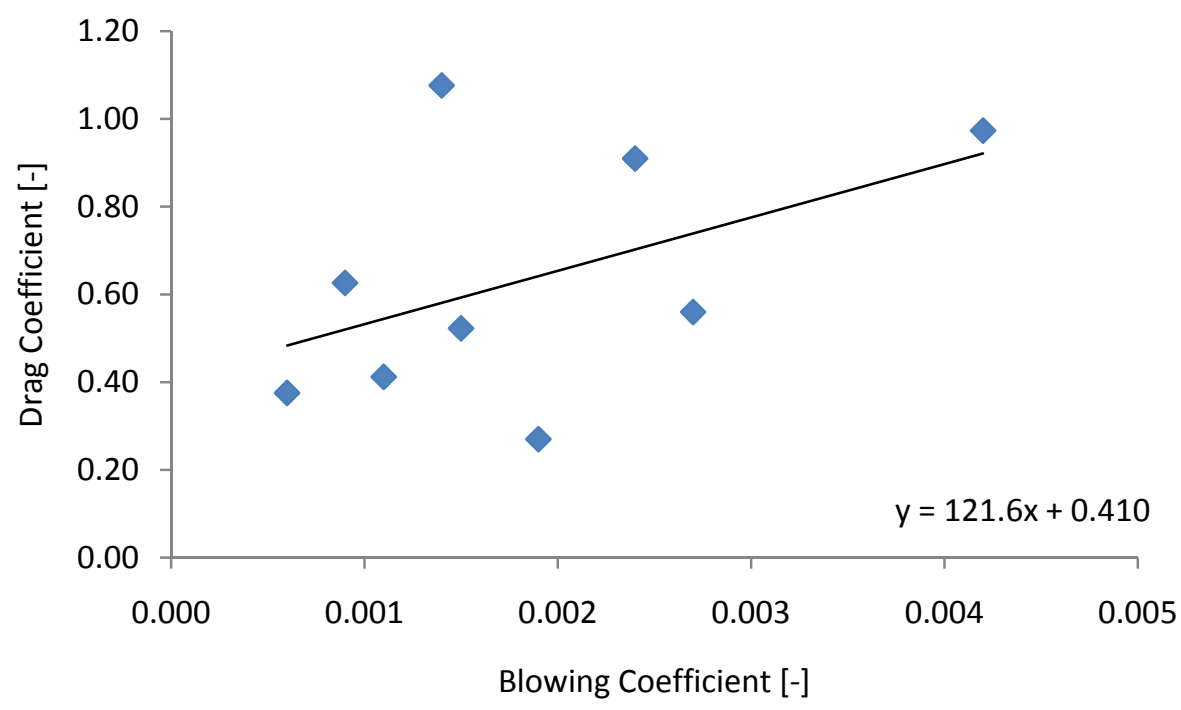

Figure D.6 Drag Coefficient versus Blowing Coefficient ( $8^{\circ}$ Angle of Attack) 


\section{Appendix E}

This appendix shows the four load cell on-axis calibration curves used to change read voltage into forces experienced by the model. Also shown in this appendix is the final on-and off axis loading formulae derived for each of the four load cells to take into account the crosstalk of the lifting direction on the drag direction. 


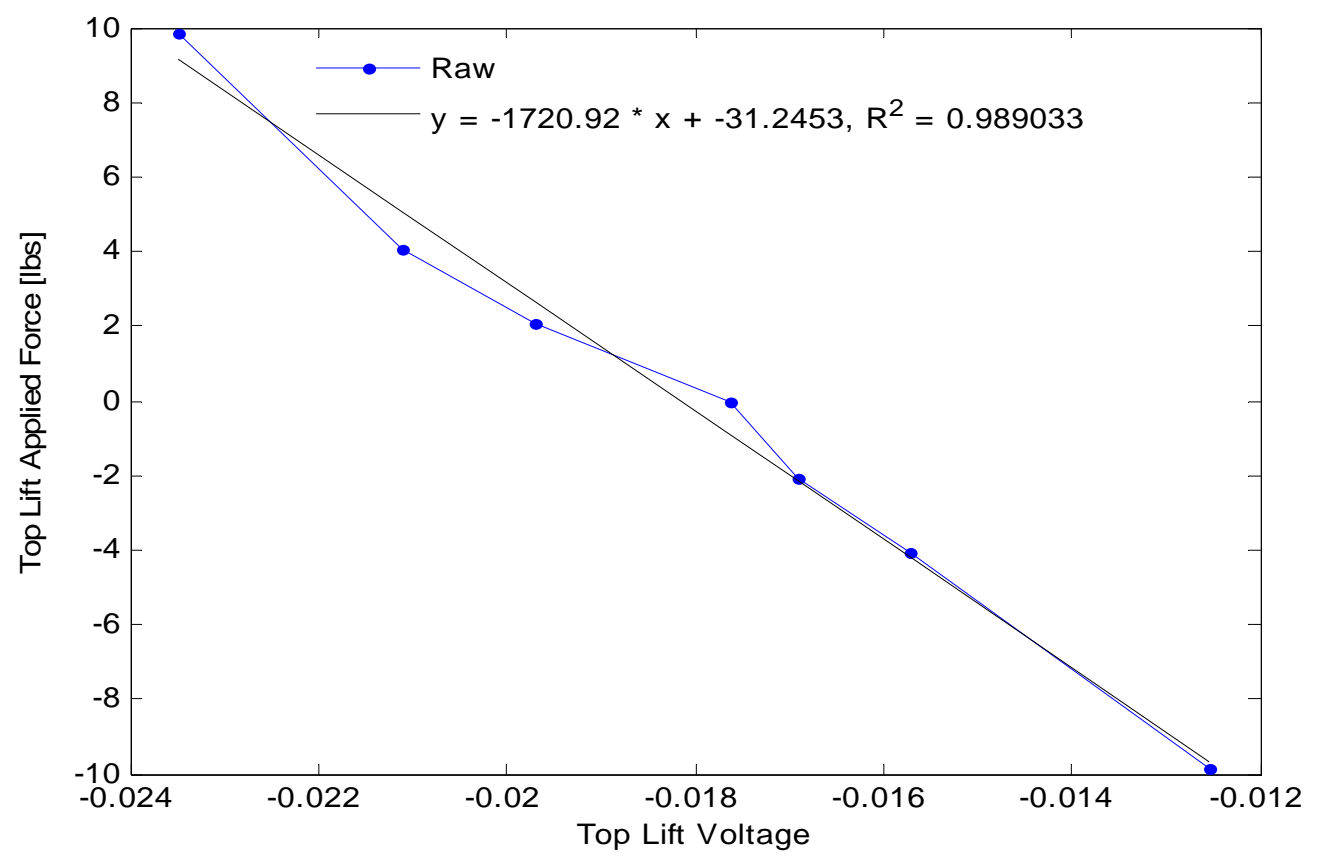

Figure E-1 Top Lift Load Calibration Curve

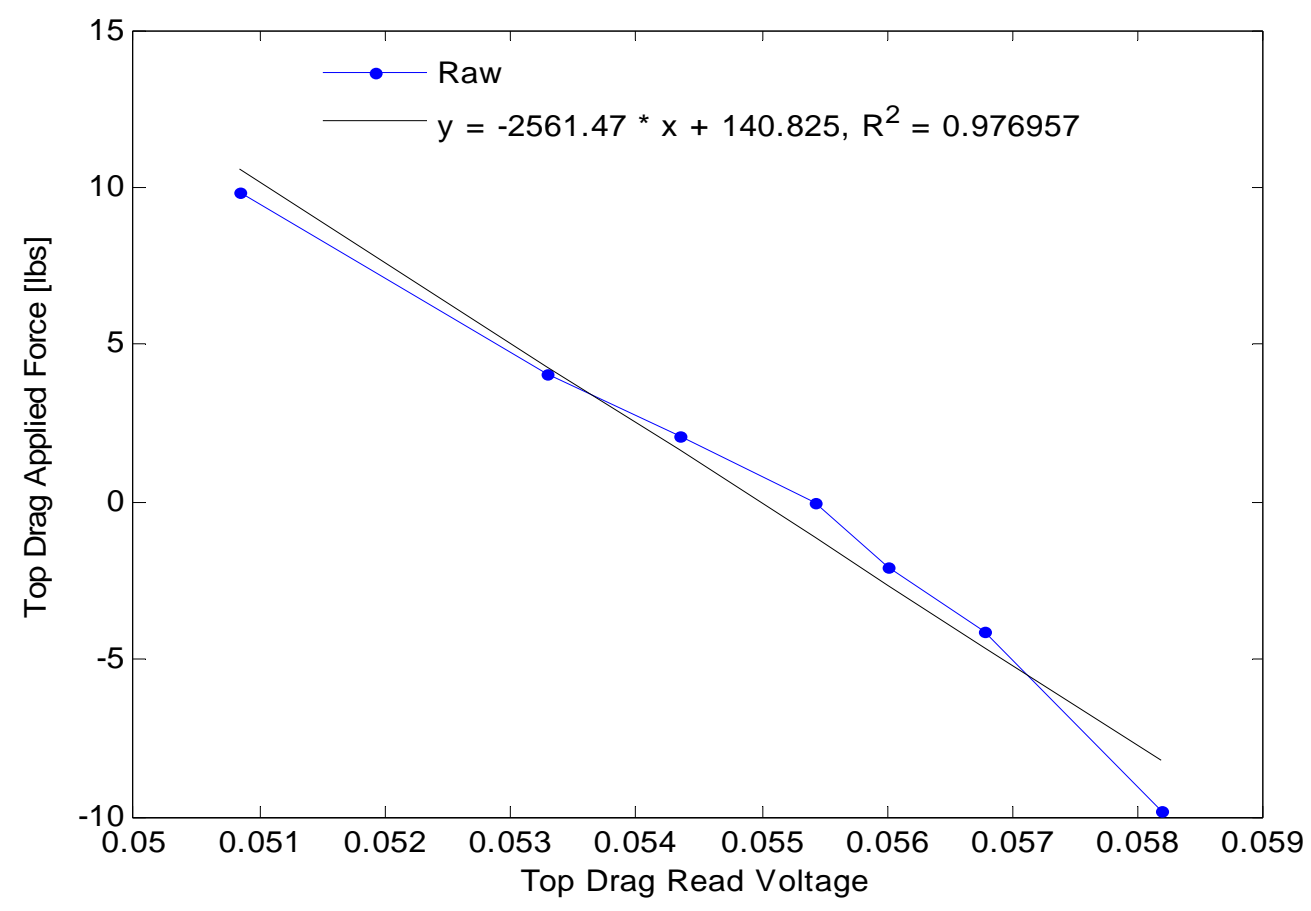

Figure E-2 Top Drag Load Cell Calibration Curve 


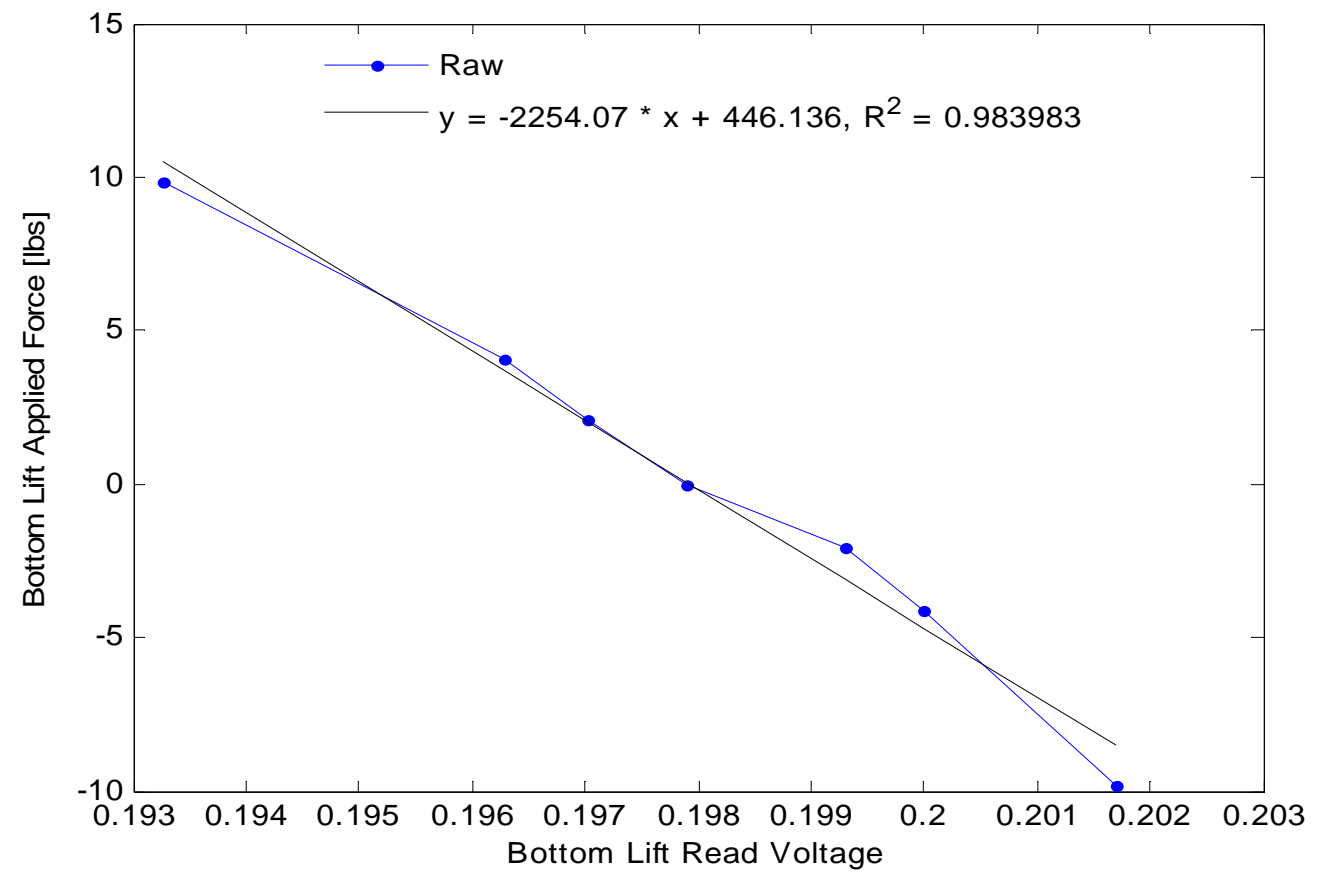

Figure E-3 Bottom Lift Load Cell Calibration Curve

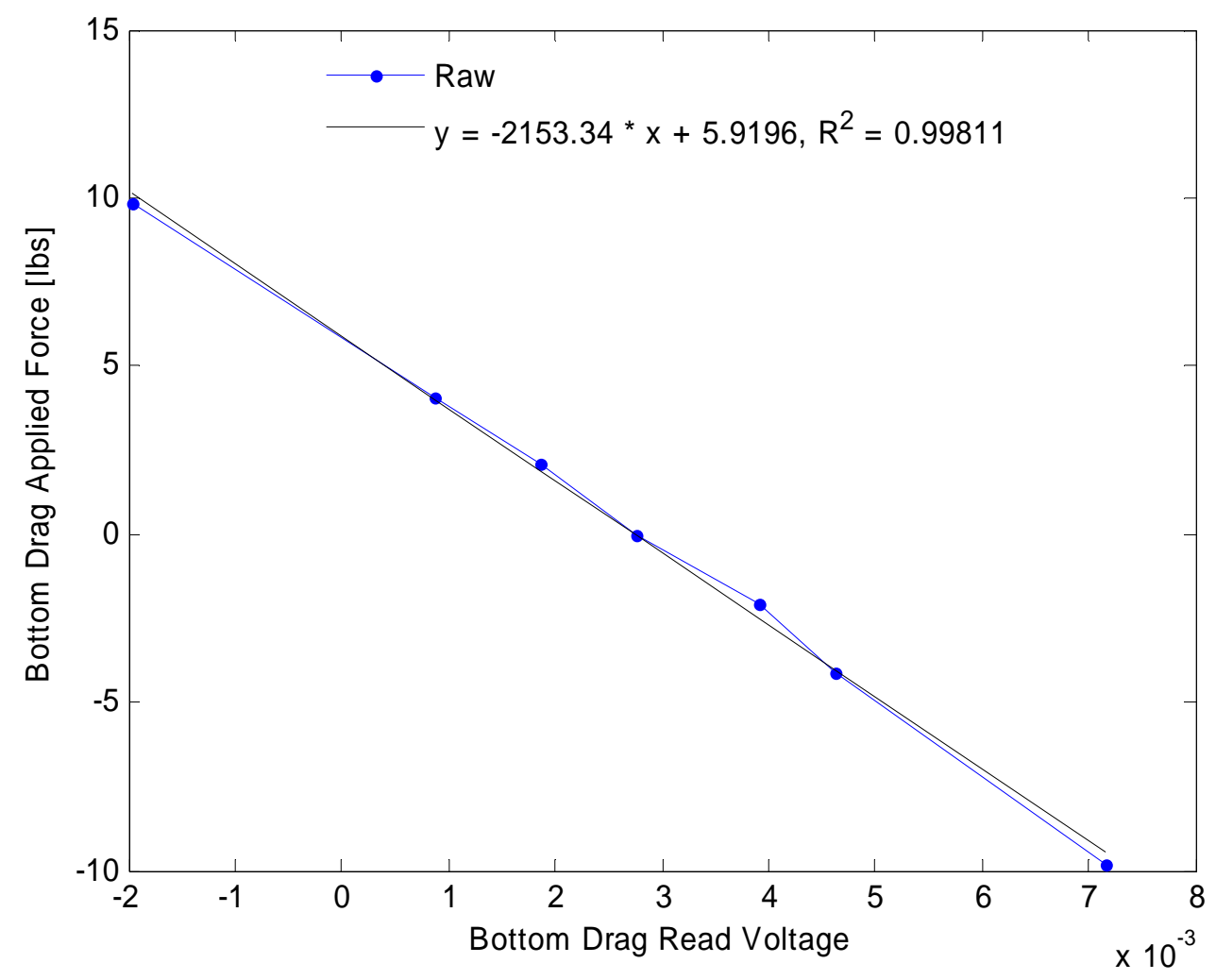

Figure E-4 Bottom Drag Load Cell Calibration Curve 


$$
\begin{array}{lr}
F T L=-1720.92(V T L)-31.2453+\left(\frac{2561.47}{3412.16}\right)(-2561.47(V T D)+140.825) & \text { Equation E-1 } \\
F T D=-2561.47(V T D)+140.825+\left(\frac{1720.92}{3316}\right)(-1720.92(V T L)-31.2453) & \text { Equation E-2 } \\
F B L=-2254.07(V B L)+446.136+\left(\frac{2153.34}{4538.38}\right)(-2153.34(V B D)-5.9196) & \text { Equation E-3 } \\
F B D=-2153.34(V B D)+5.9196+\left(\frac{2254.07}{2824.06}\right)(-2254.07(V B L)-446.136) & \text { Equation E-4 }
\end{array}
$$




\section{Appendix F}

In this appendix the results from the experimental to CFD comparison are shown for angles of attack ranging from six to eight to ten degrees. The plots are shown with both the experimental results and the computational results versus the four different blowing conditions at 120 feet per second tunnel velocity. 


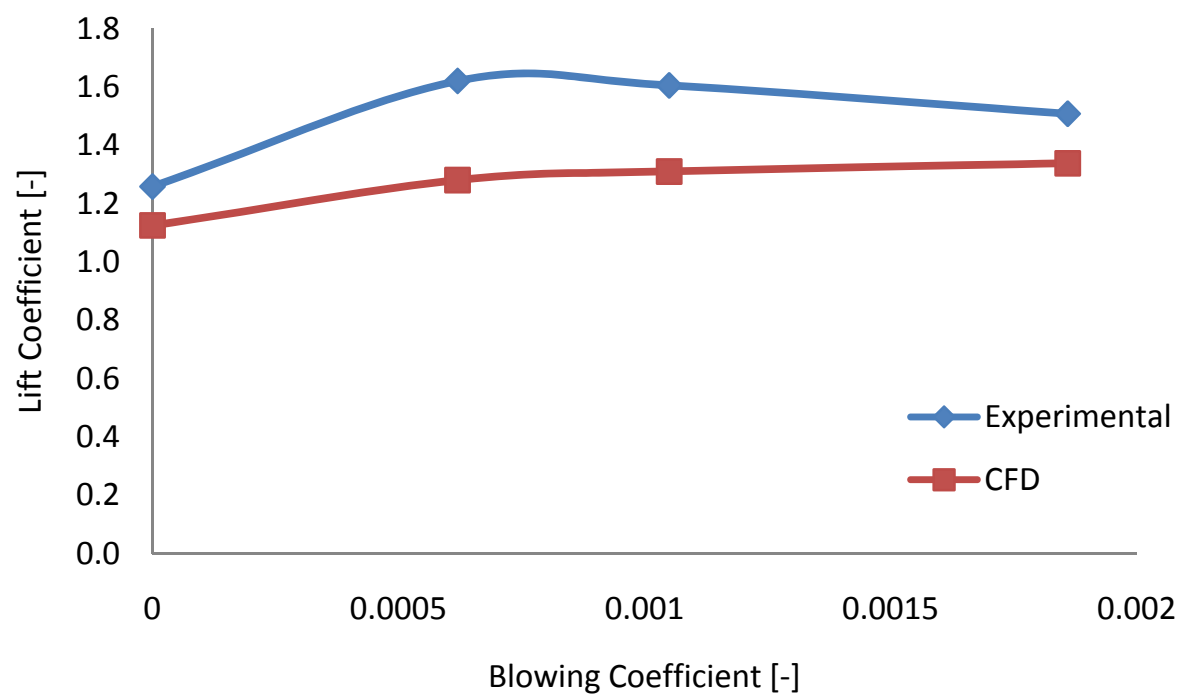

Figure F.1 Lift Coefficient versus Blowing Coefficient at $6^{\circ}$ Angle of Attack

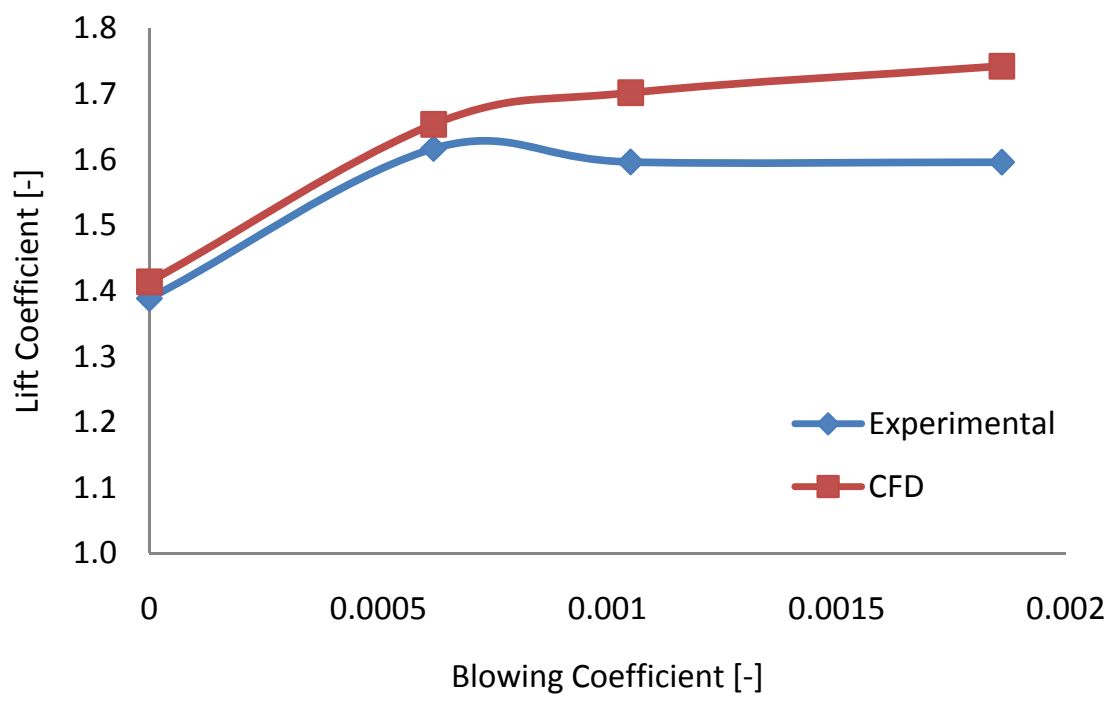

Figure F.2 Lift Coefficient versus Blowing Coefficient at $8^{0}$ Angle of Attack 


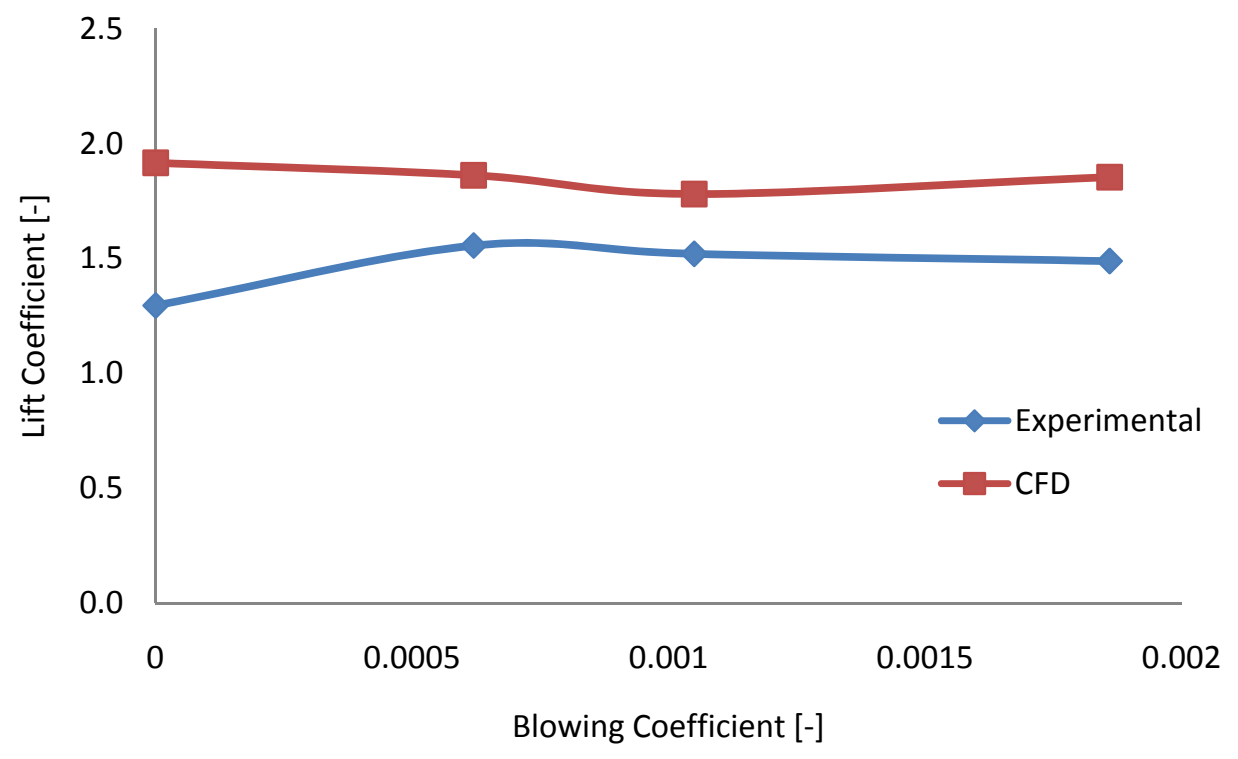

Figure F.3 Lift Coefficient versus Blowing Coefficient at $10^{\circ}$ Angle of Attack 


\section{Vita \\ Jonathan Kweder}

Jonathan Kweder was born on June $7^{\text {th }}, 1984$ to John P. and Margaret Kweder of Lake Hauto, Pennsylvania. The oldest of four boys, he graduated from Marian Catholic High School in 2002, and continued his education at West Virginia University, enrolling in the Mechanical and Aerospace Engineering program. In 2007, he received his dual Bachelors of Science degrees in both Mechanical Engineering and Aerospace Engineering (BSME, BSAE). Following Undergraduate work he pursued a Masters of Science in Aerospace Engineering (MSAE) where he is a candidate to graduate in August of 2008. 